\title{
JOURNAL
}

OF

\section{THE ROYAL SANITARY INSTITUTE}

THE RELATIVE HYGIENIC VALUES

OF GAS AND ELECTRIC LIGHTING.

\author{
By SAMUEL RIDEAL, D.Sc., F.I.C. \\ (FELL()W.)
}

\section{ObJect of Investigation.}

THE purpose of this inquiry has been to determine and compare the 1 lygienic effects of gas and electricity as used for ordinary domestic lighting.

In addition to the direct physiological effects which the two lights, pua lights, might be expected to exert on those exposed to them, it was evident that account must also be taken of their indirect effects, through the changes which they might bring about in the air of the room in which they were used. The question to be solved, therefore, was whether any injurious physical and chemical changes in the air were less nnder one form of lighting than under the other; secondarily to look for any direct results from the light itself.

Three parallel lines of research were thus inicater as requisite; the first, into the direct hygienic effect of the two lights, the second, into the indirect effect due to their products, and the third, into the nature, amount and distribution of those products.

It was recognised that to obtain the most accurate results each branch of work should be carried on independently of the others, under specially arranged conditions; and in particular that the best prospect of arriving at definite physiological results lay in experiments conclucted in a strictly physiological manner. This, however, would have been inconsistent with the general scheme of the inquiry, namely, that the subject should be studied under conditions resembling as closely as possible those of everyday life. Such lack of strict scientific accuracy as this limitation involved

YoL. Xxix. No. 2. 
was off-set by the opportunities which the parallel scheme of investigation afforded of comparing and checking against each other the results obtained in each branch of work. It was therefore decided to carry on the three branches of the inquiry simultaneously, and subsequently, on the foundations thus laid, to proceed with a series of test and control experiments, each designed to elucilate a particular question arising out of the eavlier work.

The amount of work to be done has been greatly increased through the lack of the data which might have been expected to exist on matters of such importance in relation to the public health. Thus, no reliable information could be found as to the ventilation of ordinary living rooms, though for factorics and other large buildings such statistics are met with in abundance.

Again, physiological observations on persons in ordinary health and following their ordinary avocations appear only to have been made for special purposes, such as the determination of averages of height, rate of pulse, and the like; while other physiolugical work, although carried into almost every branch of possible inquiry, does not appear to have direct bearing on the present question. Much preliminary work was therefore necessitated which would have been saved if authentic published data had been availablc.

The investigation being primarily a medical one, the physiological work has been given first place; the chemical and physical work haring been for the most part confined to arranging and recording the conditions under which the medical observations have been made. The medical observations were made by Dr. Bertolacci, and the physical determinations by Mr. A.J. Martin, M.Inst. C.E , and I have to thank both of these colleatgues and my staff generally for the assistance which they have afforded me in carrying out this investigation.

\section{Physiological Obiemitions.}

The physiological observations were made on 15 persons ; of these, 9 were assisting in the experiments, while 6 were clerks who attencled after the room was divided, as subjects for observation only.

Of the first mentioned, one was a civil engineer, another a draughtsman, another a clerk and typist, and the rest were either analytical clemists, or laboratory assistunts. The eldest was 42 years of age and the youngest 20 , while their averages work out to $25 \cdot 9$ years each. The heaviest man weighed $140.3 \mathrm{lbs}$. while the lightest was $109 \mathrm{lbs}$., the uverage weight for each being $131 \cdot 4 \mathrm{lbs}$. 
A general medical examination of each man was made, and a careful record has been kept of the family and personal history and habits. None were accepted for the work except those who could give a good account of themselves in these respects. Their hearts and lungs were examined, besides which the urine in each case was tested to ascertain that there was no renal disease.

With regard to the clerks who attended as subjects during the latter part of the investigation, the eldest was 29 and the youngest 23 years, while their average would be represented by $25 \cdot 25$ years. The heaviest man weighed $148 \cdot 75 \mathrm{lbs}$, the lightest $122 \cdot 6 \mathrm{lbs}$, and the average weight for each man was $138.8 \mathrm{lbs}$. Although a less minute medicil examination was made in these cases than in the formcr, their hearts and lungs were stethoscopically examined and inquiry was made as to any illness from which each man had suffered, sufficient to prove that all were healthy and could be classed with the other subjects as being fair physiological examples of men living and working in London.

Every man had a meal from half to three-quarters of an hour before attending. No drinking or smoking was permitted during the time they were under observation, and every care was taken to exclude those who had transient catarrhal or other symptoms which were likely to affect the results of the experiments.

The physiological data collected are very numerous and include observations on the-

Frequency of pulse and its character as shown by the sphygmograph.

Frequency of respiration.

Arterial blood pressures.

Variation in the number of blood corpuscles.

Body temperatures.

Body weights.

Mental fatigue.

Time reaction (miul and nuuscle).

Eye fatigues (differentiated).

Impressions on senses; and a

Special experiment on three subjects as to the poisonous effects of coal gas.

With the exception of the last mentioned experiment, which is complete in itself, care has been taken to collect and average the results so as to show any differences occurring under the two sprstems of lighting. 


\section{Pliace.}

The work has been carried on in the basement of the office building, No. 2x, Victoria Strect, in two rooms known respectively as $\mathrm{No}_{0} 4$ and No. 6. The aspect of the rooms is about south-east by south, and the sun shines full on them cluring the later hours of the morning and the beginning of the afternom. The floor of the rooms is $7 \mathrm{ft} .8 \mathrm{in}$. below the side walk, and the width of the intervening area is $8 \mathrm{ft}$.

The building consists of the basement, five stories and a mansard.

\section{Dinensions.}

The two rooms had previously been thrown into one, and the first series of experiments was carried on in the undivided room. In the beginning of March the two halves were separated by a wooden partition into two equal and symmetrical rooms, which were used separately for all subsequent work.

The undivided room was $29 \mathrm{ft}$. $9 \mathrm{in}$. long by $16 \mathrm{ft}$. $4 \frac{1}{2}$ in. wide and $10 \mathrm{ft} .4 \mathrm{in}$. high, and contained, allowing for chimney breasts, etc., 5,013 cubic feet. Each of the rooms as divided, is roughly square $\left(16 \mathrm{ft}\right.$. $4 \frac{1}{2}$ in. by $14 \mathrm{ft} .10 \mathrm{in.}$.) In all calculations the capacity of the undivided room has been taken, in round numbers, at 5,000 c.f., no deduction being made for.the space occupied by persons, furniture, etc.

A plan and section of the rooms are appended (Figs. 1 and 2).

\section{Stricterat Features.}

In the front wall (the only outer one) of each room there are two large windows, and in the opposite wall a cloor, giving access from the corridor and with a fanlight over it. By the side of the door in room 4 there is a large window, to give light to the corridor; but when the roons were divided, this window was covered with a close screen, flush with the wall of the room, so as to preserve the symmetry of the two rooms. In the long wall of each room (being the end walls of the original room) there is a fireplace, and a door communicating with the room adjoining. These two doors have been blocked throughout the experiments.

Outside each door into the corridor a baize door has been hung, the intermediate space forming an air lock to minimise the disturbance of the air of the rooms by persons entering and leaving them. Each window has a holland blind, which was kept drawn down.

In the chimney of each room near the ceiling a ventilating grating bas been built, the net area of the openings being 7 sq. in. Fach grating is provided with mica flap ralres and a sliding door, which was kept closed 


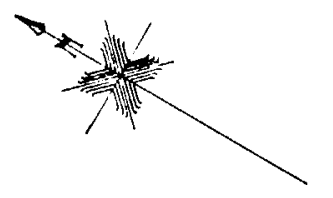

\section{PLAN OF ROOMS}

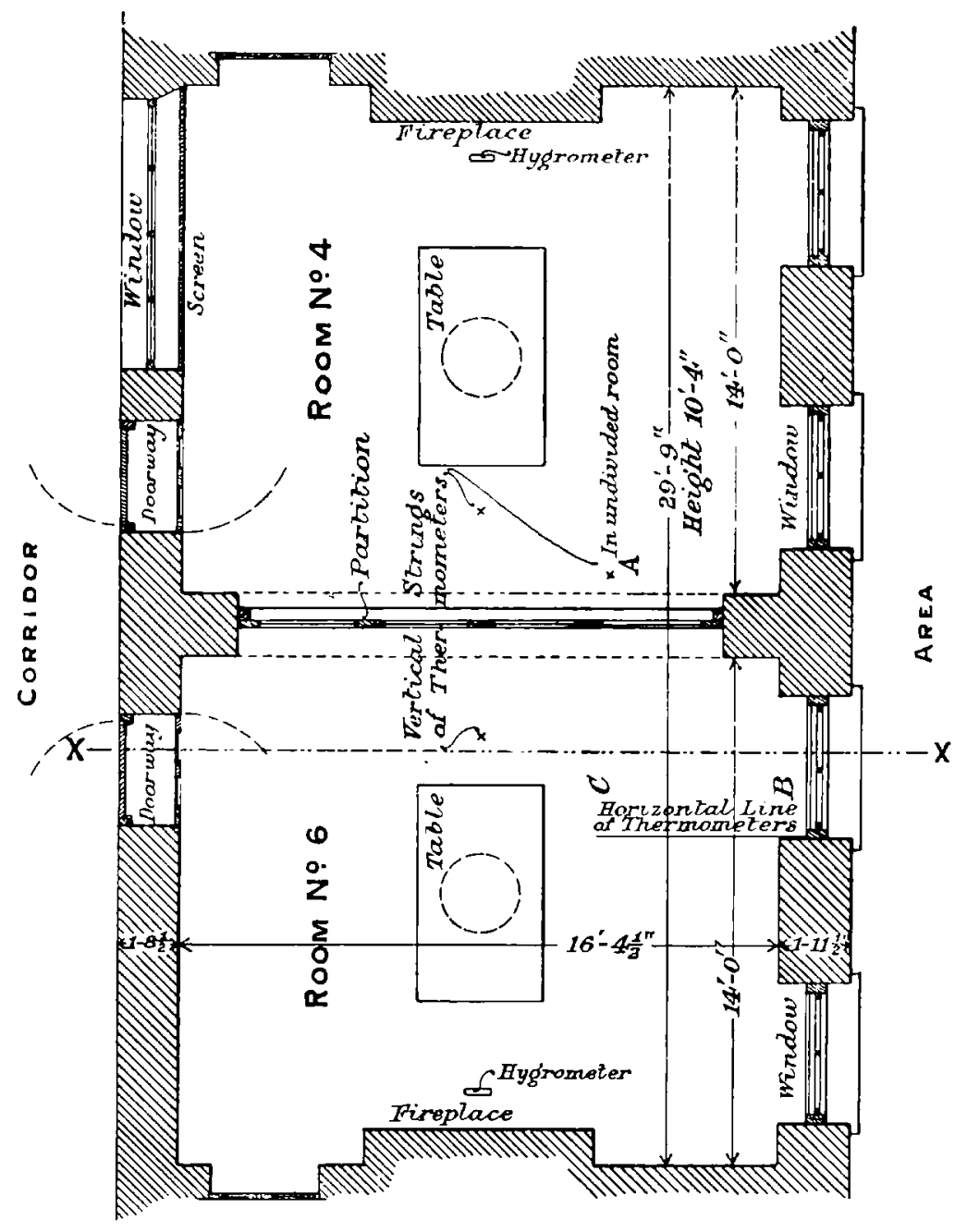

Scaze of Feet

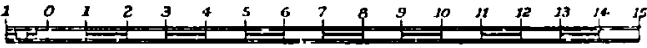




\section{SECTION THROUGH ROOM}

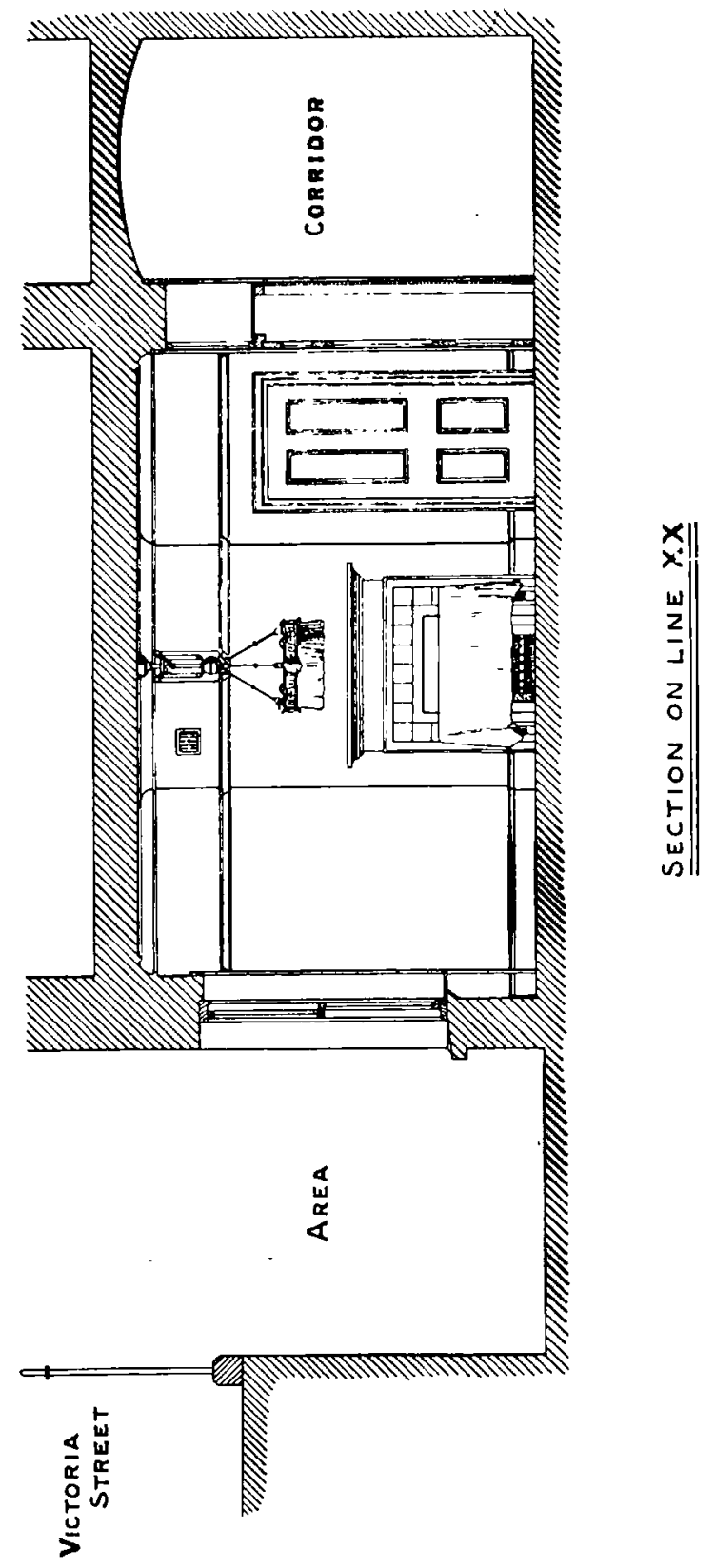




\section{PHOTOMETRIC CHART.}

FIG. 3 .

CasTests in Black made $20^{\text {th }}$ Feb. 1907.

Consumptions N:3 Burner $=1.36 \mathrm{cuft}$.

Ni4 " $\quad 1.18$ "

(including by-passes)

Electric Tests in Rea made 6th March 1907.

Consumptions:-

No3 Burner $=90.7$ Watts

NO4,$\quad=1 / 3.4$,

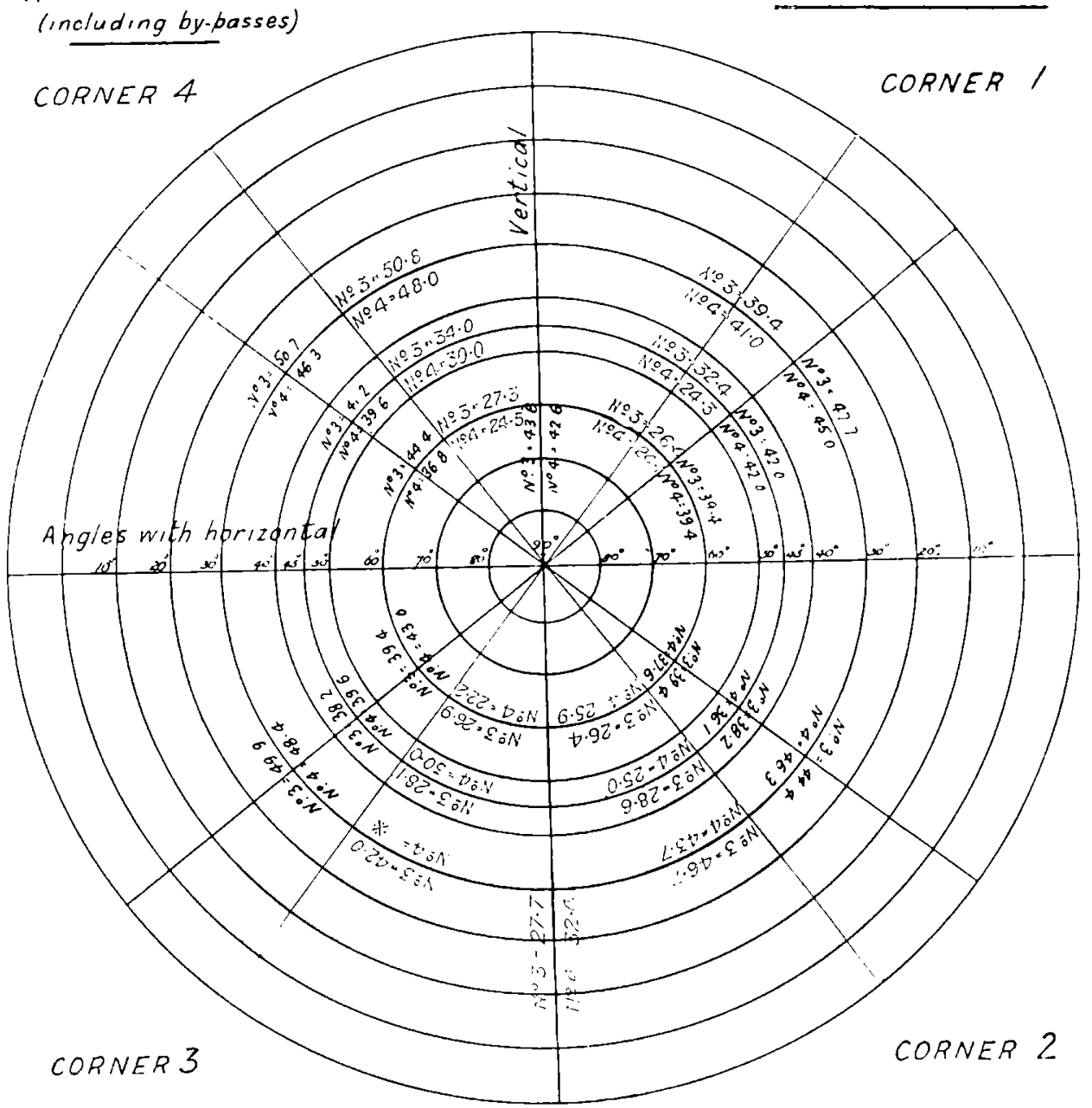

CORRIOOR

* Not chtainable owing to erection of partition 
$\therefore$

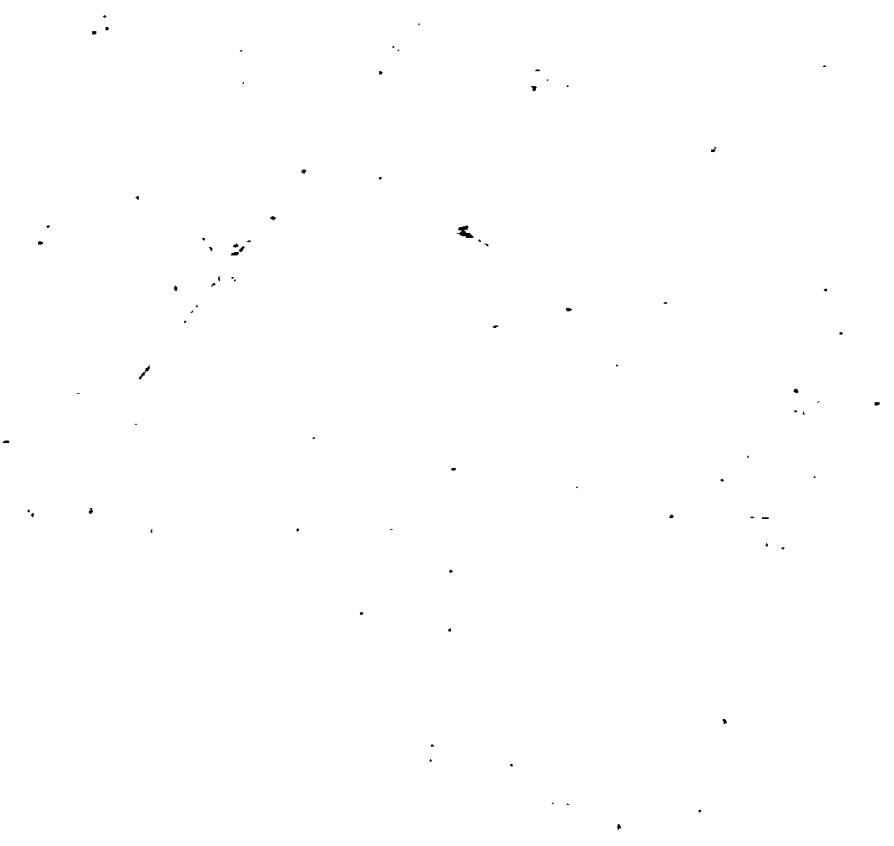

Downloaded from rsh.sagepub.com at East Carolina University on July 14, 2015 
during all but a few of the experiments, the fireplace also being blocked by a tight-fitting screen.

The floor is of wood in the form of planks nailed to sleepers which are bedded on concrete. It is covered with linoleum, over which felt is laid to within about a foot of the walls. The front wall is $1 \mathrm{ft} .11 \frac{1}{2} \mathrm{in}$. thick, and that against the corridor $1 \mathrm{ft}$. $8 \frac{1}{2}$ in., both being very solidly built of brickwork and cement. The room was distempered and whitewashed before taking possession on December 17th, by the workpeople of the Westminster Trust. When the work was completed it was ascertained that about 50 lbs. of whiting was used on the walls and ceilings, and this quantity was put on by the landlord, irrespective of any use to which the room was subsequently to be put, and can be said therefore to be the normal amount used by ordinary decorators in refitting rooms for a new period.

With the lighting at 4 c.f. of coal gas, and sulphur contents at a maximum of 60 grains per 100 c.f., there will be 2.4 grains of sulphur produced in the room per lighting hour, and a five hours' run per night will give a total daily evolution of 12 grains of sulphur.

Fifty pounds of whiting are equal to 350,000 grains, and as 100 grains of whiting combine with 32 grains of sulphur, the sulphur which the new whitewash is capable of fixing is equal to 112,000 grains, so that the room will remain basic, and therefore not require fresh whiting for 9,333 days, or say 25 years.

\section{LIGIITING.}

Each room can be lighted either by gas or electricity, and the consumption of both is recorded by fine reading meters in addition to the ordinary meters supplied by the companies. The scheme of lighting adopted has been that of an ordinary dining room, the lights having been disposed over a large central table, around which the subjects have sat. With a view to a fair comparison, the number, power and position of the lighting units has been as nearly as possible the same for gas and electricity, and the same for each room.

In the centre of each room was placed a brass pendant, having a hoop $2 \mathrm{ft} .1 \mathrm{in}$. in diameter and $4 \mathrm{in}$. deep, surrounded by a silk flounce, white inside and red out, and 12 in. deep. Each pendant is fitted with two gas and two electric lamps, placed alternately within the hoop in a circle 12 in. in diameter.

\section{GAS SLPPLY.}

The gas used was the ordinary supply of the Gas Light and Coke Co. of 16 prescribed candle power. The price is 2 s. $11 \mathrm{~d}$. per 1,000 c.f. 


\begin{tabular}{|c|c|c|c|}
\hline 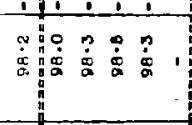 & 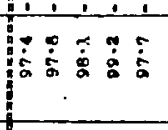 & 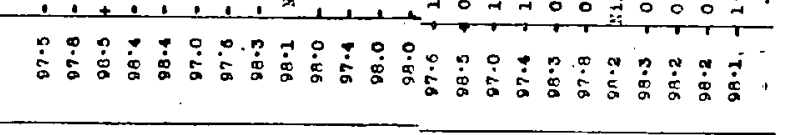 & 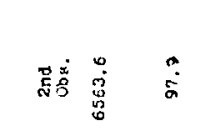 \\
\hline & 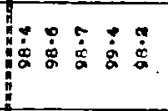 & 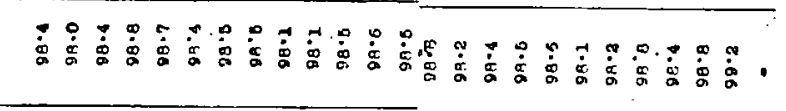 & \\
\hline & & 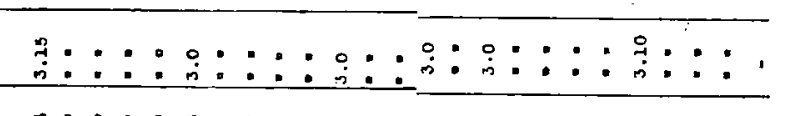 & \\
\hline & & $\ldots \ldots \ldots \ldots \ldots \ldots \ldots \ldots \ldots$ & \\
\hline & 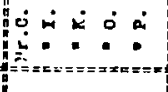 & 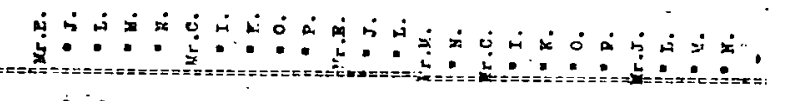 & \\
\hline 每 & 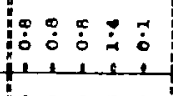 & 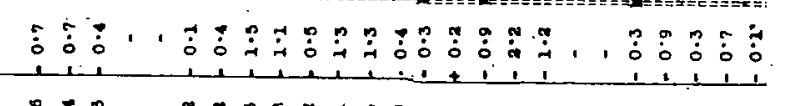 & \\
\hline 2 & 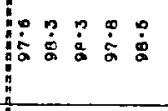 & 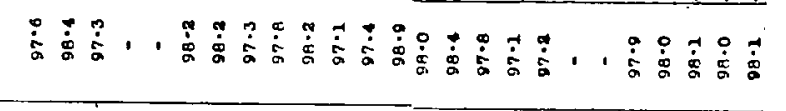 & 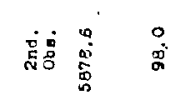 \\
\hline 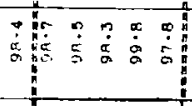 & 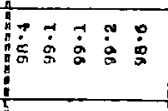 & 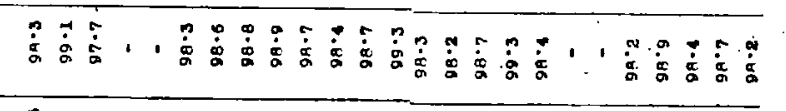 & \\
\hline $\begin{array}{l}:::: \\
\cdots:\end{array}$ & 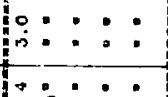 & 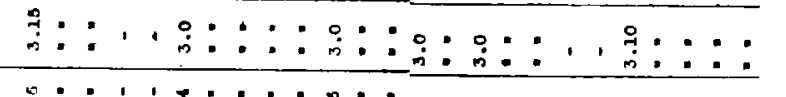 & 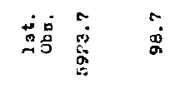 \\
\hline 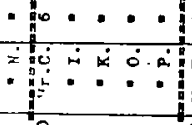 & 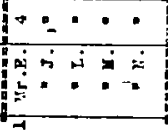 & 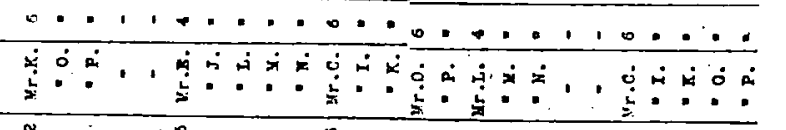 & \\
\hline & & $\ldots \ldots \ldots \ldots \ldots$ & \\
\hline
\end{tabular}




\section{Relative Hygienic Values of Gas and Electric Lighting.}

The ordinary pressure in the mains during the erening was 34 tenths of an inch, which was reduced by means of a governor to 19 tenths at the lamps.

The gas is officially tested each day for calorific power, the highest values recorded during the period covered by the experiments being 644 British thermal units gross and 578 B.T.U. net on January 18 th ; on two occasions the values fell to 582 13.T.U. and 519 B.T.U. respectively. The average values during the whole period were very close to 600 B.T.U. gross and 540 B.T.U. net, and these figures have been used in all general calculations. On any particular night, however, the observed value for that date has been taken.

The carbonic acid production per c.f. of coal-gas was determined each day by an explosion analysis and found to average 0.6 per c.f. of gas.

Similarly the amount of water produced by the gas was directly determined from the amount condensed in the calorimeter, allowance being made for that escaping as gas, and show an average of 39.5 grains of water produced per c.f. of gas. The figures for February are given in the table below.

TABLE shoving the amount of carbonic acid gas, water, and heat produced ly! burning coal gas.

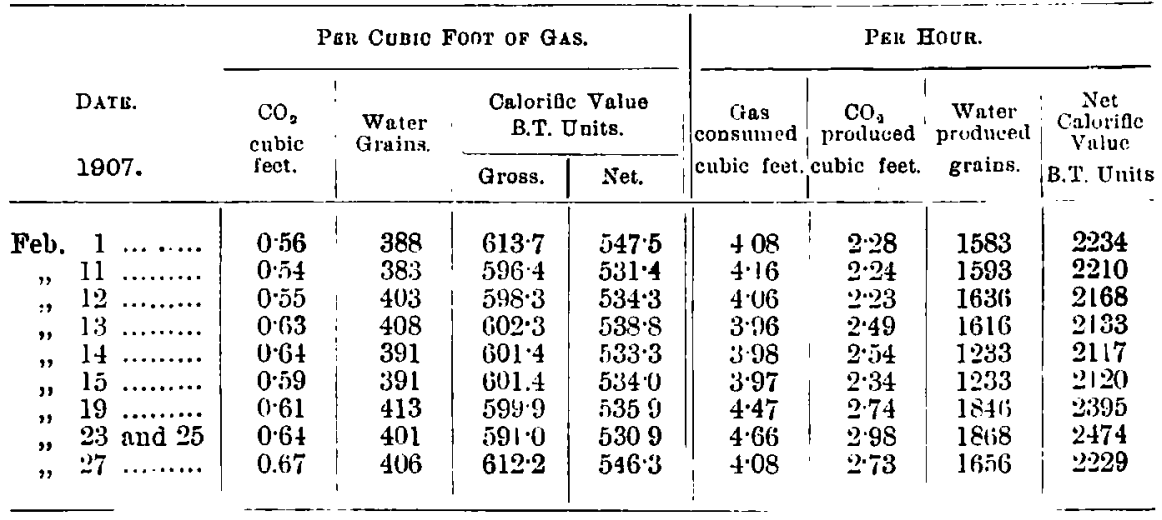

\section{Gas Burvers.}

The gas burners were of the Darwin Bijou inverted incandescent type, of 25 nominal candle power, consuming on the average about 1.28 c.f. per hour. Each burner was furnished with a by-pass, and the two burners in each pendant were controlled by a pneumatic switch at the door.

At the outset a difficulty was experienced with the gas-burner's in room 4 , in their sensitiveness to slight vibrations, such as the click of a 
typewriter or the musical note made by tapping the neck of a flask. 'The burners in room 6 were much less sensitive to influences of the kind. The first governor put in proved too large to regulate the small flow of gas to the lamps, and in its efforts to ro so set up oscillations which caused the flames to flicker violently and continuously. These initial troubles having been got over with the gas-lamps, they become very steady and satisfactory in all respects.

\section{Electric Stoplay.}

The current used for the electric lighting was supplied by the Westminster Electric Supply Corporation at a pressure of 200 volts. The ordinary price is $5 \frac{1}{2} \mathrm{~d}$. per Board of Trade unit (kw. hour).

\section{Glow Lamis.}

The lamps were "Rojal Ediswan" glow lamps of 25 nomiual candlepower. The arerage consumption of current was about 94 watts per lamp.

\section{EFficiencr ind Life (IF Ixcindescent Lanips.}

The candle-power obtained depends on the pressure at which the electric current is supplied. A rise in the voltage produces in the first instance a proportionate increase in the current taken by the lamp. The larger current raises the temperature of the filament, the resist:ance of which is thereby lowerel. This results in a further increase in the current passing, the rariation in which is consequently somewhat greater than that in the voltage.

The watts consumed are equal to the product of the volts by the amperes. If the latter were proportional to the former, the watts would vary as the square of the volts, but, owing to the lowering of the resistance above referred to, the watts increase somewhat faster than the square of the voltage.

Practically the whole of the energy supplied to the lamp is converted into heat, the generation of which also increases somewhat faster than the square of the voltage.

The temperature of the filament was recently given by Hadfield as $1,800^{\circ} \mathrm{C}$. or $3272^{\circ} \mathrm{F}$.

The light emitted depends on the temperature obtained, and is stated to vary approximately as $\mathrm{V}^{5 \cdot \bar{j}}, \mathrm{~V}$ being the voltage.

H. A. Clark* has shown that the variation in candle-power with change in the voltage is considerable. Thus a 16-c.p. lamp, when running under two-thirds of its normal pressure, and taking 40 per cent. of its

* H. A. Clark, in Fowler's "Mechanical Engineers' Pucket-book." 


\section{Relative Hygienic Values of Gas and Electric Lighting.}

normal energy, gave practically no light, while an excess of $13 \frac{1}{2}$ per cent. in the voltage and 37 per cent. in the watts raised the candle-power nearly 140 per cent. above the normal, with an increase in efficiency of 73 per cent.

The voltage of the Westminster supply is said to be liable to vary from 197 to 205 , volts, giving a range of 8 volts, or 4 per cent. The resultant variation in candle-power is from 23 c.p. to $30 \frac{1}{2}$ c.p., showing a difference of $7 \frac{1}{2}$ c.p., or 30 per cent. The watts per candle range from 3.4 at the lower voltage to 2.86 at the higher. The lamps used were very steady throughout the inquiry.

It will be seen from the foregoing that an increase in voltage is accompanied by a very considerable gain in efficiency, but this gain is only realised at the expense of a serious falling-off in the life of the lamp. Thus, experiments have shown that a lamp which, at its normal pressure of 100 volts, has a life of 1,000 hours, lasts under 105 volts only about 250 hours. This consideration will generally render it advisable to run lamps well under their maximum efficiency.

Neither the efficiency nor the candle-power of a lamp remains constant, both showing a progressive falling-off cluring the period of use. It is therefore not usually economical to use a lamp longer than from 450 to 500 hours.*

It seems established that the deterioration in the efficiency of a lamp would be more rapid if the voltage were variable, especially if the standard voltage were exceeded. $\dagger$

\section{Photomethic Obsenvations.}

Photometric observations were made in the rooms on Jan. 4th and 10th, Feb. 20th, March 13th, and April 8th. The instrument used was one of Simmance and Abady's flicker photometers. Each lamp was tested separately in position, with the flounce hanging behind it. The values obtained denote, therefore, not the power of the naked lamp, but its actual illuminating effect under the conditions in which it was used. Measurements were taken immediately under each lamp and at angles of $60^{\circ}, 45^{\circ}$, and $30^{\circ}$ from the horizontal from each of the four corners of the room. The chart (Fig. 3, p. 53) shows the manner in which the results were recorded, the black figures referring to the gas and the red to the electric lamps.

* F. C. Bailey, Cincinnati. Proc. Inst.C. E., Vol. CLI., p. 522.

+ Sir W. Preece, Brit. Ass. Reports, 1906. 
FIC. 4

ILLUMINATION OF TABLE.

In Candles at one foot distance.

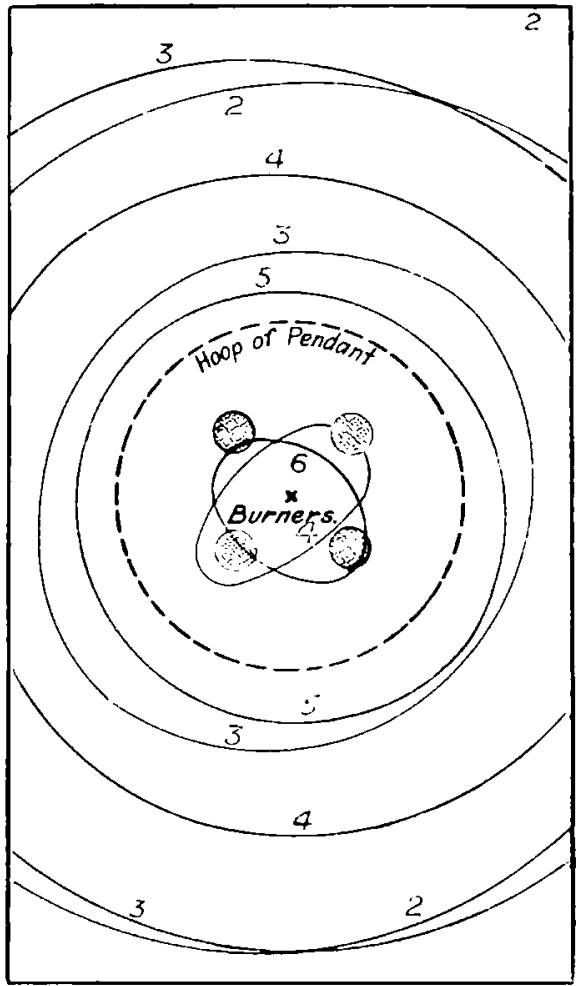

Green cuxves show illumination by Gas (Tests mede 20" Feb. 190z.) Red " " " "Electricity(Test's made $\rho^{i k}$ Mar.100\%) 


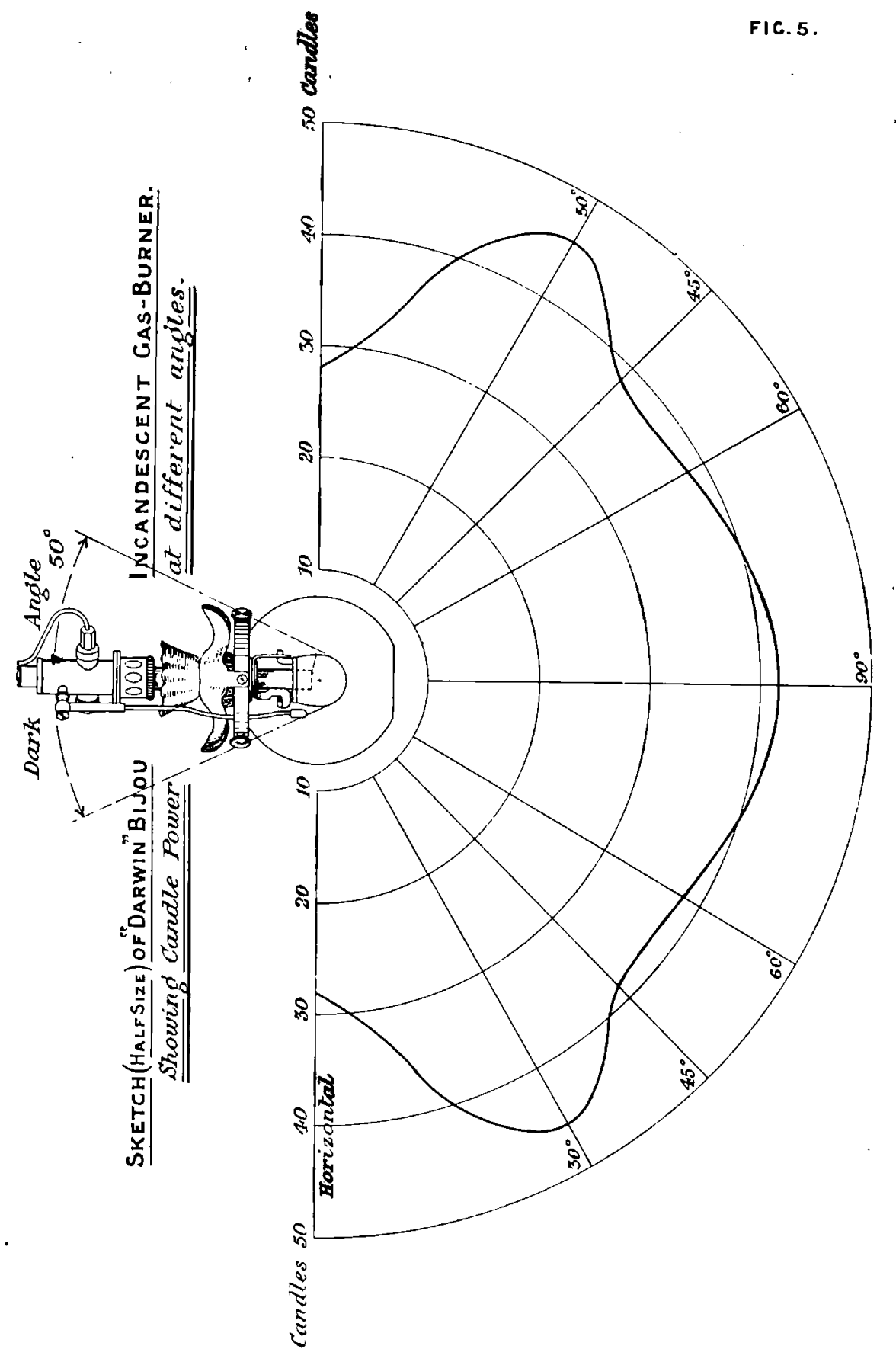


FIC. 6 .

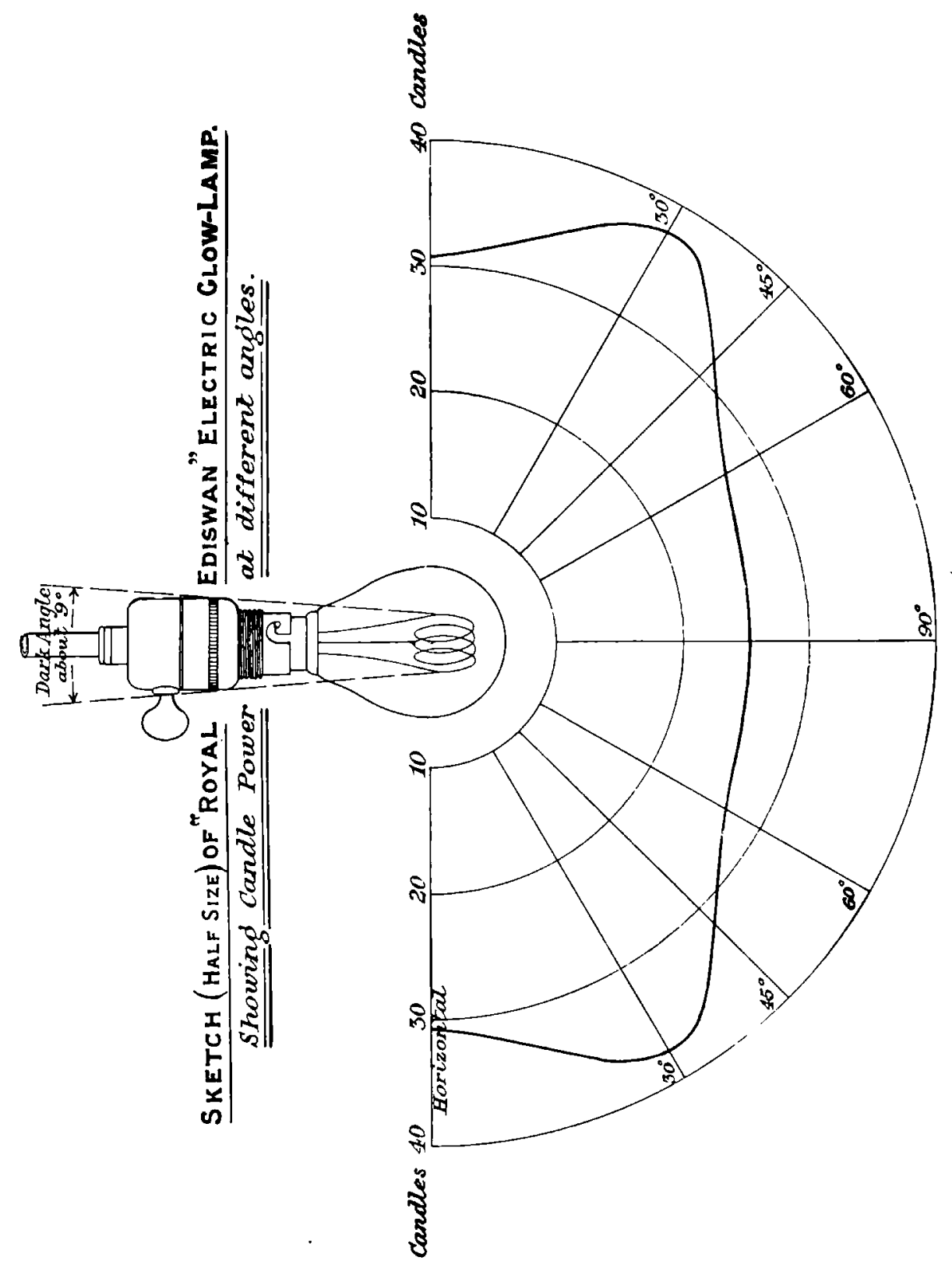


The hemispherical intensities of the various gas and electric units were as follows :-

\begin{tabular}{|c|c|c|c|c|c|c|c|c|}
\hline \multirow[b]{3}{*}{ Burner. } & \multicolumn{4}{|c|}{ GAS BUHNERS. } & \multicolumn{4}{|c|}{ ELectrio La MPS. } \\
\hline & \multicolumn{2}{|c|}{ Room 4.} & \multicolumn{2}{|c|}{ Rnom 6.} & \multicolumn{2}{|c|}{ Room 4.} & \multicolumn{2}{|c|}{ Room 6.} \\
\hline & 1 & 2 & 3 & 4 & 1 & 2 & 3 & 4 \\
\hline Jan. $4 \& 10 \ldots$ & $41 \cdot 6$ & $31 \cdot 3$ & $40 \cdot 4$ & $39 \cdot 6$ & $37 \cdot 3$ & $34 \cdot 0$ & $38 \cdot 0$ & $41 \cdot 4$ \\
\hline Eeb. $20 \ldots \ldots . .$. & $38 \cdot 9$ & $33 \cdot 5$ & $39 \cdot 9$ & $39 \cdot 0$ & & & & $\because 7$ \\
\hline Mar. $6 . . . . . . . . . .$. & & & & & $27 \cdot 4$ & $29 \cdot 0$ & $34 \cdot 0$ & $34 \cdot 2$ \\
\hline Mar. 13 .......... & $39 \cdot 0$ & $35 \cdot 7$ & $40 \cdot 8$ & $34: 4$ & $\ldots$ & & & $\dddot{80}$ \\
\hline 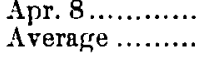 & $3 \ddot{9} \cdot 8$ & $3 \dddot{H} \cdot 5$ & $\dddot{40 \cdot 4}$ & $\ddot{3 \pi} \cdot 7$ & $\begin{array}{l}33 \cdot 4 \\
32 \cdot 7\end{array}$ & $\begin{array}{l}27 \cdot 7 \\
30 \cdot 5\end{array}$ & $\begin{array}{l}27 \cdot 6 \\
33 \cdot 2\end{array}$ & $\begin{array}{l}28 \cdot 0 \\
34 \cdot 5\end{array}$ \\
\hline Average of all & \multicolumn{4}{|c|}{$38 \cdot 1$} & \multicolumn{4}{|c|}{$3: 7$} \\
\hline
\end{tabular}

The following were the yields of light per c.f. of gas and per 100 watts respectively :-

\begin{tabular}{|c|c|c|c|c|c|c|c|c|}
\hline \multirow[b]{3}{*}{ Burner. } & \multicolumn{4}{|c|}{ Gas Burners. } & \multicolumn{4}{|c|}{ Elactric Lamps. } \\
\hline & \multicolumn{2}{|c|}{ Room 4.} & \multicolumn{2}{|c|}{ Room ti. } & \multicolumn{2}{|c|}{ Room 4.} & \multicolumn{2}{|c|}{ Room 6.} \\
\hline & 1 & 2 & $\mathbf{3}$ & 4 & 1 & 2 & 3 & 4 \\
\hline Feb. 20 .. & $33 \cdot 0$ & $27 \cdot 9$ & $29 \cdot 3$ & $33 \cdot 0$ & & & & \\
\hline Mar. $6 \ldots \ldots \ldots \ldots$ & & & & & $33 \cdot 4$ & $33 \cdot 6$ & $37 \cdot 5$ & $30 \cdot 1$ \\
\hline Mar. $13 \quad \ldots \ldots \ldots$. & $29 \cdot 6$ & $27 \cdot 3$ & $30 \div 2$ & $24 \cdot 0$ & अ & $30 \cdot 0$ & $9 \ddot{g}$ & $\ddot{B}_{4}$ \\
\hline Average ............. & $3 \ddot{11} 3$ & $27 \cdot 6$ & $29 \cdot 75$ & $28 \cdot 5$ & $33 \cdot 65$ & $31 \cdot 8$ & 33.65 & $28 \cdot 25$ \\
\hline A rerage of all & \multicolumn{4}{|c|}{$20 \cdot 3$} & \multicolumn{4}{|c|}{$31 \cdot 8$} \\
\hline
\end{tabular}

These figures show an apparent falling-off in efficiency of $13 \cdot 3$ per cent. in the case of gas and 14.5 per cent. for electricity. Other tests, made under conditions more favourable for accurate photometric work, give somewhat different results. Thus a mantle, similar in all respects to those used in the experiments, was tested for durability at No. 7, Tudor St., Blackfriars, on a continuous run of 603 hours, the consumption of gas averaging as above, $1 \cdot 28 \mathrm{c.f} . \mathrm{hr}$. The average horizontal illuninating value was $28 \cdot 1$ c.p., equal to 22 c.p. per cubic foot of gas per hour. During the first 400 hours the candle-power per c.f.hr. remained practically steady at 22.5 ; at the end of the 603 hours it had fallen to $20 \cdot 1$.

The electric lamps were removed from the pendants at the close of the experiments, and tested horizontally. The average horizontal candle- 


\section{Relative IIygienic Values of Fus and Electric Lighting.}

power of the four lamps was $27 \cdot 8$, measured in the plane of the filament, rings, and $33 \cdot 6$ in the axes of the rings, giving a mean of $30 \cdot 7$ c.p. The average consumption of current was therefore 3.06 watts per candle (horizontal) corresponding to an efficiency of 0.327 candles per watt. A new lamp, similar to these four, gave $26 \cdot 1$ c.p. when tested with the edges of the rings to the photometer, $24 \cdot 5$ c.p. When turned at right angles, and an average of $2 \pi 3$. The new lamp was thus inferior to those which had been in use, and the mean horizontal candle-power of the gas bumers was midway betwcen those of the old and the new electric lamps.

\section{ILLC MITATIUX.}

The illumination obtained from each pair of lamps, on the table $3 \mathrm{ft} .7 \frac{1}{2}$ in. below them, varied (for gas) from the equivalent of $6 \cdot 1$ candles at $1 \mathrm{ft}$. distance in the centre to about 2 candles at the comers of the table, the size of which was $6 \mathrm{ft}$. by $3 \mathrm{ft} .6 \mathrm{in}$. The electric illumination ranged from $4 \cdot 2$ candles at the centre to $1 \cdot \pi$ candles at the corners. A diagram is appended showing the distribution of light on the table in Room ti, as measured on February 20th and March lith. (Fig. 4, p. 5li.)

It will be seen that the gas burners threw considerably more light on the table than the electric lamps. The latter, on the other hand, gave a better illumination in the borly of the room, this superiority being particularly noticeable in reading the thermometers and the carbonic acid apparatus. The difference in the distribution of the light from the two types of lamp was due to differences in their form and in the disposition of the luminous surfaces, the broad metal monntings of the inverted gas burners intercepting most of the light which would otherwise have passed upwards, while the electric filaments were free to radiate in all directions except vertically upwards. This is clearly shown by the sketches of the two lamps. (Figs. 5 and 6, p. 56.) It is of course possible fur electric lamps to be so shaded as to give a high percentage of downward illumination, as obtains in an inverted gas burner.

\section{Hestixci.}

As a general rule the rooms were not heated, except by the lamps and the inmates themselves, but during the latter part of January the weather became so cold as to necessitate some means of warming. A coal or gas fire would have been out of the question, as destroying the control which it was desired to exercise on the ventilation. An electric heater was accordingly put in, the dark type being selected in order that the lighting of the rooms might not be interfered with. Current for the purpose was 
supplied through a separate meter, at a cost of one penny per unit, the consumption being about one unit per hour. After the room was divided, a second heater of about the same capacity was installed.

\section{A mRajgenent of Work.}

Down to the end of February all the experiments were carried on in the undivided room, the illumination being varied from night to night, or in some cases from week to week. After the rooms were separatel, gas was generally used in one room and electricity in the other, the two illuninants being alternated from room to room in order to neutralise any difference which there might be in the characteristics of the two rooms. In addition to the medical obserrations the following physical and chemical work was carried on.

The air supply was generally measured before and after each evening's run.

The temperature at various points in the room, and the difference between the dry bulb and wet bulb thermometers were noted, as a rule, every half-hour.

The proportion of carbonic acid gas in the air was measured at short intervals, generally from ten to twenty minutes. In addition, the organic matter and the carbon monoxide present was determined from time to time, and the bacteriological contents of the air under the various experimental conditions was also specially investigated.

The temperature of the corridor and the outer air, the readings of the gas and the clectric meters, and the gas pressures were noted before and after cach erening's work.

\section{Meteorologiche Record.}

A record was also kept of the meteorological conditions, as reported by the Meteorological Office; the readings of the dry and wet lualb thermometers in St. James's Park and the churchyard in Victoria Street, by the Windsor Hotel, being specially supplied by the ()ffice.

\section{Thales of Restats.}

A consecutive summary of each day's ubservations was prepared in tabular form and supplementary tables were added, bringing together the results for those days on which identical conditions were maintained. These results are dealt with in their respective sections, but their general character will be apparent from the following abstract. 
60 Relative Hygienic Values of Gas and Electric Lighting.

Classified Summary of Observations.

\begin{tabular}{|c|c|c|c|c|c|c|c|c|c|c|c|c|}
\hline \multirow{2}{*}{\multicolumn{2}{|c|}{ Room. }} & \multirow{2}{*}{ 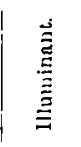 } & \multirow{2}{*}{ 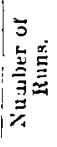 } & \multirow{2}{*}{$\mid$} & \multirow{2}{*}{$\begin{array}{l}\text { Air supply } \\
\text { c.f. per hr. }\end{array}$} & \multirow{2}{*}{ 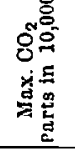 } & \multicolumn{3}{|c|}{ Temperalure } & \multicolumn{3}{|c|}{ Percentage humidity. } \\
\hline & & & & & & & Sturt. & Finish. & Change. & Start. & Finish. & chinge. \\
\hline Un:livinled. & & Gias.. & 22 & $8 \cdot 1$ & $\begin{array}{l}3,525 * \\
7,835 \%\end{array}$ & $\begin{array}{l}30 \cdot 1\} \\
14.9 j\end{array}$ & $53 \cdot 6^{\circ}$ & $57.0^{\circ}$ & $+3 \cdot 4^{\circ}$ & $74: 2$ & 76.8 & +26 \\
\hline$"$ & . & Elec. & 19 & $\varepsilon \cdot 4$ & $\left\{\begin{array}{l}3,355 * * \\
7,191+\end{array}\right.$ & $\begin{array}{l}23 \cdot 0\} \\
12 \cdot 9 j\end{array}$ & $54 \cdot 0^{\circ}$ & $57 \cdot 2^{\circ}$ & $+3 \cdot 2^{\circ}$ & $73 \cdot \overline{7}$ & 760 & $+2 \cdot 3$ \\
\hline Divided & ... & Gas.. & 15 & $7: 5$ & $\begin{array}{r}2,045 * \\
i 11,300+1\end{array}$ & $\begin{array}{l}37 \cdot 21 \\
12.81\end{array}$ & $60 \cdot 9^{\circ}$ & $64 \cdot 0^{\circ}$ & $+3 \cdot 1^{\circ}$ & $69 \cdot 1$ & $70 \div$ & $+1 \cdot 3$ \\
\hline$"$ & .. & Elec. & 15 & $7 \cdot 5$ & $\frac{1}{11,9611^{*}}$ & $\begin{array}{l}29 \cdot 9 ! \\
12 \cdot 3 j\end{array}$ & $60.5^{\circ}$ & $63 \cdot 3^{\circ}$ & $+2 \cdot 8^{\circ}$ & $71 \cdot 1$ & 7 & +0.8 \\
\hline
\end{tabular}

On some occasions in the divided rooms the windows and doors were also opens.

For reasons giren on page 70 the higher ventilation figures must be regarded as approximations only.

\section{General Obseivation on Resilts.}

In order to ascertain the influence of the two morles of lighting on health, it was first necessary to determine the mode in which these effects are occasioned, and especially the influence of the products of the illuminants.

Light from gas combustion is accompanied by heat, water vapour, carbonic acid and other products. In ordinary indoor electric lighting, as there is no combustion, chemical products are absent, and this is of ten claimed as establishing the hygienic superiority of electricity. Gas, on the other hand, is said to poison the air with $\mathrm{CO}_{2}$ and other products of combustion, to heat it to an undesirable extent, to dry it, or (alternatively) to overload it with moisture.

Ultimately the lygienic effects of the two moles of lighting must be a medical question, but their causation involves a consideration of the physical and chemical conditions.

\section{Qcantities of tine Prodicts Gexenatio by Gas Combleston.}

Heat.--The 25 c.p. gas burners each consumed on an average 1.28 c.f. per hour or 2.56 c.f. hour per pair. The average calorific value of the gas used was about 600 B.T.U. (gross) and 540 B.T.U. (net). The lower 
figure is the ouly one of importance in this inquiry, since the 60 units expended in the vaporisation of water are not recovered within the room. The net heat obtained from $2.5 \%$ c.f. of gas is therefore 1,382 B.T.U.

Moisture.- Tach c.f. of gas gave as an average 295 grains of water; $2 \cdot 5$ it c.f. therefore yield 1,012 grains.

Carbonic -leid.--The ( $\mathrm{O}_{2}$ formed per c.f. of gras areraged $0 \cdot 6$; the two burners, consuming $2 \cdot 56$ c.f. of gas, produced $1-54$ c.f. of $\left(\mathrm{C}_{2}\right.$.

\section{IIeat from Electricity.}

Each 25 c.p. glow lamp constuned on an average 94 watts, or 188 watts f $\because r$ the pair. The heat equivalent of one watt is 3435 B.T.U. per hour, and that of 188 watts $=6558$ 13.T.U. per hour.

It is of ten assumed that a glow lamp gives off practically no heat; but it will be seen from the foregoing that for an equal illumination the yield of heat by electricity is close on one-half that of gas.

\section{Prodicts of Respiration.}

In a gas-lighted room the gas is not the only source of heat, moisture, or carbonic acid gas, all of which, in appreciable quantities, are given off by the skin and lungs of the immates of the room. The publishecl estimates of the human untput of moisture and carbonic acid differ widely, but the present experiments have incidentally furnished some data concerning them.

Carbonic Acid.-The $\mathrm{CO})_{2}$ determinations, taken in conjunction with the volume of air entering and leaving the room, indicate a human production of this gas approaching eight-tenths of a c.f. per hour. (Sce page i1.)

Mvisture-Before January $24 \mathrm{th}$, each subject was weighed at the beginning and end of each evening's run, the average loss of weight in $7 i$ cases orer periods ranging from two and two-thirds to four-and-a-half liours being $0 \cdot 113$ pound per man per hour. This mostly represents water evaporated from the skin and lungs, the output of $\mathrm{C}_{2} \mathrm{O}_{2}$ being loss on the exchange of these gases leaves $0 \cdot 10+\mathrm{lb}$. as each man's hourly nearly balanced by the oxygen talken into the body. Allowing for the output of water vapour, equal to $2 \frac{1}{2}$ lbs. per day, or about the mean of the figures which have been published. Expressing the result in grains, we have in round numbers 700 grains of water per man per hour.

Heat.- Information as to the amount of heat generated in the body is scanty. Dr. Cxorlon, in his report on the rentilation of the House of Commons, issued in 1906, quotes an estimate by Rubner amounting to 


\section{Relative Hygicnic Values of Gas and Electric Lighting.}

2,700 (large) calories per adult man per day, equivalent to $446 \cdot 4$ B.T.U. (gross) per hour. Nearly a quarter of this (107.5 B.T.U.) is expended in evaporating the above-mentioned tenth of a pound of water, leaving 338.9 B.T.U. (or say 340 B.T.U.) as the net calorific value of an adult man.* The human production of heat is thus equal to about a half of that of a 25 c.p. Darwin gas-burner, and slightly more than that from an electric glow lamp of the same power.

In an ordinary dining-room of the size of those now in question, there would often be as many as six men at a time. The yields of heat, moisture, and $\mathrm{CO}_{2}$ from two burners and six men respectively are set out in the following table:-

\begin{tabular}{|c|c|c|c|}
\hline Hourly Psoduction of & $\begin{array}{c}\text { Tжо } 25 \text { c.p. } \\
\text { Electric Lamps, }\end{array}$ & $\begin{array}{l}\text { Two } 25 \text { c.p. } \\
\text { Gas Lumps. }\end{array}$ & Six MIon. \\
\hline 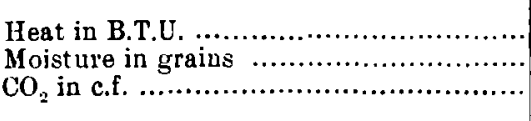 & $\frac{658}{-}$ & $\begin{array}{c}1,382 \\
1,012 \\
1 \cdot 54\end{array}$ & $\begin{array}{c}2,040 \\
4,200 \\
4.8\end{array}$ \\
\hline
\end{tabular}

The next table shows the changes which these quantities would bring about in one hour in the temperature and composition of the air of the room, the capacity being taken at 2,500 c.f., the initial temperature at $40^{\circ} \mathrm{F}$., the humidity $69 \mathrm{per}$ cent. (corresponding to $-21 \mathrm{gr}$. of water per c.f.), and the carbonic acid at the ordinary figure for town air, viz., 4 parts in 10,000 .

\begin{tabular}{|c|c|c|c|}
\hline & $\begin{array}{l}\text { Two } 25 \text { c.p. } \\
\text { Electric Lamps. }\end{array}$ & $\begin{array}{l}\text { Two } 25 \text { c.p. } \\
\text { Gas Lamps. }\end{array}$ & Six Mfon. \\
\hline 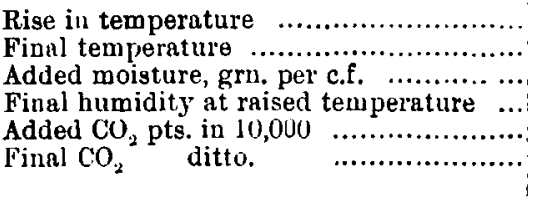 & $\begin{array}{c}13.9^{\circ} \mathrm{l} . \\
53.9^{\circ} \\
0 \\
43 \text { per cent. } \\
- \\
-\end{array}$ & $\begin{array}{c}29 \cdot 1^{\circ} \mathrm{F} . \\
69 \cdot 1^{\circ} \\
0 \cdot \pm \\
31 \text { per cent. } \\
6 \cdot 2 \\
10 \cdot 2\end{array}$ & $\begin{array}{c}43^{\circ} \mathrm{r} \\
85^{\circ} \\
1.68 \\
31 \text { per cent. } \\
19 \cdot 2 \\
23 \cdot 2\end{array}$ \\
\hline
\end{tabular}

It will be seen that the alterations brought about in the air of the room by the human contributions far exceed those from either illuminant. The figures assume that the air of the room is stationary: in actual experience the variation is much less, on account of ventilation. With an air supply equal to three times the contents of the room, which may be

* Benedict and Miller from their respiration calorineter experiments show that a man at rest evolves from 258 B.T.U. per lour when sleeping, to 347 B.'T.U. when sitting up.U. S. Bourd of Ayriculture Reports. 
taken as a measurable maximum, the changes would be proportionabily smaller, the increase in the $\mathrm{CO}_{2}$ becoming $2 \cdot 1$ and $6 \cdot 4$ parts from gasburners and men respectively.

A ir consumed.-Gas differs from electricity in requiring a certain amount of air to support combustion. $A$ c.f. of the gas used in these experiments consumes about $1 \%$ c.f. of oxygen, representing about $5 \cdot 7$ c.f. of air. Two burners, therefore, using together 2.56 c.f. of gas per hour, require $14 .(;$ c.f. of air. The average amount of air admitted per hour to each of the divided rooms, with the restricted ventilation adopted, was 2,000 c.f., of which the gas-burners consume just 0.73 per cent. The consequent reduction in the amount of oxygen in the room is precisely the same as would result from a fall in the barometer from $30 \mathrm{in.}$ to $29 \cdot 78 \mathrm{in}$.

Each man consumes about 1 c.f. of oxygen per hour, representing 4.8 c.f. of air, or two-thirds of the quantity required by each gas-burner.

\section{Calibunic Acin.}

Modes of sampling air.-In order to obtain average samples of the room air, a ring of tubing was laid along the walls $3 \frac{1}{2} \mathrm{ft}$. from the floor, with branches of indiarubber tubing ending in perforated plugs, which could be fixed in any desired position. A small enclosed electric fan comected with the main pipe drew air simultaneously and in equal quantitics through all the inlets. It was discovered, however, later that samples could be taken at a single point, which, if not absolutely identical with the arerage of the room, were proportional to it and sufficiently near for all purposes of the investigation. A glass tube was, therefor: placed in a convenient position near the centre of the room about $6 \frac{1}{2} \mathrm{ft}$. above the floor, and connected with a small pump, worked by a water-jet, whereby a constant current of air could be drawn through it.

The determination of carbon dioxide.-The most accurate results are obtained by the use of large volumes of air drawn for a considerable length of time through appropriate absorption reagents. Such a method was obriously excluded in the present case, since the samples had to be collected as rapidly as possible on a time basis, and Haldane's instrument, which admirably fulfils this condition, was, therefore, nsed throughout. After the observer had got accustomed to his instrument it was found that the arerage error of a single reading was \pm 0.5 part per 10,000 . Duplicates on outside air would frequently agree to 0.2 part per 10,000 , but on the other haud, readings would occasionally vary without assignable cause ly more than 1 part per 10,000 .

Numerous measurements were made as a check with an absolute 


\section{Relative Hygionic Values of Gus and Electric Lighting.}

baryta method, Hesse's modification of the original process of Pettenkofer being adopted. The average error of this was $\pm 0 \cdot 1$ part per 10,000 less than with the Haldane instrument, but this increased accuracy was more than neutralised, in the measurement of a rapidly falling carbonic acid content, when determining the ventilation, by the time required to take a sample, having regard to the necessity for the complete displacement of the air in the flask.

In other words, the value of each estimation then depends on two measurements, carbon dioxide and time, and it is useless to increase the accuracy with which the first is determined, if thereby an increased error is introduced into the time measurement. (See Vextilation. p. 66.)

It will be seen from the general tables that the occasions were rave on which the $\mathrm{CO}_{2}$ lid not reach 10 parts in 10,000, that it more often ranged between 20 and 30 parts, and that on two evenings (March 20th and 21 st) figures exceeding 50 were attained.

Hygienic Significance of Carbonic Acid.-The objection which is raised on hygienic grounds to lighting by means of gas is centred on the production of carbonic acid gas, which it is common to describe as a poison. It will be well to inquire what this means.

To begin witl, $\mathrm{CO}_{2}$ is a necessary constituent of the atmosphere, in which it is invariably present in the proportion of at least about 3 parts in every 10,000. If then it is a poison it follows that the purest air is poisoned to this extent. It is true that no man or other animal could exist in an atmosphere of $\mathrm{CO}_{2}$, but an atmosphere of nitrogen or even oxygen would be equally fatal; no one, however, speaks of these gases as poisonous. It is true also that a very large increase in the proportion of $\mathrm{CO}_{2}$ in the air would produce unpleasant, or even fatal effects, but the same holds good of any of its other constituents.

The question, therefore, resolves itself into one of amount,-in what proportion can $\mathrm{CO}_{2}$ be alded to the air without producing untoward results? This gas is used for airating mineral waters, and is present in the air of the factories where they are made in very large quantities ranging up to 300 parts in 10,000 . If the proportion reaches 500 parts $(5$ per cent.) it induces sickness or even death. In this connection it is important to note that the air expired from the lungs contains on an average 4.3 per cent. of $\mathrm{CO}_{2}$. It is not surprising that an atmosphere which approaches in composition the air which is ordinarily ejected from the lungs should be unsuitable for human respiration.

Under the extreme conditions which were maintained for the purpose of the experiment, the $\mathrm{CO}_{22}$ figure rose as high as 53.2 parts in $10,(100$ on 
one occasion, and frequently was orer 40 without becoming apparent to the senses or in any way affecting the health of those present. On many occasions the high figures were reached in electric-lighted rooms, so that the carbonic acid was entirely of human origin. It would be a rery poorly ventilated room in which even 20 parts in 10,000 would be found.

Dr. Angus Smith found that 300 volumes $\left(\mathrm{O}_{2}\right.$ per 10,000 of air produced feebleness of circulation, slowed the heart and quickened respiration, but felt no inconvenience with 20 in 10,000 . Pettenkofer and Voit, after long exposure to air containing 100 in 10,000 , found no discomfort.

Wilson, on the other hand, states that when $\mathrm{CO}_{2}$ is produced from persons and the amount reaches 15 per 10,000 in the air, headache is of ten produced, but he cloes not take into account any other factors.

Clande Bernard considered $\mathrm{CO}_{2}$ non-poisonous, as it could be injected into the borlies of animals without causing injury, and that it is purely negative in action.

Herman has definitely proved that increase of carbon dioxide up to 4 per cent., and a reduction of oxygen down to 15 per cent., rlo not produce any poisonous action in human beings.

Benedict and Milner quite recently, in an investigation on metabolism of matter and energy in the liuman body (U.S. Board of Agriculture Reports), have established that a subject in a respiration calorimeter can read, sleep and eat meals with the usual regularity and show no deviation from his usual physical and mental condition in an atmosphere containing 226 per $10,000\left(2 \cdot 3\right.$ per cent.) of $\mathrm{CO}_{2}$.

The harmlessness of carbonic acid gas in the largest quantities which are liable to occur is freely recognised by medical men and others who have dealt with the subject, and it is now acknowledged that the ill effects popularly attributed to this gas are actually due to entirely different causes. Thus the "Black Hole of Calcutta" is quoted by Dr. Billings as "an extreme instance of the co-existence of high temperature and excess of moisture in the air of an enclosed apartment." ("Ventilation and Heat," p. (66; see also Ilaldane and Lorrain Smith, J. Path., Edin., 1892).

Why, then, has so much stress been laid on the amount of ( $^{\circ} \mathrm{O}_{2.2}$ in air? It is because this gas, though innocuous in itself, is of ten associated with other substances of a more or less harmf ul nature. As a product of respiration it is accompanied by a certain amount of organic matter more or less offensive, and even by infective material and the germs of disease. The liability to convey disease germs is shared by many other substances, milk for example, which it is not customary to describe as poisonous. It may be guarded against by stcrilising the substance, in the case of milk

voL. xrix. No. 2. 
by boiling it. The $\mathrm{CO}_{2}$ from gas is necessarily sterile, and from a health point of view bears the same relation to that of respiratory origin as sterilised milk does to the unsterilised product.

The worst that can lue said even of respiratory $\mathrm{C}^{\prime} \mathrm{O}_{2}$ is that it is of ten found in bad company, and, as in other cases of the kind, it is made the scapegoat for the real culprits, which it is not always easy to identify. As an indicator of the amount of respiratory pollution, $\mathrm{CO}_{2}$ determinations will always be valuable, but it would he as absurd to compare the indicator with the obnoxious matter which it indicates, as it would be to regard the high chloride, which leads the chemist to suspect a drinking water of being contaminated with sewage, as the real polluting matter. They are both indicators, and nothing more.

The importance of the distinction between the $\mathrm{CO}_{2}$ from gas and that of respiratory origin is clearly recognised by the Departmental Committee on Ventilation in Factories, who, while recommending a maximum limit of 12 parts of $\mathrm{CO}_{2}$ in 10,000 in the day time, when the excess above that found in outer air is wholly or chiefly due to respiration, allow 20 parts after dark in places where gas or oil (but not electricity) is used for illuminating purposes.

\section{Vextilitiox.}

In considering the question of air contamination, there is a tendency to assume that the longer a room is in use the fouler the air will become. This is only partially true. It would hold good absolutely if the room were like a stagnant pond in which the effete matters accumulated to an indefinite extent. But no room is or can be like this; it is more analogous to a lake through which a river flows, changing its contents slowly and continuously. If such a lake receives a polluting liquid it will be seen at once that the extent of the contamination depends, not on the size of the lake, but on the proportion which the polluting flow bears to the volume of the river. Exactly the same thing will occur in the case of a room. The state of the air will depend, not on the size of the room, but solely on the ratio of the contamination to the incoming air. Since the matters which pollute air are not all readily measurable, it will be convenient to deal with a gas, such as $\mathrm{CO}_{2}$, the proportion of which can be exactly determined. Take the case of a room containing 2,500 c.f., in which there are six men, and two gas burners, producing respectively $4.8 \mathrm{c.f}$. hour, and 16 c.f. hour of $\mathrm{CO}_{2}, 6 \cdot 4$ c.f. hour in all. If the air supply is 3,200 c.f. hour, the excess of the $\mathrm{CO}_{2}$ which the outgoing air will contin as compared with incoming air will be $\frac{6 \cdot 4 \times 10,000}{3,200}=20$ parts in 10,000 . If $b, 400$ c.f. 
are admitted every hour, the proportion will be 10 in 10,000 and so on. This is the ultimate or steady state of the air, and is independent of the size of the room, which is only important as determining the length of time required to arrive at the steady state. It is difficult to follow the change in composition if the $\mathrm{CO}_{2}$ is regarded as added to the air of the room, but the difficulty disippears if we remember that the procluction of this gas and the admission of fresh air go on concurrently, and if we take the two in conjunction. Every c.f. of air that enters the rom may be regarded as carrying its quota of $\mathrm{CO}_{2}$ and displacing 1 c.f. of the old air. In most cases, especially in air filtering through the walls, it will not be far wrong to assume that the incoming air mingles fairly uniformly with that already in the room. Thus, when the first foot has passed in, the room contains $\frac{1}{2,500}$ part of new air and $\frac{2,499}{2,100}$ parts of old air. The second foot of new air displaces $\frac{1}{2,500}$ of each of these, and leaves $\frac{2,499}{2, i t(1)}$ of each. Therefore, when 2 c.f. hare passed in, there remains of the old air $\frac{2,499}{2,500} \times \frac{2,499}{2,500}$ parts, or $\left(\frac{2,499}{2,500}\right)^{2}$. Similarly after 3 c.f. have entered there will be $\left(\frac{2,49 !}{\frac{2,300}{2,03}}\right)^{3}$ parts of the old air, and after $\|$ c.f. $\left(\frac{2,499}{2,560}\right)^{n}$ parts. The calculation on these lines is an exceedingly simple one. It is merely necessary to multiply the logarithm of $\frac{2,498}{2,500}$ by the number of c.f. of air admitted to the room in the period in question, and the product will be the logarithm of the proportion of old air which remains. The balance will, of course, be new air, containing its proportion of $\mathrm{CO}_{2}$, and by spreading the latter over the whole contents of the room the percentage of this gas will be obtainerl. The change in the composition of the air of the room which results from the admission of varying volumes of new air is shown by the following table :-

$\begin{array}{rcccccc}\text { New air almitted...... } & 2,500 & 5,000 & 7,500 & 10,000 & 12,500 & 15,000 \\ =\text { Contents of room ... } & 1 & 2 & 3 & 4 & 5 & 6 \\ \text { Percentage old air left } & 36 \cdot 5 & 13 \cdot 5 & 5 \cdot 0 & 1 \cdot 8 & \cdot 7 & \cdot 25 \\ , \quad \text { new air ... } & 63 \cdot 2 & 86 \cdot 5 & 95 \cdot 0 & 98 \cdot 2 & 99 \cdot 3 & 99 \cdot 75\end{array}$

It will be seen that when the quantity of air admitted reaches three times the contents of the room only 5 per cent. of the old air will remain, and that when six volumes have passed through the change in the composition of the air of the room will be practically complete. Thus, with an air supply of $7,500 \mathrm{c}$. $\mathrm{f}$. per hour, a single hour will suffice to bring the room within 5 per cent. of the steady state.

Ventilation is brought about by a variety of causes, of which the chief are the wind and the difference of temperature inside and out. A tire 
burning under a chimney, or a gas cluster under a shaft, creates a powerful draught, and a gas burner, even when provided with no special outlet, sets up currents which stimulate the rentilation.

The measurement of large flows of air is always a difficult problem, especially in the case of ventilation, where the flow takes place not only through definite openings such as doors and windows, but also by the chinks around them, and even through the substance of the walls and ceiling.

In orrler to make sure of detecting the differences between the results of the two methods of lighting, it was decided to restrict the ventilation, and thus, by concentrating the products, to magnify their effects. Hence the closing of ventilators and fireplaces and the intercepting baize doors already referred to.

In such a case mechanical modes of measurement are out of the question. It was therefore decided to introduce into the room a large quantity of carbonic acid gas, mix it thorouglyly, and then at short intervals determine the proportion present. One or two trials were made as described by Pettenkofer, by burning a number of candles in the room, weighing them, calculating the amount of $\mathrm{CO}_{2}$ produced, and determining the proportion of the latter in the room atmosphere. As compared with the original or "fall" method this process has the disadvantages of being much slower and less accurate, and of involving a somewhat intricate calculation. The fall method was accordingly reverted to, and was used for the majority of the determinations.

Carbon dioxide was introduced from a cylinder of the liquefied gas, following the suggestion of Petri (Zrits. f. Hyg., Bd. VI.), and thoroughly mixed with the air of the room by means of an electric fan. The room was then closed, allowed to stand for at least thirty minutes, and samples drawn out at regular intervals of time througl the glass tube already mentioned.

The theory of the method* shows that, assuming rapid uniform

* let thie colume of fresh air entering the room be $v$. c.f. per hour. The volume of the room belny $T^{-}$c.f. Take the $\mathrm{CO}_{2}$ in the outside air as $a$ c.f. per c.f. (approximately 0.0004).

Let the (' $O_{2}$ at the start be $x$ (e.f. per c.f. of air) and consider the case where no fresh $\mathrm{CO}_{2}$ is bellly prorluced in the room. Three assumptions are requisite :-

1. That at the start the $\mathrm{CO}_{2}$ is uniformly diffused.

2. That the volume of fresh air entering the room per hour remains constant.

3. That the fresh air instantaneourly diffuses thruughout the room.

The fimt condition can be controlled by thoroughly mixing the air of the room mechanicilly before corwuencing measurements.

The secind condition cannot be controlled, but seems to have been fairly well fulfilled (see page lio). 
VENTILATION. SEMI-LOCARITHMIC DIACRAM

FIG. 7.

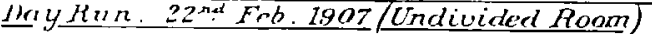

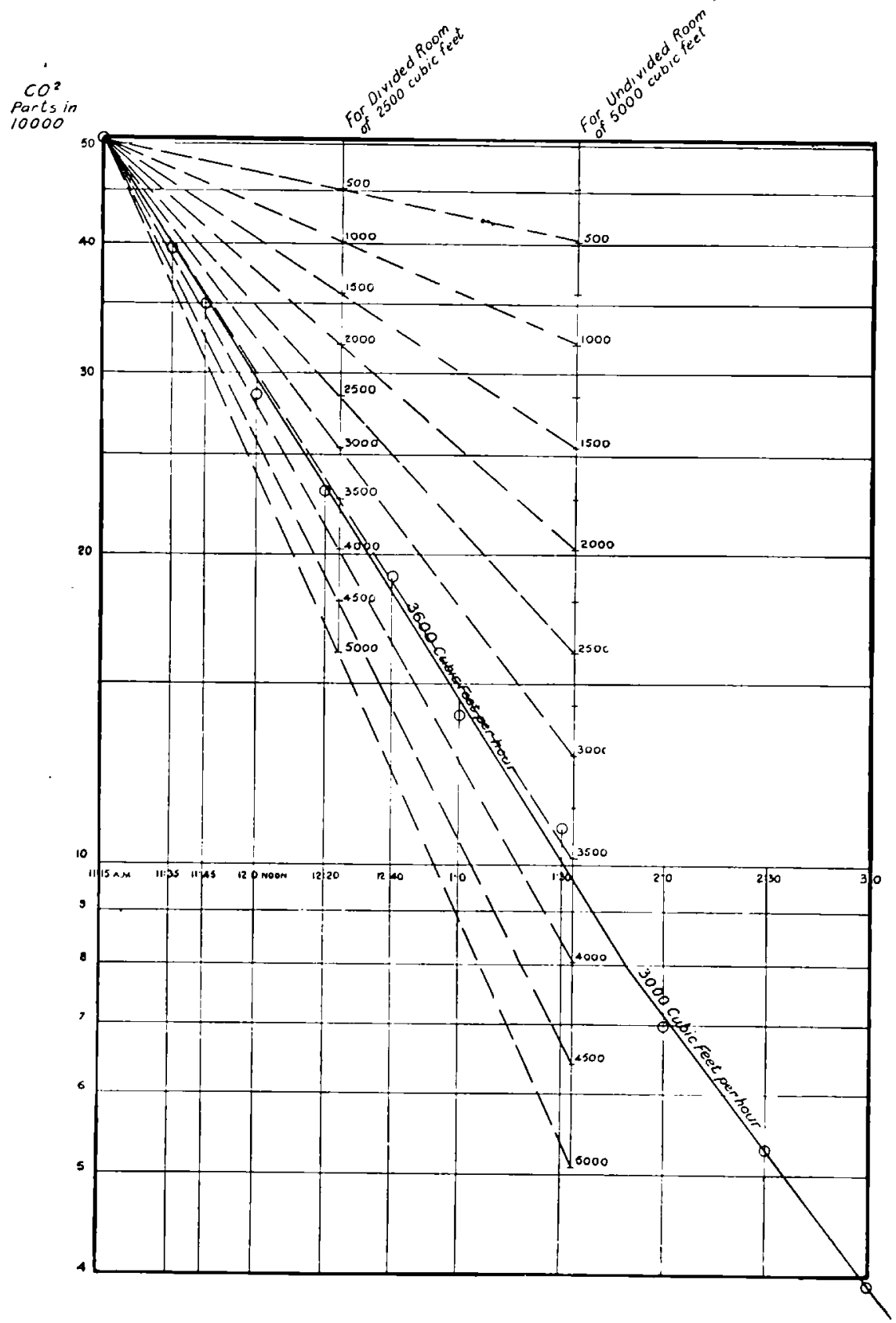


FIG. 8 .

RATE OF CHANCE OF AIR WITH WIND BLOWING FROM DIFFERENT QUARTERS (Urudivided Room)

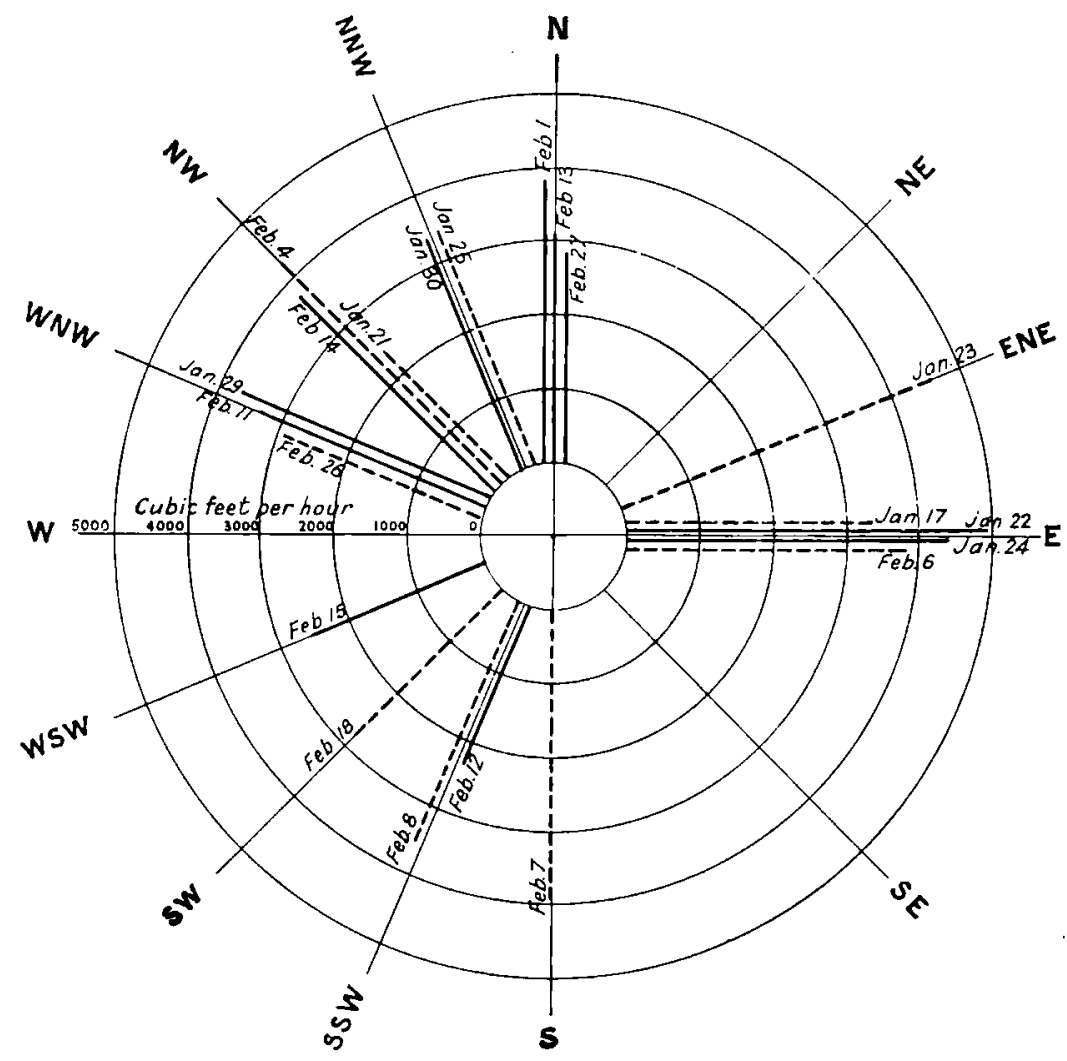

Calm Days

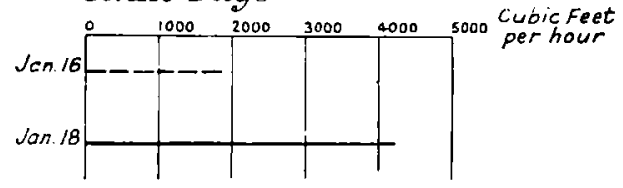

Arerage on days ulten there was aind.

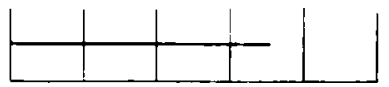

Gas evenings shom" by firm lines.

E7rotricity " " " totted lines. 
diffusion and uniform infux of fresh air, the logarithm of the carbon dioxide found (less the carbon diovide in the outside air) should be a linear function of the time. This suggested a new and rapid method of dealing with the experimental data, which was found in practice to be very advantageous. In the usual method of calculation, two logarithms have to be looked out for any pair of observations, their difference taken, and this, after reducing to Napicrian logarithms by the factor $2 \cdot 303$, multiplied by the volume of the room. Each pair of observations thus gives an independent value for the ventilation, and there is no means of discovering or rejecting a barl observation. Since on each day the ventilation was measured both immediately before and after the experimental run, necessitating at least ten or twelve observations, it was desirable that a more rapid methol of reduction should be employed. For this purpose the observations (less the outside air carbon dioxide) were directly plotted on semi-logarithmic paper, in which the ordinates were the logarithms of the $\mathrm{CO}_{2}$, the abscissa the times (Fig. $\bar{T}$ ). The fact that the points thus plotted are found to lie approximately on a straight line shows that the conditions assumed in reducing the logarithmic formula are fairly well fulfilled, and cloubtful observations can be eliminated at a glance. The difference of the ordinates for one hour taken off with a pair of dividers

The third condition can only be approxinately fultilled, and fails altogrether when the air enters in rapid currents at a few apertures.

It the start there is $x$. c.f. of $\mathrm{CO}_{2}$ per c.f. of air. In the time dt. the volume of air enteriug is v. dt. c.f. and the same vulume of air is expelled contuining vx. dt. c.f. of $\mathrm{CO}_{2}$. Hence, after the time dt. the total carbmic acid in the room will be $\mathbf{V x}-v x$. dt. + Fa, dt. in c.f. In worls this means the original carbunic acid, less the amount remuved ly the outening air plus the amount introduced by the fresh arr.

This equals Vx. - (x. - a) v dt. and this divuled by the rolume of the room gives the carbonic acid per c.f. af ter the time dt. (hours).

$$
x-\frac{v}{v}(x .-a) d t
$$

Calling the change in carbonic acid $\mathrm{dx}$. in the time dt., this gives

Therefore, by arranging and integrating

$$
-d x .=\frac{v}{v}(x-a) d t .
$$

$$
\log _{\theta}(x-\mathfrak{a})=\frac{\nabla}{V} t+c
$$

In this expression V., the volume of the room is a constant, $v$, the amount of fresh air entering per hour, is assumed (Conditiun 2) to lemain constant, and hence the Napierian logarithm of the $\mathrm{CO}_{2}$ (less that of the muside air) should be a linear function of the time. Ilence the use of the semi-logarithmic squared proper.

The constant $C$ cim be eliminated by integrating between limits, and the expression then becomes

$$
\operatorname{Loge}\left(x_{1}-a\right)-\log _{e}\left(x_{2}-a\right)=-\frac{v}{v}\left(t_{1}-t_{2}\right)
$$

where $x_{\text {, and }} x_{22}$ are the amounts of carbonic acil at the times $t_{1}$ and $t_{2}$ hence, disregarding the negative sign, the practical expression becomes

$$
\nabla=\frac{2 \cdot 3103 V}{t_{1}-t_{2}}\left\{\log _{10}\left(x_{2}-a\right)-\log _{10}\left(x_{2}-a\right) \cdot\right\}
$$




\section{Relative Hygienic Values of Gas and Elcclric Lighting.}

and laid along the scale of equal parts forming the abscissae gives immediately, without referring to a table of logarithms, the difference of the logarithms to the base 10 , and this multiplied by a constant 2.303 times the volume of the room, gives the rentilation in c.f. per hour.

Even this last calculation may be avoided by the use of a scale on tracing paper which, being superimposed over the logarithmic diagram, enalles the ventilation figure to be read directly.

Later on recourse was occasionally had to a thirl process, consisting in burning gas in the room until a steady state was reached, when the rate of air-change could be quickly computerl from the proportion of $\mathrm{CO}_{2}$ present and the quantity made.

To control the application of the logarithm formula, some continuous runs, extending over several hours, were taken. On one of these, when there was little or no wind, the whole of the results fell upon a straight line within the limits of the known experimental error, but point on the whole to a slight change in the rentilation about the middle of the run. When the ventilation was increased to a maximum by opening the doors, chimney, etc., the carbon dioxide fell so rapidly that accurate measurements were impossible. The condition of uniform diffusion could hardly be assumed to hold on these occasions, and although the results fell moderately well on a straight line, the use of the usual formula appears hardly legitimate. For this reason, ventilation figures of over 8,000 c.f. per hour must be regarded as rough approximations only.

\section{Compalison of Venthlitiox Ficicien.}

As the ventilation figures began to accumulate, wide variations became apparent in spite of the precautions taken to maintain uniform conditions in the room. It was thought that these variations might be due to changes in the direction and force of the wind, and careful search was made for indications of some relation between the air supply and these factors. Fig. 8., p. 68, shows the ventilations observed in the undivided room when the wind was blowing from various points of the compass, and it will be seen that the variations in the former bear no relation to the direction of the latter. The air supply seems to be independent also of the strength of the wind, some of the highest rates recorded having coincided with light winds, and even with calms.

In the absence of any constancy in the rentilation conditions the air supply was measured both before and after each evening's run, and in the preliminary calculations the ventilation during the evening was taken as the mean of those observed in the fore and after periods. 


\section{Ayount of Respiratory C().2.}

The first use which was made of the rentilation figures was fur the purpose of arriving at the amount of carbonic acid cxpired by the inmates of the room. Attempts had been made to obtain this information by means of a spirometer. The air expired during a definite time was received in a large bag of goldbeater's skin, the total volume and percentage of carbon dioxide being then determined. $\Lambda$ s data were accumulated, however, it became clear from the variation of the results for the same individual among themselves, and the divergence of the mean from the usually accepted figures, that the method was unreliable, and that no use could be made of the results. The inherent weakness of the spirometer method lies in the difference between the freedom of natural respiration and the constraint induced by having to breathe through a mouthpiece into a bag.

The measurement of the respiratory $\mathrm{CO}_{2}$ in the act of production proving thus impracticable, it was decided to estimate it in the gross by calculation from the proportion of $\mathrm{CO}_{2}$ in the room air and the ventilation figures. This method was only arailable on those evenings on which a steady maximum vilue for the ( $\mathrm{O}$, contents of the room was obtained. The ventilation of the room being known, say 3,000 c.f. per hour, and the steady $\mathrm{C}^{\prime} \mathrm{O}$, being also known, say 25 parts per 10,000 or .0025 c.f. per 1 c.f. of air (the distribution of the $\mathrm{C}^{\prime} \mathrm{O}_{2}$ being assumed to be uniform), the $\mathrm{CO}_{2}$ produced per hour would be-

$$
3,000(\cdot 0025-\cdot 0004) \text { or } 6 \cdot 3 \text { c.f. per hour. }
$$

On evenings when gas was burning the known volume of $\mathrm{CO}_{2}$ derived therefrom would have to be deducted from the total before the respiratory $\mathrm{CO}_{2}$ was worked out.

Since the experimental errors on the two quantities measured can be taken as under 5 per cent., the $\mathrm{C}_{2} \mathrm{O}_{2}$ produced should be known to the same accuracy, subject, as stated, to the assumption of uniform diffusion. This method has the alvantage over the spirometric one, that the respiratory $\mathrm{CO}_{3}$ is produced under perfectly natural conditions of breathing.

From a series of calculations on these lines it appeared that in the undivided room up to $\mathrm{March} 1$ st the $\mathrm{CO}$, produced per man under electric light averaged 0.74 c.f. per hour, between the limits 0.60 and 0.90 . The average figure obtained on gas evenings was 0.59 c.f. per man per hour, with a range from $0 \cdot 49$ to $0 \cdot 79$.

There was thus a striking difference between the apparent output of 


\section{Relative Hygienic Values of Gas and Electric Lighling.}

respiratory $\mathrm{CO}_{2}$ under gas and that under electricity, but that the real ontput varied in anything like the same proportion was a suggestion palpably untenable. There were, moreover, wide variations between the productions under the same illuminant, which could not be accounted for by any such hypothesis. The obvious conclusion, therefore, was that the ventilation during the run was not accuratcly represented by the mean of the fore and after periods. Closer examination of all the data clisclosed the fact that the changes in the ventilation rate were closely comected with those in the temperature of the room, or rather with the difference between this temperature and that of the outer air. This relation is clearly shown by the diagram (Fig. (1) of the ventilation rates for two weeks under gas and electric light. The dotted and firm black lines represent the ventilation in the fore and after period respectively, and the blue line the difference between the internal and the external temperatures. It will be seen that the ventilation figure was consistently much higher after the run than before it. The difference of temperature during the latter part of the evening, when the stearly $\mathrm{CO}_{2}$ figure was reached, was practically the same as it was in the after period, and it follows that the ventilation during the steady state was much nearer the second (or higher) figure than the first; consequently those values for the respiratory ( $\mathrm{O}_{2}$ obtained when there was least difference between the mean and final ventilations were to be preferred. These indicate a production of about 0.80 c.f. per head per hour, a figure which is very near the estimates of several well-known anthorities, and has accordingly been adopted for the purpose of these calculations.

Careful record was kept of the number of people present from time to time, and of the quantity of gas burnt per hour, and from these data the hourly production of $\mathrm{CO}_{2}$ could be calculated fairly closely. This being known, and the steady value of the $\mathrm{CO}_{2}$ in the air of the room determined, the air supply could be arrived at by a calculation the reverse of that given on page 71 . Thus on January 18 th there were 7 people in the room and 4.51 cubic feet of gas were being burnt each hour.

7 people at 0.8 c.f. per head give $\quad \ldots \quad \ldots \quad \ldots \quad 5 \cdot 1$ c.f. $\mathrm{CO}_{2}$ 4.51 c.f. gas at 0.58 c.f. give $\quad \ldots \quad \ldots \quad \ldots \quad \underline{\underline{2} \cdot 62} \quad, \quad$ ",

Total hourly production of $\mathrm{CO}_{2} \quad \ldots \quad \overline{5 \cdot 2 \cdot} \quad, \quad$,

The $\mathrm{CO}_{2}$ in the room reached a steady value of 23.5 per 10,000 , or $19 \cdot 5$ above the outer air; and from these figures the volume of air which entered the room in the hour is obtained by simple proportion

as $19 \cdot 5: 8 \cdot 22:: 10,000: 4,215$ 


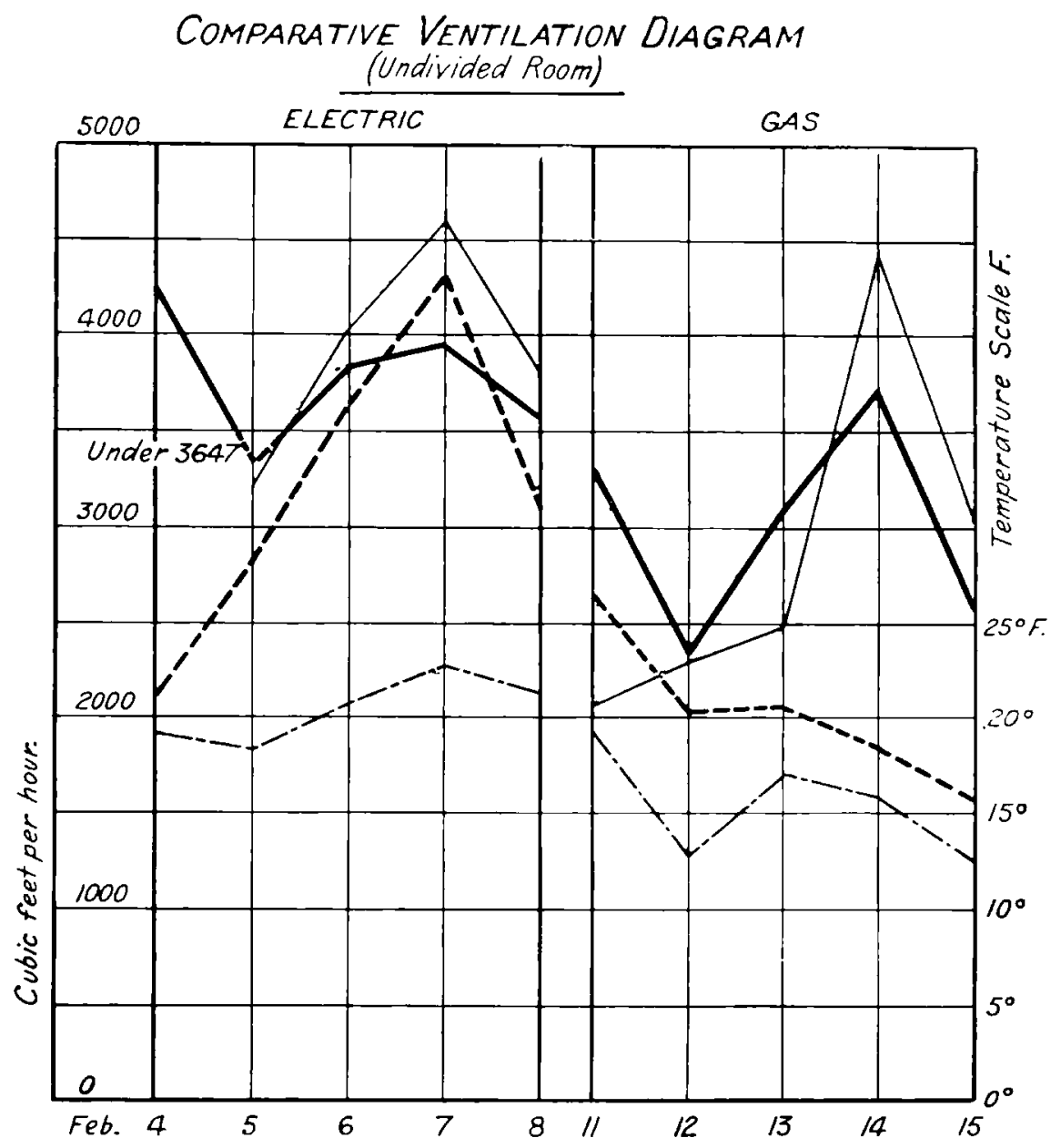

Air Supply before run shown thus" "during ", " $"\left\{\begin{array}{l}\text { Electric } \\ \text { Gas }\end{array}\right\}$

"Difference in Temperature between Roomand outer Air shown thus _.................... 
FIC. 10 .

\section{APPARATUS FOR ESTIMATION OF MOISTURE.}

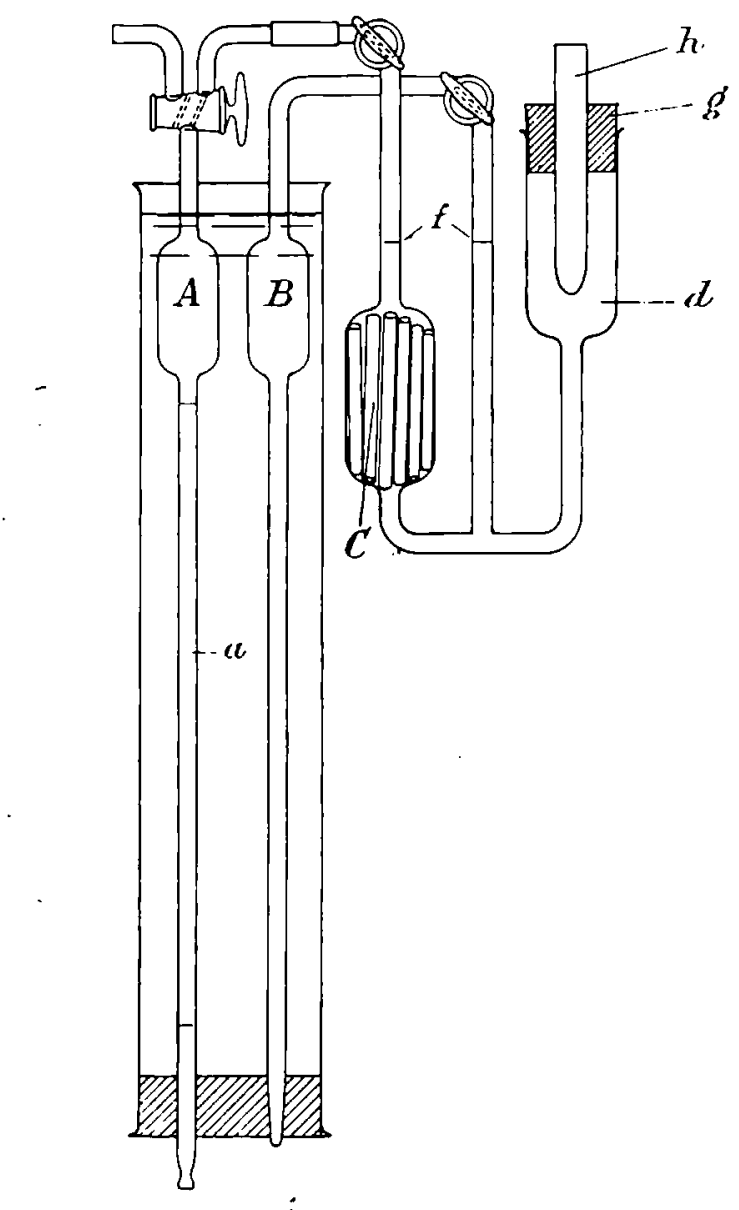

A, Haldone gas burette: bulb, $15 c c$, tube "a",6cc,graduated in .ol cc.

$B$, Compensating tu'se, useddry : both in water jacket.

$C$, Cylindrical bulb containing glass tubes and sulphuric acid.

$f$, Datum lines for the adjustment of the burette volume against the compensator.

$d$, Reservoir to contain the overflow of sulphuric acid.

g. Ordinary cork fitting loosely into " $d$ ".

$h$, Tube closed at one end sliding easily in " $g$,"serving to adjust acid level. 
The ventilation figures for each erening have been calculated by this method, and with those for the fore and after periods were arranged in Tables, of which the following is a summary. The lines in Fig. 9 show the ventilations so calculated.

Air Supply in Cubic feet per hour.

\begin{tabular}{|c|c|c|c|}
\hline & Arerage. & Maximum. & Minimum. \\
\hline 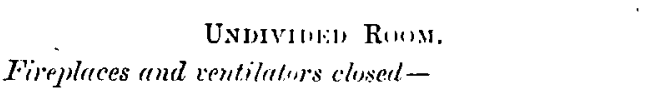 & & & \\
\hline 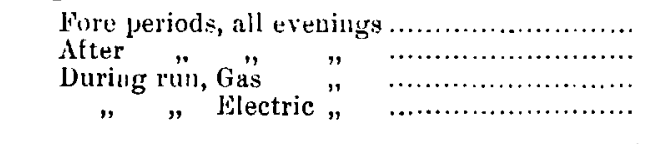 & $\begin{array}{l}2,6100 \\
3,21: 3 \\
3,5,5 \\
3,3 \overline{5} 5\end{array}$ & $\begin{array}{l}+, 300 \\
5,700 \\
5,100 \\
4,600\end{array}$ & $\begin{array}{l}1,100 \\
1,600 \\
2,3110 \\
1,800\end{array}$ \\
\hline \multicolumn{4}{|l|}{ Fireplaces and ventilutors open- } \\
\hline 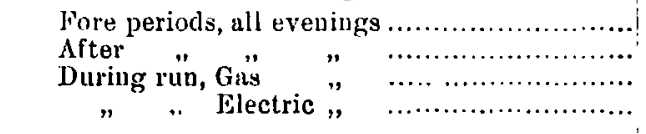 & $\begin{array}{l}8,025 \\
8,000 \\
7,835 \\
7, \geq 00\end{array}$ & $\begin{array}{l}9.000 \\
\text { (Single ob } \\
8,8110 \\
\text { (Sivgle ob }\end{array}$ & $\begin{array}{c}7.000 \\
\text { servition.) } \\
\quad(6,000 \\
\text { servation.) }\end{array}$ \\
\hline \multicolumn{4}{|l|}{ Fireplaces and ventilators closed- } \\
\hline 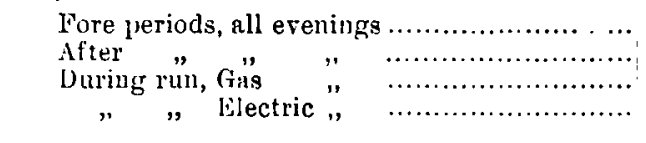 & $\begin{array}{l}1,597 \\
2,280 \\
2,11+5 \\
1,961\end{array}$ & $\begin{array}{l}3,400 \\
5,0000 \\
3,0000 \\
2,400\end{array}$ & $\begin{array}{r}800 \\
1,300 \\
1,+111 \\
1,400\end{array}$ \\
\hline \multicolumn{4}{|l|}{ Fireplaces and ventiletors upen- } \\
\hline 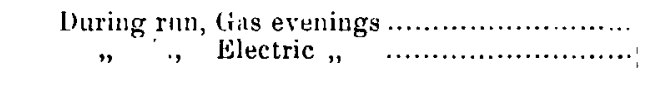 & $\begin{array}{l}.7,175 \\
3.7+8\end{array}$ & $\begin{array}{l}5,900 \\
4,0.0\end{array}$ & $\begin{array}{l}+.300 \\
3,500\end{array}$ \\
\hline 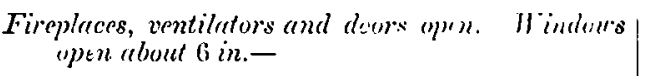 & & & \\
\hline 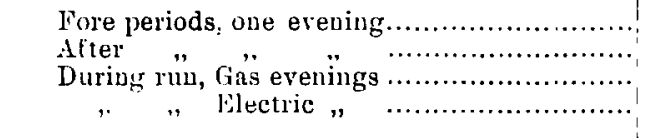 & $\begin{array}{l}* 17,5190 \\
* 17,10100 \\
* ! 1,1010 \\
* 17,000\end{array}$ & $\begin{array}{l}*-\overline{0} \\
*+1,010 \\
* 16,010 \\
*: 21,0<0\end{array}$ & $\begin{array}{l}- \\
*: 0,1000 \\
* * 1+000 \\
* 13,000\end{array}$ \\
\hline 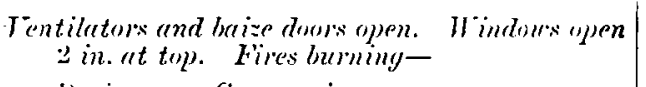 & & & \\
\hline $\begin{array}{c}\text { During run, Gas erening } \\
, y \ldots \ldots \ldots \ldots \ldots \ldots \ldots \ldots \ldots\end{array}$ & $\begin{array}{l}* 16,000 \\
* 15,100\end{array}$ & 二 & - \\
\hline * Rough approximations only. See note o & limitation & tho:1, p. 7i. & \\
\hline
\end{tabular}

It will be seen that the average hourly air supply to the undivided room during the preliminary period, all inlets and outlets being closed, was 2,600 c.f., equal to one-half its contents, and that the quantity of air admitted to each of the divided rooms under similar conditions areraged 1,600 c.f. per hour, or two-thirds of the whole, and in each case considerably higher values were obtained later on. On certain days preliminary 


\section{Relative Hygienic Values of Gas and Electric Lighting.}

ventilation figures were obtained without the corresponding cvening or final ones, or vice versâ, and these are included in the foregoing averages, which are, therefore, not strictly comparable. As the relation between the ventilation in the different periods is of some importance, separate tables (Appendix 1 and 2, pp. 125, 126) have been prepared giving in parallel columns the values obtained on all the evenings for which the information is complete, arranged according to the state of the room and the illuminant used. The average ventilation during each period, the ratio of each to the value in the preliminary period, and the proportion of $\mathrm{CO}_{2}$ recorded when the steady state was reached are as follows:-

\begin{tabular}{|c|c|c|c|c|c|c|}
\hline & \multirow{2}{*}{$\begin{array}{l}\text { Prelimi- } \\
\text { nary } \\
\text { ventilu- } \\
\text { tion. c.f. } \\
\text { per buur. }\end{array}$} & \multicolumn{2}{|c|}{$\begin{array}{l}\text { Tentilation } \\
\text { during rua. }\end{array}$} & \multicolumn{2}{|c|}{ Fival Ventilation. } & \multirow{2}{*}{$\begin{array}{c}\mathrm{CO}_{2} \\
\text { during } \\
\text { steady } \\
\text { state. } \\
\text { Parts in } \\
10,000 .\end{array}$} \\
\hline & & $\begin{array}{c}\text { c. f. } \\
\text { per bour. }\end{array}$ & $\begin{array}{l}\text { Ratio to } \\
\text { 'relimi- } \\
\text { nary. }\end{array}$ & $\begin{array}{c}\text { c. f. } \\
\text { per hour. }\end{array}$ & $\begin{array}{l}\text { Ratio to } \\
\text { Prelimi- } \\
\text { nary. }\end{array}$ & \\
\hline \multicolumn{7}{|l|}{$\begin{array}{c}\text { UNDIVIDED ROOn. } \\
\text { Fireplaces and rentilnturs closed- }\end{array}$} \\
\hline 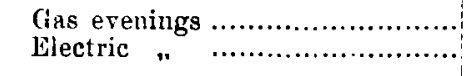 & $\begin{array}{l}2,587 \\
2,913\end{array}$ & $\begin{array}{l}3,579 \\
3,492\end{array}$ & $\begin{array}{l}1 \cdot 38 \\
1 \cdot 20\end{array}$ & $\begin{array}{l}3,18 \pi \\
3,667\end{array}$ & $\begin{array}{l}1 \cdot 23 \\
1 \cdot 26\end{array}$ & $\begin{array}{l}29 \cdot 5 \\
22 \cdot 6\end{array}$ \\
\hline \multicolumn{7}{|l|}{$\begin{array}{c}\text { DIrIdin Rooms. } \\
\text { Fiveplaces and Ventilators clused-- }\end{array}$} \\
\hline 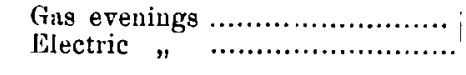 & $\begin{array}{l}1,335 \\
1,4: 25\end{array}$ & $\begin{array}{l}2,002 \\
1,950\end{array}$ & $\begin{array}{l}1 \cdot 50 \\
1 \cdot 37\end{array}$ & $\begin{array}{l}2,230 \\
2,016\end{array}$ & $\begin{array}{l}1 \cdot 67 \\
1 \cdot 41\end{array}$ & $\begin{array}{l}41 \cdot 1 \\
31 \cdot 1\end{array}$ \\
\hline \multicolumn{7}{|l|}{ Fireplaces and Ventilators open- } \\
\hline 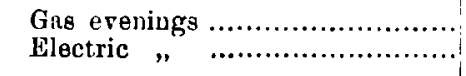 & $\overline{-}$ & $\begin{array}{l}5,078 \\
3,748\end{array}$ & $\overline{-}$ & $\bar{z}$ & $\overline{-}$ & $\begin{array}{l}194 \\
19 \cdot 3\end{array}$ \\
\hline $\begin{array}{l}\text { Fireplaces, Ventilators, duors and } \\
\text { windows open- }\end{array}$ & & & & & & 1 \\
\hline 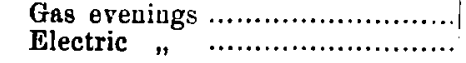 & - & $\mid \begin{array}{l}* 15,260 \\
* 17,01,27\end{array}$ & - & 二 & $\overline{-}$ & $\begin{array}{l}8 \cdot 7 \\
7 \cdot 2\end{array}$ \\
\hline
\end{tabular}

('omparing the results in the undivided room, although the conditions, as shown both by the preliminary and final tests, were more conducive to ventilation on the electric than on the gas evenings, the actual ventilation during the run was greater on the latter than on the former. In buth cases the air changes were more active during the evening's run than either before or after it, but whereas the evening ventilation under electricity showed an increase of only 20 per cent. over the preliminary figure, the rise under gas was 38 per cent. or nearly double.

The conditions in the divided rooms were somewhat different, the ventilation before the run having generally been determined by the steady 
state method, the $\mathrm{CO}$, being obtained by burning gas. This doubtless helps to account for the preliminary ventilation figures being proportionately higher than in the undivided room. These figures were generally from 10 to 20 per cent. higher in Room 6 than in Room 4, a difference which does not affect the comparison betwcen the two lights, as these were alternated from room to room.

The average air supply during the run was again much greater than that during the fore period, the larger increase being as before observed in the gas-lit room. The final rentilation figures in both cases were still higher, the reverse having been the case before the room was divided. This was clue in part to the candles which were burnt during a part of each evening for the purpose of the optical work, and which might at any time have added from 5 to 8 per cent. to the carbonic acid actually taken account of. It is possible, therefore, that some or all of the ventilation figures griven for the mid period are from is to 8 per cent. too low. It may be observed also that complete scts of results were available for five evenings only in the case of gas and for eight in that of electricity, and although the figures are on the whole fuirly consistent, they do not afford a sufficiently broad basis to justif y close comparisons. Looking, however, at the results as a whole it is evident that better ventilation was secured with gas than with electricity, and there is little doubt that this was due to the strong currents set up by the heated gases from the burners. That this experience is not an exceptional one is shewn by the results of some German experiments in the illumination of school rooms and drawing o.fices reported in the Zeitschrift fïr Architehtur und Ingenieurwesen of Wiesbaden for 1905 . It was found that in occupied rooms with the crudest ventilation, such as openings near the ceiling, the carbonic acid was actually less with gas than with electricity, a result which is attributed to the increased circulation due to higher temperature.

In the case of the divided rooms the greater ventilation during the run cannot be accounted for in this way, as the gas was usually burning while the preliminary ventilation figure was being determined. The increase on these occasions was due to the occupants themselves, who, on an average, contributed to the room twice as much heat as the gas burners, besides keeping the air in motion by their own movements and their respiratory currents.

It remains to note the effect of the increased ventilation in reducing the proportion of carbonic acid in the air. The average hourly air supply in the undivided room being 2,587 c.f. and the yield of $\mathrm{CO}_{2}$ from the gras 2.41 c.f., it follows that the gas burners would have increased the $\mathrm{CO}_{2}$ 


\section{Relative Hygienic Values of Gas and Elcctric Lighting.}

content by $\stackrel{2 \cdot 41}{2,58 \pi}=1000^{2}=9 \cdot 33$ parts in 10,000 , if all the other conditions had remained the same. The arerage $\mathrm{C}^{\mathrm{O}}$, figure for the electric erenings: was $22 \cdot 61$ and that for the gas evenings $29 \cdot 46$, or 6.85 higher. This difference, which is only about three-quarter's of the $\mathrm{CO}_{2}$ produced by the gas, would have been still less if the original rentilation conditions had been equal, as the average ventilation, both in the preliminary and funal periods, was considcrably greater on the electric nights. Two sets of figures are therefore appended, each giving the results for an electric evening and a gas evening when the means of the fore and after ventilations and the number of people in the room were approximately equal.

Ventilation.

\begin{tabular}{|c|c|c|c|c|c|c|c|}
\hline Date. & & Illuminant. & lnitial. & Finel. & Mean. & $\begin{array}{l}\text { Persons } \\
\text { present. }\end{array}$ & $\begin{array}{l}\mathrm{CO}_{2} \text { parts } \\
\text { in } 10,000 .\end{array}$ \\
\hline January 25 & & Blectricity & 2,860 & 3,340 & 3.100 & $7 \cdot 0$ & $20 \cdot 4$ \\
\hline,$\quad 18$ & ..... & 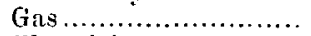 & $3,+21)$ & $2,8 \times 0$ & 3,150 & 70 & $23 \pi$ \\
\hline February (; & ......... & Electricity & 3,1500 & 4,050 & $3,8 \div 0$ & $7 \cdot 4$ & $19 \cdot 4$ \\
\hline January 22 & & 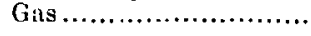 & 3,$9 ; 0$ & 4,000 & 3,080 & $6 \cdot 7$ & 198 \\
\hline
\end{tabular}

The foregoing results were obtained with restricted ventilation in the undivided rooms. The steady state ventilation determinations in the

Amount of Carbonic Acid in Divided Rooms during Preliminary "Steady State" determination and subsequent mun.

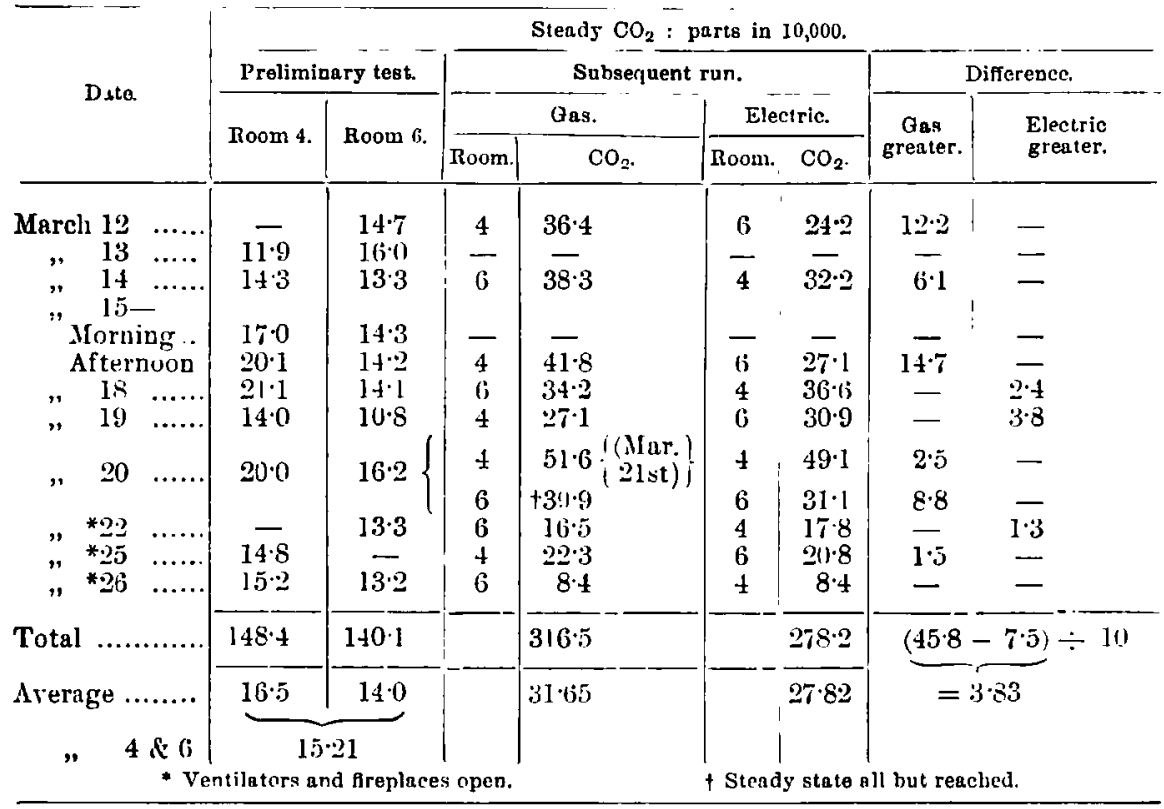


divided rooms gave an opportunity of determining directly the proportion of $\mathrm{CO}_{2}$ present when the gas had been burning continuously for twelve hours or more, and the $\mathrm{CO}_{2}$ had therefore attained its maximum value.

The average $\mathrm{CO}_{2}$ obtained in the nineteen preliminary trials was 16.5 in 10,000 in Room 4, and 14.0 in Room 6, giving for the two rooms a mean value of $15 \cdot 2$, or 11.2 above the outside air. It might therefore have been expected that the carbonic acid in the gas-lit room would have exceeded that in the electric room to this extent. Instead of this, the average of the former is only 3.83 parts above the latter, or for the restricted rentilation evenings 5.4 parts, representing respectively onethird and one-half of the excess produced. With orlinary ventilation the excess disappears altogether, the $\mathrm{CO}_{2}$ figures in the gas-lit and electric-lit rooms with fireplaces and ventilators open being practically identical. The high excesses in the gas room on March 12 th and 15 th are partly due to the population of this room having been slightly the higher, but chiefly to the inferior ventilation of Room No. 4, which was 20 per cent. below that of No. 6. Taking the series as a whole both disturbing elements disappear, each light having been used on the same number of occasions in each room, and the number of people in each being almost identical $(7 \cdot 17$ for tras as against 6.97 for electricity).

\section{Distribltion of Prodects of Combestion and Respilitin.}

From a lyggienic point of view the average composition of the air of a room is of less importance than the character of that within the breathing zone, say from $3 \frac{1}{2}$ to $6 \mathrm{ft}$. above the floor. The sampling system already described was laid ont specially to collect the air at different levels, and determinations were about to be put in hand when the work was brought to a close. Some information on the subject has, however, been obtained from a few sets of simultaneous samples taken at intervals along a single vertical line. Four gas sampling tubes with mercury bulbs were fitted to a frame with inlet tubes at the heights stated. By lowering a part of the frame carrying the bulbs all the tubes could be filled simultaneously with air from the corresponding levels. The contents of the tubes were then transferred over mercury to the Haldane apparatus and analysed in duplicate.

The following results were obtained : the numbers indicate the heights above floor level which are given in the table of averages:- 
Proportion of $\mathrm{CO}_{2}$ at different periols.

\begin{tabular}{|c|c|c|c|}
\hline Date. & No. & $\mathrm{CO}_{2}$ per 10,000 . & \\
\hline February $2 \pi$ & 1 & $32 \cdot 2$ & Gas aliglit for $1 \frac{3}{4}$ hours \\
\hline & 2 & $32 \cdot 8$ & before taking simples, \\
\hline & 3 & $31 \cdot 6$ & 8 people in room. \\
\hline & 4 & $26 \cdot 7$ & \\
\hline February 28 & 1 & $25 \cdot()$ & Gas alight 45 minutes only \\
\hline & 2 & $22 \cdot 0$ & before taking samples, \\
\hline & 3 & $23 \cdot 3$ & 8 people in room. \\
\hline & 4 & $2: 3 \cdot 3$ & \\
\hline March $1 \ldots \ldots \ldots$ & 1 & $17 \cdot 9$ & Gas alight $\supseteq$ hours before \\
\hline & 2 & $16 \cdot 1$ & taking samples, 5 people \\
\hline & 3 & $18 \cdot 7$ & in room. \\
\hline & 4 & $11 \cdot 3$ & \\
\hline March 20 & 1 & $53 \cdot 8$ & (Sample at 9 feet gave \\
\hline & 2 & $52 \cdot 4$ & $53 \cdot 2)$ \\
\hline & 3 & $54 \cdot 0$ & \\
\hline & 4 & $43 \cdot 7$ & \\
\hline April 4 & 1 & $16 \cdot 7$ & Gas. \\
\hline & 2 & $13 \cdot 9$ & \\
\hline & 3 & $13 \cdot 4$ & \\
\hline & 4 & $10 \cdot 7$ & \\
\hline April 5 & 1 & $25 \cdot 0$ & Electric with previous gas. \\
\hline & 2 & $26 \cdot 8$ & \\
\hline & 3 & $20 \cdot 1$ & \\
\hline & 4 & $15 \cdot 6$ & \\
\hline
\end{tabular}

The arerage figures from these results are:-

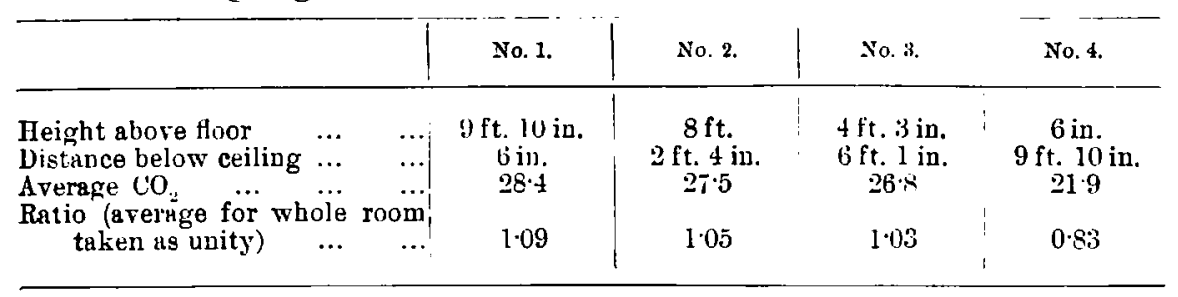

It is clear, therefore, that at levels above $4 \mathrm{ft}$. from the floor the composition of the air is practically uniform, and that only just above the floor level is a lower $\mathrm{CO}_{2}$, content $t$ (s) be found.

\section{Genelil. Obsirkytion ox lexthlatiox.}

The foregoing results are the more significant in view of the massive character of the walls and ceiling of the rooms. It will be remembered that in the undivided room with fireplaces and ventilators closed, the hourly air supply was only equal to one-half of the contents of the room. In an experiment of Pettenkofer's, under similar conditions, an ordinary room in his house, of 5,620 c.f., that is to say, about equal in capacity to 
one of the divicled rooms, had its entire contents changed in one hour. There can be no doubt therefore, that in a dwelling house of the ordinary construction, much higher ventilation figures would have been obtained than are recorcled in this Report, and that the superiority of the gas burners in point of ventilating effect would have been still more striking.

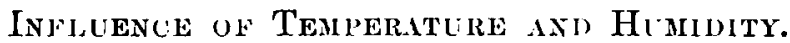

It has recently been pointed out by German writers, and in this country last year by Dr. Gordon, that the oppressive condition of the air of a crowded or badly ventilated room, and the unpleasant sensations which result from them are due, not as had been supposed, to any organic contamination of the atmosphere, but to its excessive temperature and humidity.

In 1883, Herman's experiments, already referred to, rendered it probable that respired air from healthy individuals was not very detrimental to health. Brown-Sequard and d'Arsonval came to the opposite conclusion, holding that an "Anthropotoxin" was given off, but this was disproved by Ben, Bauer, Lübbert, Lehmann and Jessen, Tormanek and others. Rietschel, in 1893, in addition to studying the chemical changes, considered the effects of the heat given off by human beings; and Kruger (1899) and Mehl (1903) brought forward the view that the ill effects of expired air were due to heat and moisture only.

More recently Flügge, making use of the result of the experiments of Heymann, P'aul and Ercklentz, concludes that the thermal effects are the only ones needing consideration hygienically, and considers that the temperature of the room should never rise above $21^{\circ} \mathrm{C}$. (say $70^{\circ} \mathrm{F}$.), and where people are working $17^{\circ}$ to $19^{\circ} \mathrm{C}$. (say $65^{\circ} \mathrm{F}$.)

Flügge summarises numerous experiments on healthy and sick people, and shows that the chemical changes produced in the gaseous condition of the air by the presence of human beings are not deleterious, but that the storage of lieat (Warmestauung) in closed rooms is. He shows that temperature, moisture, and movement of the air are of much greater importance than mere chemical change, and that much of the benefit produced by ventilation is due to the removal of heat from the human body rather than to the chemical purity of the fresh air introduced.

The evil effects of overheating a room can frequently be avoided by increasing the circulation of the air within it.

L. Paul in 1905 placed ten persons in glass vessels of three cubic metres' capacity, measuring temperatures by hanging thermometers and moisture by Kop's hygrometer, and observing :- 
1. Subjective symptoms.

2. Respiration and pulse.

3. Gärtner's tonometer (no results worthy of note).

4. Nosso's ergograph.

5. Mental test by performance of arithmetical work.

6. Measurements with Griesbach's asthesiometer.

The methods aimed at the accumulation of chemical impurities, but these were found to have not much influence. Normal persons first experienced unpleasant symptoms at $70-86^{\circ} \mathrm{F}$. with humidities of $45-86 \%$, the effect occurring with a lower humidity at the higher temperatures, while in a single case it appeared at $69.8 \%$ with $56^{\circ} \%$ humidity. The final conclusion was that "heat accumulation, and not chemical change of the air, is solely responsible for any unpleasant effects observed."

W. Frcklent\% (1905) continucd these experiments with sick instead of healthy people, noting the pulse, respiration, sensation and body temperatures only. No ill effects were observed except in one case of heart disease.

In the Joumnal of Hygiene, 1905, .J. S. Haldane mentions the difficulty of working in a mine when the temperature of the air is liggh, especially if it is also very moist.

We have seen that the human product of greatest quantity is tho water vapour; and the fact established by various inrestigators and confirmed by the present experiments, that the carbonic acid per se has no direct physiological infuence, is in harmony with the now accepted opinion that temperature and moisture are the two sole factors bearing on the problem. From a careful comparison of the physical data with the physiological records, no aberration of any note has been established, and it must therefore be inferred that the physical variations were too small to produce any clefinite physiological phenomena. This was to be anticipated, seeing that the human organism has ample powers of accommodation, and it would therefore only be when the physical environment was beyond the common range that any derangement of the balince of physiological action would be developed. Although no comparison has been noticed of general import, the chart showing the fall in body temperatures has a general resemblance to that recorded by the hygrometric tables, so that it may be stated approximately that the drier the air the greater will be the fall in body temperature during the experimental period. The amount of moisture given off by the persons in the room is the determining factor, and that from the gas is so small as to make very little alteration in the hygrometric state of the room. 
It seems established that high temperature and moisture have a pronounced action upon the respiratory exchange, which so alters the metabolism of those subjected to such change in the environment, as to render them less resistant to bacterial infection.

Attempts were made to ascertain, by actual experiment with the spirometer, the amount of water vapour and carbon dioxide given off by the breath. It was found that the number of respirations per minute did not appreciably alter the carbonic acid content of the expired air, but the experiments were abandoned, as it was impossible to get a determination of the amount of water evolved. Pflïger has, however, shown that the carbonic acid discharged is independent of the rate and depth of respiration, and that it is about $7 \cdot s$ grammes per man per minute. Haldane and Priestly have also established the fact that the percentage of this gas in the alveolar air remains constant (5.6-6.31 per cent.) for the same individual, even when the rate of respiration is altered. It may therefore be concluded that the lower respiratory rate noticed in these experiments at the end of the evening's observations with both kinds of lighting had no effect upon the normal respiratory exchange.

Rubner (Avc. f.' Hygiene, 1897), quoted by Leonard Hill ("Recent Advances," p. 268), has shown that the water output varies inversely as the humidity when the external temperature is constant. He found that the loss of water might be reduced 75 per cent. by surrounding the animal with wet instead of dry air, without any sign of disturbance. Again, the actual difference in heat production which resulted from varying the wetuess of the air 35 per cent. was not equal to that produced by altering the external temperature $1^{\circ} \mathrm{C}$. In another experiment a 25 per cent. increase in humidity equalled in effect a change in external temperature of $2^{\circ} \mathrm{C}$. In the case of warmed air $\left(25-30^{\circ} \mathrm{C}\right.$.) the evaporation of sweat proved to be a factor of greater amount, a 50 per cent. increase of humidity having the same effect as an increase in temperature of $5^{\circ} \mathrm{C}$. A temperature equal to or above that of the body cannot be tolerated if the air be saturated with moisture. The favourable conditions of relative dryness of the air for workers are, at $18-20^{\circ} \mathrm{C}, 60-40$ per cent. relative dryness; at $15^{\circ} \mathrm{C}, 30$ per cent. relative dryness; and at $25-30^{\circ} \mathrm{C}$, as $\mathrm{dry}$ as possible; at $\left.25-30^{\circ} \mathrm{C} ., 30-4\right)$ per cent. relative dryness is distinctly unfavourable (Wolpert).

Boycott and Haldane's "Study of the Effects of High External Temperatures" is in agreement with these conclusions. (Proc. Physs. Soc. Edin., 1905.)

VOL. Xxix, No. 2. 


\section{Relntive Hygienic Values of Gas and Electric Lighting.}

A simple practical rule for regulating the humidity of occupied roums is supplied by Dr. Gordon, who states that comfort may be secured by keeping the wet bulb thermometer below $60^{\circ} \mathrm{F}$.

The lower limit at which unpleasint symptoms begin to be felt has been variously stated. Dr. Billings, the Amcrican authority on ventilation, sars that the humidity may fall as low as 15 or 21 per cent. without causing discomfort, but this opinion appears to conflict with that of Professor de Chaumont.

The results obtained during the present investigation are recorled in the subsequent sections.

(a) Temperature.-It was first of all necessary to determine the ordinary distribution of heat within the room, with a view to devising a system whereby its true average temperature might be ascertained from a reasonable number of observations. There were two directions in which temperature gradients were to be looked for, namely, in successive horizontal layers from the ceiling downward, and in successive circumferential zones from the walls inward. Accordingly a vertical chain of o thermometers was hung from the ceiling at point $A$ on plan, p. 52, and a horizontal line of 6 thermometers a foot apart was placed between $B$ and $C$ about $i \mathrm{ft}$. from the floor. Thermometers were also set on each mantelpiece, on the inner buttress of the arch between the two rooms, on the ceiling close to the head of the rertical (hain, and on the floor near the outer wall.

The temperature at the floor level was generally about $5^{\circ}$ below the average of the room; but with this exception the temperature was fairly uniform throughout, more particularly under electric conditions. Thus at 8.45 p.m. on Jan. $22 \mathrm{nd}$, when the temperature of the outer air was $32^{\circ}$ and the arerage of the room $52 \cdot 9^{\circ}$ (gas being the illuminant), the temperature at the ceiling was $2.9^{\circ}$ above the average, and that at the floor $3.9^{\circ}$ below it. Except at these two stations the highest temperature was $1 \cdot 6^{\circ}$ above the average, while at two points only were the readings as much as $1.4^{\circ}$ below it. On the following evening the electric light was used. At $8.45 \mathrm{p}$.m. the average temperature of the room was $50.3^{\circ}$, and that of the outer air $29 \cdot 8^{\circ}$. The ceiling and floor temperatures were respectively $0.7^{\circ}$ above the arerage, and $3 \cdot 4^{\circ}$ below it. Of the remaining readings there was one only as much as $1.3^{\circ}$ below the average, and only two which exceeded it by a like amount. On the gas night the difference between the top and the hottom of the vertical series was $3^{\prime \prime}$, and on the electric evening $1.8^{\circ}$, the greatest differences found in the horizontal line being $1^{\circ}$ and $1 \cdot 1^{\circ}$ respectively. The temperature has usually been about a degree higher towards the centre of the room than at the wall, but 
the proximity of an assistant or subject to a thermometer has often cansed rुreater rlifferences.

It thus appeares that the only temperature gradient which need be aken into account in a study of the heat conditions was the vertical one, und that by taking the temperature of each horizontal stratum of air at a ingle point a good average figure miglit be obtained for the whole room. Accordingly, when the rooms were divided, a single vertical line of ; thermometers was hung in each about $3 \mathrm{ft}$. from the centre of the artition, and two other instruments were placed on the mantelpiece and in the partition about $; \mathrm{ft}$. from the floor. The temperatures given for he undivided room are therefore, with few exceptions, the averages of ?1 or 22 readings at different points, and those in each of the divided noms the averages of $x$ observations.

It was remarkable how, in spite of the difference in the readings of the arious thermometers, they all rose and fell together. Thus in Room 6 'n April 2nd the greatest rise at any point from $7 \cdot 2.5$ to $\$ \cdot 2.5$ p.m. was $1.8^{\circ}$, and the least $11 \cdot 6^{\circ}$. Thungl the agreement was not on every recasion quite so close, it was sufficiently so to show that the temperature of the room rose and fell as a whole. There is every reason to believe hat the heat was distributed by convection currents rather than by :onduction. From this rapid and unif $ı$ rm distribution of the heat mparted to the air of the roum, it seems reasonable to infer that the raseous constituents of the air were similarly distributed, and hence that he samples taken were fairly representative of the whole.

In this comnection the lifference which has been pointed out between he temperature of the air against the wall and that nearer the centre of he room is not without significance. If two columns of air, each a foot quare and as high as the room, one being a degree warmer than the other, he former will weigh just 11 grains less than the latter, and this lifference, slight as it is, will suffice to maintain an active and constant irculation. The heated streams of air from the gas-burners and the ungs of the occupants will rise rapidly to the ceiling, and spread outwards o the walls, down which they will flow, losing heat at every step of the var. The room will thus loe surrounded by a shell of air in which the roducts of combustion and respiration will be present in somewhat ;reater proportion than in the boily of the room. To this extent, thereore, their distribution will not be strictly uniform. The products in puestion, by reason of their proximity to the walls, will be favourably itnated for removal by the constant interchangre which talses place hrongh them, as well as by more definite channels. It follows that the 


\section{Relative Hygienic Values of Gas and Electric Lighting.}

ventilation figures which have been calculated from the known production of $\mathrm{CO}_{2}$ may be slightly in excess of the truth. Seeing, however, that, the function of ventilation is to carry off the combustion and respiratory products, its efficiency is to be measured by the thoroughness with which it does so rather than by the actual quantity of air remover. From a hygienic point of view, therefore, the conclusions reached are in no way vitiated by any inaccuracy of the ventilation figures due to the cause indicated. Bearing in mind that heat is the chief agent in promoting ventilation, it is significant that the amount grenerated in the undivided room was on the average 20 per cent. greater uncler gas than under electricity.

The temperature of the room, unlike the $\mathrm{CO}_{2}$, has rarely reached a steady state during the evening's run. This difference in behaviou between heat and the gaseous products is due to the fact that the walls ceiling, and windows of the room, which oppose a barrier (though ar imperfect one) to the escape of air and its contained ('(), actually conduct away the heat.

An examination of the temperature figures on several occasions show: that of the total heat lost from the room, only about 28 per cent. was carried off by the outgoing air, the remainder, amounting to 72 per cent of the whole, passing off by conduction and radiation. These proportion! varied within wide limits, according to the air supply and the differences ir temperature between the room, the building generally, and the onter air Thus, on April 2nd, when the ventilation was very low, only 5 per cent of the heat was carried off by the outgoing air, whilst on March 25 th, witl very rapid air changes, nearly the whule of it escaped in this way.

The following table gives a summary of the average temperatures a the beginning and end of the runs, arranged according to the state of the room and the lighting :-

\begin{tabular}{|c|c|c|c|c|c|c|c|c|}
\hline \multirow{3}{*}{ Arrangement. } & \multicolumn{4}{|c|}{ Gas. } & \multicolumn{4}{|c|}{ ELECTRIO., } \\
\hline & \multirow{2}{*}{ 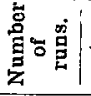 } & \multicolumn{3}{|c|}{ Degrees F. } & \multirow{2}{*}{ 竞品离 } & \multicolumn{3}{|c|}{ Degrees F. } \\
\hline & & Initial. & Final. & Rise. & & Initial. 1 & Fiual. & Rise. \\
\hline \multicolumn{9}{|l|}{ Restricted T'entilation. } \\
\hline Undivided room................. & 22 & $53 \cdot 6$ & $5 \% \cdot 0$ & 34 & 18 & 540 & $57 \cdot 2$ & $3 \cdot 2$ \\
\hline Diviled room ..................... & i & $59 \cdot 0$ & $63 \cdot 4$ & $4 \cdot 4$ & 6 & $58 \cdot 7$ & $62 \cdot 9$ & $4 \cdot 2$ \\
\hline \multicolumn{9}{|l|}{ Fireplaces and Ventilators open. } \\
\hline Divided room ................... & 2 & $60 \cdot 8$ & $63 \cdot 9$ & $3 \cdot 1$ & 2 & $59 \cdot 2$ & $6 \cdot 2 \cdot 7$ & $3 \cdot \overline{5}$ \\
\hline \multicolumn{9}{|l|}{$\begin{array}{l}\text { Fireplaces, Tentilators, Doors, } \\
\text { and II indou's open. }\end{array}$} \\
\hline Divided room .................... & 2 & $58 \cdot 4$ & $57 \div 5$ & $-0 \cdot 9$ & 2 & $58 \cdot 3$ & $56 \cdot 9$ & $-1 \cdot 4$ \\
\hline
\end{tabular}


In the case of the undividerl room the arerages of the initial and final temperatures are the same within half a degree for gas and electricity. In view of the fact that the observations were not made on the same, but on alternate evenings, and that the electric heater was in use a part of the time, the figures might have been regarderl as a mere coincidence, had they not been closely confirmed by the experiments in the divided room, which were made on the same evenings in both cases and under strictly parallel conditions. It thus appears that in spite of the much larger yield of heat from the gas burners (more than double that from the clectric limps) the ultimate heating effect of the two illuminants was practically identical.

This somewhat unexpected result is probably due to the porverful ventilating effect of the currents set up by the gas flames. The greater part of the heat arising from the combustion of the gas is imparted to the air which passes through the globes, emerging at a temperature of from $450^{\circ}$ to $500^{\circ} \mathrm{F}$. At such temperatures it weighs barely half as much as the colder air of the room, and therefore mounts in a steady and rapid stream to the cciling, orer which it spreads, transferring to the cciling most of its heat. The ceiling with its skeleton of steel joists thus performs for the air of the room the same office as the radiator of a motor car does for the circulating water. Hence only a small part of the heat from the gas is communicated to the main body of the air. The larger influx of fresh air due to the more active circulation set up helps further to moderate the temperature.

The hot column of air from the gas burners parts with its heat very rapidly, so that the ceiling temperature near the sides of the room shows no great excess above the room generally. The difference in the gas room was usually between one and two degrees, and that in the electric room under one degree. The air current from the electric lamps, being more sluggish, does not reach the ceiling so rapidly and hence the heat from them is not so rapidly dissipated.

A further observation which suggests itself is the very small extent to which the temperature rose on each occasion, in spite of the length of the rum, the crowded state of the room, and the severely restricted ventilation. The conclusion may fairly be drawn that with modern methods of lighting the heat question is practically eliminated. On two occasions, March 11th and 12th) the lights were left burning all night, and the temperatures noted early the following morning, the results being given in the table :- 


\section{Relative IIygienic Values of Gus and Electric Lighting.}

\begin{tabular}{|c|c|c|}
\hline Average temperature at beginning of run & $\begin{array}{l}\text { Gas. } \\
55 \div 5^{\circ}\end{array}$ & $\begin{array}{r}\text { Electric. } \\
56.5^{\circ}\end{array}$ \\
\hline Rise......... & $+\cdot 6$ & $3 \cdot 7$ \\
\hline Average temperature at end of evening .... & $60 \cdot 1$ & $60 \cdot 2$ \\
\hline Fall during night $\ldots \ldots \ldots \ldots \ldots \ldots$ & $4 \cdot 3$ & $4 \cdot 0$ \\
\hline Average temperature next morning . . . . . . & $55 \cdot 8$ & $56 \cdot 2$ \\
\hline
\end{tabular}

These figures show that neither illuminant was able to maintain the temperature which had been reached during the evening, which is thus shown to have been chiefly due to the heat given off by the occupants of the rooms. Further details of temperature are given in Appendix 3 and 4, pp. 127, 128.

(b) Humidity. - In the determination of moisture use was made throughout of the wet and dry bulb thermometers. The drawbacks of this instrument are well known. It is sluggish in its indications, and the usual tables for oltaining from the readings either the relative humidity or the absolute quantity of moisture, are calculated for outiloor conditions, and are, therefore, not directly applicable to instruments in a closed room. As, however, nearly all investigators, in working out the relations between quantity of moisture and physiological effects, have made use of the wet and dry bulb thermometers, the results are of practical value for comparisons.

Constants for the reduction of indoor observations were calculated by Regnault; but, as pointed out by Dr. W. N. Shaw, who has given some valuable suggestions bearing on this side of the enquiry, these constants probably hold good only when the air is near saturation, i.e., when the difference between the readings of the bulbs is least. When the reading of the wet bulb is considerably below that of the dry bulb, convection currents are thereon set up which bring the indoor conditions into closer conformity with the outdoor, thus reducing the errors which result from using the outdoor table just where they would be most serious. In the absence of special tables for indour work Glaisher's tables are generally used, and this has been done in the present case, since any corrections would be too small to affect the conclusions.

It was thought desirable, however, that the absulute amount of moisture per cubic foot of air should be determined if possible, and this on samples taken rapidly, as in the carbon clioxide determinations, so that rapid changes in the humidity of the air could be followed.

An examination of the previous attempts in this direction (see "Report on Hygrometric Methods, First Part, including the saturation method and 
the chemical method, and Dew-point instruments," by W. N. Shaw, Phil. Irans., 1888) showed that the problem was one of considerable difficulty. A special instrument was therefore constructed following on the lines of Schwackhöfer's apparatus, but provided with an automatic compensating arrangement like that used in the Haldauc ( $\mathrm{O}_{2}$, instrument. In the latter the two manometer tubes and the levelling bullo containing the caustic potash are connected by rubber tubing. For a hrgrometer confaining strong sulphuric acid this arrangement is obviously inarmissible, and the following was therefore substituted. A large model Haldane burette and compensator were adopted, the graduatel portion of the burette $(a)$ containing 600 divisions, one of which was equal to $\frac{1}{2,100}$ th of the whole volume enclosed, and as it was easy to read to 11, th of this by estimation, the accuracy of reading was 0.005 per cent. The spherical absorption bulb of the $\mathrm{CO}_{2}$ apparatus was replaced by a cylindrical bulb containing glass tubes, to increase the exposed surface of acid, and this was joined in one piece to the tube leading from the compensating bull, and to the bull, for holding the acid during the absorption. Since this arrangement does not permit of the latter bulb being used to adjust the levels, the adjustment in question is effected by means of a closed tube sliding loosely through a cork in the upper part of the acid reservoir. The delicacy of the adjustment can be altered by altering the size of the closed tube. It will be seen that the instrument is a modified Schwackhöfer, with the advantage that any changes in temperature and pressure are automatically compensated. This allows of a finer graduation, thus giving increased accuracy of reading, and as the readings are compensated no after currections are required. Preliminary experiments with this apparatus disclosed one difficulty; whereas in the estimation of carbon diuxide two or three transferences between the burette and absorption pipette are ample for the complete removal of the gas, this is not sufficient to remove the moisture when strong sulphuric acid is used as the absorbent. There can be no doubt that the air is completely dried by one contact with the acid, the second transference being required by the air left in the dead spaces of the instrument. When this dried air is passed back into the burette for measurement it takes up a further proportion of moisture from the walls, and a third passage over into the acid bulb shuws a slight diminution in volume. Each time the air is dried a small proportion of fresh moisture comes away from the colass walls of the burette, so that the realings of volume aplroximate slowly to a constant value. On this account from eight to ten transferences are required before the readings become constant. This is a serious disadrautage, as a 


\section{Relative Hygienic Values of Gas and Electric Lighting.}

single determination becomes a tedious affair. A modification which may get over this difficulty was proposed, namely, that the sulphuric acid should be replaced by water, and the increase of volume required to saturate the air noted. Further experiments on this instrument were put a stop to by the shutting down of the work. It can probably be developed into a practical working instrument, but the hygroscopic properties of the glass will put a limit to its accuracy and speed of use.

The apparatus is shown in Fig. 10, p. 72.

The word "humidity" is always understood in a relative sense: that is to say, it signifies not the actual amount of moisture in the air, but the ratio between this amount and the quantity which is required to saturate the air. This quantity varies with the temperature, being least at low temperatures, and rising in a much higher ratio than the temperature.

Air which is saturated with water vapour at $32^{\circ}$ will consequently be comparatively dry when raised to $60^{\circ}$, the relative humidity falling from 100 per cent. to 35 per cent., although the actual amount of moisture remains unchanged. For this reason the humidity in the rooms has generally been less than that of the outer air, the increase in the temperature having lowered the (relative) humidity more than the addition of moisture from the gas and lungs has raised it.

The difference between the intermal and extermal humidities would liave been still greater had it not been for the action of the surfaces of the room. These also, though apparently dry, hold moisture in large quantities; so that a shallow layer of the surface of the walls and ceiling contains more water than all the air in the room. There is ordinarily a continual exchange between the air and the room surfaces: if either becomes moister it gives up water; if it becomes drier it receives moisture. In this way the walls serve as a compensating reservoir to help to maintain the humidity of the air approximately constant. When the air has been hotter and drier than the walls, the latter have ordinarily parted with moisture to the former. Afterwards, when the air has cooled and become (relatively) moister, it has given back moisture to the walls.

In the undivided room the final humidity was 80 per cent. or over on twelve evenings, seven under gas and five under electricity; but on all but one occasion, when water was purposely evaporated in the room, the temperatures were low, ranging down to $51.9^{\circ}$. Had the room been warmed to $60^{\circ}$, or over, all these high humidities would have been reduced. The livided rooms were warmer, and on no ordinary occasion was the humidity in either of them at the end of the evening over 79 per cent.

It was thought desirable to push the humidity in both directions to 
such a point as to permit a study to be made of the effects of a large excess and a large deficiency respectively. On several occasions, therefore, water was evaporated during the day by means of electric liettles and beakers placed on the electric heater and (when gas was to be used during the evening) by a Bunsen burner: This was done in the undivided room on February 26 th, 27 th and 28 th, the 27 th being a gas evening and the other two electric. The largest quantity evaporated was about twelve pints on February 28 th, and the highest humidity reached 84 per cent., at $8.25 \mathrm{p} . \mathrm{m}$. on that evening. A notable feature of these experiments was the small proportion (from 10 to 12 per cent.) of the water vaporised which was found in the air of the room. On none of these occasions were any noticeable effects produced.

The experiment was repeated in the divided room on March 20th and 21 st. On the former evening gas was used in both rooms and on the latter electricity. Water was evaporated during the day by means of the electric kettle and (for forty minutes in the case of Room 6) by a Bunsen burner. By $4.20 \mathrm{p} . \mathrm{m}$. humidities of 94 per cent. were reached in both rooms (with temperatures of $62 \cdot 4^{\circ}$ and $61 \cdot 7^{\circ}$ ) but by 6 p.m. these figures had dropped to 76 per cent. and 72 per cent. respectively.

(On the following evening the electric kettles were kept going till 8.30 p.m., the temperatures and humidities being as follows -

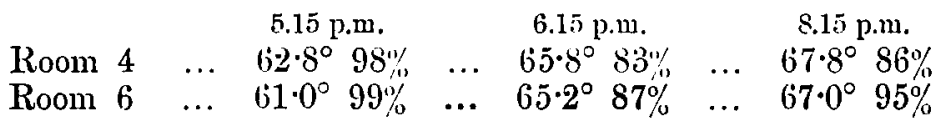

'The air in both rooms was distinctly close, but no marked discomfort was experienced.

() March 28th an experiment was made with dry heat, each room being warmed by a good coal fire and an electric heater. The rentilators and the baize doors were open, and the windows were opened $2 \mathrm{in}$. at the top. The temperatures, etc., were as follows :-

\begin{tabular}{|c|c|c|c|c|c|}
\hline & $\begin{array}{l}\text { Average } \\
\text { temp. }\end{array}$ & $\begin{array}{c}\text { Dry } \\
\text { bulb. }\end{array}$ & $\begin{array}{l}\text { Wet } \\
\text { bulb. }\end{array}$ & Difrerence. & Humidity. \\
\hline Roon 4-(Electric): $\begin{array}{l}7 \text { p.m. } \\
9.30 \text { p.m. }\end{array}$ & $\begin{array}{l}68.8^{\circ} \\
71^{\circ} 1^{\circ}\end{array}$ & $\begin{array}{l}69 \cdot 6^{\circ} \\
73^{\circ} \cdot 6^{\circ}\end{array}$ & $\begin{array}{l}59 \cdot 3^{\circ} \\
61 \cdot 2^{\circ}\end{array}$ & $\begin{array}{l}10 \cdot 3^{\circ} \\
12 \cdot 4^{\circ}\end{array}$ & $\begin{array}{l}52 \% \\
46 \%\end{array}$ \\
\hline 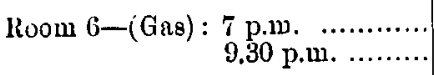 & $\begin{array}{l}70 \cdot 3^{\circ} \\
74 \cdot 0^{\circ}\end{array}$ & $\begin{array}{l}69 \cdot 0^{\circ} \\
73 \cdot 0^{\circ}\end{array}$ & $\begin{array}{l}61 \cdot 0^{\circ} \\
63 \cdot 2^{\circ}\end{array}$ & $\begin{array}{l}8 \cdot 0^{\circ} \\
9 \cdot 8^{\circ}\end{array}$ & $\begin{array}{l}61 \% \\
55 \%\end{array}$ \\
\hline
\end{tabular}

Both rooms felt very warm, but not oppressive. 


\section{Relative Hygienic Values of Gas and Electric Lighting.}

\begin{tabular}{|c|c|c|c|c|c|c|c|}
\hline & \multicolumn{3}{|c|}{ Thermometer: } & \multicolumn{3}{|c|}{ Grains of Moisture. } & \multirow{2}{*}{ 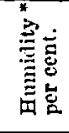 } \\
\hline & Dry Bulb. & Wet Bulb. & $\begin{array}{l}\text { Differ- } \\
\text { ence. }\end{array}$ & $\begin{array}{l}\text { Per } \\
\text { c. f. }\end{array}$ & $\begin{array}{l}\text { Whole } \\
\text { Roomi. }\end{array}$ & $\begin{array}{l}\text { Keypired } \\
\text { to cont- } \\
\text { piete satu- } \\
\text { rntion. }\end{array}$ & \\
\hline 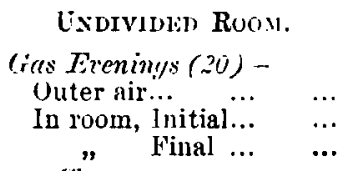 & $\begin{array}{l}430 \\
53 \cdot 36^{\circ} \\
56 \cdot 70^{\circ}\end{array}$ & $\begin{array}{l}390 \\
49 \cdot 17^{\circ} \\
52 \cdot 87^{\circ}\end{array}$ & $\begin{array}{l}3^{\circ} \\
4 \cdot 19^{\circ} \\
3 \cdot 83^{\circ}\end{array}$ & $\begin{array}{r}3 \cdot 46 \\
3 \cdot 43 \\
3 \cdot 97 \\
\end{array}$ & $\begin{array}{l}12,300 \\
17,150 \\
19,850 \\
\end{array}$ & $\begin{array}{l}\dddot{5}, 900 \\
5,950\end{array}$ & $\begin{array}{l}78 \\
73 \cdot 9 \\
76 \cdot 6 \\
\end{array}$ \\
\hline Change $\quad \ldots \quad \ldots$ & $+334^{\circ}$ & $+370^{\circ}$ & $-\overline{0.36^{\circ}}-$ & +0.54 & $+2,700$ & +50 & $+2 \cdot 7$ \\
\hline 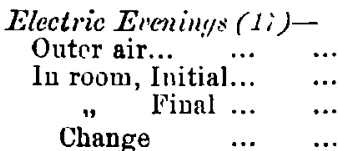 & $\begin{array}{l}42^{\circ} \\
53 \cdot 17^{\circ} \\
56 \cdot 21^{\circ} \\
+3 \cdot 04^{\circ}\end{array}$ & $\begin{array}{l}39^{\circ} \\
48 \cdot 79^{\circ} \\
52 \cdot 20^{\circ} \\
+3 \cdot 41^{\circ}\end{array}$ & $\begin{array}{l}3^{\circ} \\
4 \cdot 38^{\circ} \\
4 \cdot 01^{\circ} \\
-0 \cdot 37^{\circ}\end{array}$ & $\begin{array}{r}2 \cdot 43 \\
3 \cdot 35 \\
3 \cdot 85 \\
+0 \cdot 50\end{array}$ & $\begin{array}{r}12,150 \\
16,750 \\
19,2,50 \\
+2,500\end{array}$ & $\begin{array}{c}\dddot{6,150} \\
6,150 \\
0\end{array}$ & $\begin{array}{l}77 \\
72 \cdot 7 \\
75 \cdot 4 \\
+2 \cdot 7\end{array}$ \\
\hline 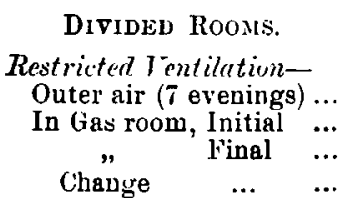 & $\begin{array}{l}47 \cdot 8^{\circ} \\
59 \cdot 2^{\circ} \\
63 \cdot 1^{\circ} \\
+3 \cdot 9^{\circ}\end{array}$ & $\begin{array}{l}+4 \cdot 3^{\circ} \\
54 \cdot 1^{\circ} \\
58 \cdot 3^{\circ} \\
+4 \cdot *^{\circ}\end{array}$ & $\begin{array}{r}3 \cdot 5^{\circ} \\
51^{\circ} \\
+8^{\circ} \\
-0.3^{\circ}\end{array}$ & $\begin{array}{r}296 \\
398 \\
4 \cdot 70 \\
+0 \cdot 72\end{array}$ & $\begin{array}{r}7,400 \\
9,950 \\
11,750 \\
+1,800\end{array}$ & $\begin{array}{l}\ldots \ldots 00 \\
4,1050 \\
+150\end{array}$ & $\begin{array}{l}76 \cdot 6 \\
70 \cdot 1 \\
72 \cdot ! \\
+2 \cdot 8\end{array}$ \\
\hline 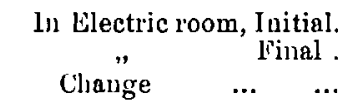 & $\begin{aligned} 58 \cdot 3^{\circ} \\
62 \cdot 5^{\circ} \\
+2 \cdot 20\end{aligned}$ & $\begin{array}{r}53 \cdot 4^{\circ} \\
57 \cdot 9^{\circ} \\
+4 \cdot 5^{\circ}\end{array}$ & $\begin{array}{r}4 \cdot y^{\circ} \\
4 \cdot 6^{\circ} \\
-0.30\end{array}$ & $\begin{array}{r}391 \\
467 \\
+076\end{array}$ & $\begin{array}{r}11,775 \\
11,675 \\
+1,910\end{array}$ & $\begin{array}{l}3,050 \\
4.000 \\
+150\end{array}$ & $\begin{array}{r}71 \cdot 4 \\
736 \\
+203\end{array}$ \\
\hline 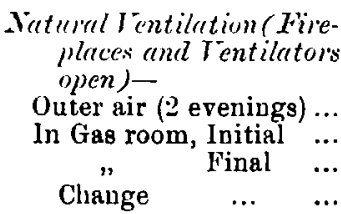 & $\begin{array}{r}54 \cdot 2^{\circ} \\
61 \cdot 6^{\circ} \\
64 \cdot 5^{\circ} \\
+2 \cdot 2^{\circ}\end{array}$ & $\begin{array}{r}50 \cdot 1^{\circ} \\
56 \cdot 3^{\circ} \\
59 \cdot 1^{\circ} \\
+2 \cdot 8^{\circ}\end{array}$ & $\begin{array}{r}4 \cdot 1^{\circ} \\
5 \cdot 3^{\circ} \\
5 \cdot 4^{\circ} \\
+0.1^{\circ} \\
\end{array}$ & $\begin{array}{r}3.54 \\
4.27 \\
4.71 \\
+0 \cdot 44 \\
\end{array}$ & $\begin{array}{r}8,850 \\
10,675 \\
11,775 \\
+1,100\end{array}$ & $\begin{array}{l}4,550 \\
4,975 \\
+425\end{array}$ & $\begin{array}{l}74.5 \\
69.5 \\
70 \cdot 0 \\
+0.5\end{array}$ \\
\hline $\begin{array}{c}\text { In Electric room, Initial. } \\
\text { Pival }\end{array}$ & $\begin{array}{l}59 \cdot 6^{\circ} \\
63 \cdot 0^{\circ}\end{array}$ & $\begin{array}{l}5 \pm 7^{\circ} \\
57 \cdot 8^{\circ}\end{array}$ & $\begin{array}{l}4 \cdot y^{\circ} \\
5 \cdot 2^{\circ}\end{array}$ & $\begin{array}{l}4.07 \\
4.52\end{array}$ & $\begin{array}{l}10,175 \\
11,300\end{array}$ & $\begin{array}{l}4,050 \\
4,650\end{array}$ & $\begin{array}{l}71 \cdot 0 \\
70.5\end{array}$ \\
\hline $\begin{array}{lll}\text { Change } & \ldots & \ldots\end{array}$ & $+34^{\circ}$ & $+3 \cdot 1^{\circ}$ & $+0.3^{\circ}$ & $+0 . \overline{45}$ & $+1,125$ & +600 & $-0 \cdot 5$ \\
\hline $\begin{array}{l}\text { Increased Tentilation } \\
\text { (Door's and W"indous } \\
\text { open)- } \\
\text { Outer air (2 evenings) ... } \\
\begin{array}{ccc}\text { In Gas room, Initial } & \ldots \\
\text { Change } & \text { Final } & \ldots \\
\text { Change } & \ldots\end{array}\end{array}$ & $\begin{array}{l}54 \cdot 9^{\circ} \\
58 \cdot 4^{\circ} \\
57 \cdot 3^{\circ} \\
-1 \cdot 1^{\circ}\end{array}$ & $\begin{array}{r}51 \cdot 0^{\circ} \\
52 \cdot 2^{\circ} \\
51 \cdot 5^{\circ} \\
-0 \cdot 7^{\circ} \\
\end{array}$ & $\begin{array}{r}3 \cdot 9^{\circ} \\
6 \cdot 2^{\circ} \\
5 \cdot 8^{\circ} \\
-0 \cdot 4^{\circ} \\
\end{array}$ & $\begin{array}{r}3 \cdot 68 \\
3 \cdot 58 \\
3.52 \\
-0 \cdot 06 \\
\end{array}$ & $\begin{array}{l}9,200 \\
8,950 \\
8,800 \\
-150\end{array}$ & $\begin{array}{l}\dddot{4} 7.25 \\
4,350 \\
-375\end{array}$ & $\begin{array}{r}75.5 \\
65 \cdot 0 \\
66 \cdot 0 \\
+1 \cdot 0\end{array}$ \\
\hline $\begin{array}{c}\text { In Electric room, Initial. } \\
\text { "lingl } \\
\text { Clange }\end{array}$ & $\begin{array}{r}58.4^{\circ} \\
56.5^{\circ} \\
-1 \cdot 9^{0}\end{array}$ & $\begin{array}{r}52 \cdot 5^{\circ} \\
51 \cdot 2^{\circ} \\
-1.3^{\circ}\end{array}$ & $\begin{array}{r}5 \cdot 9^{\circ} \\
5 \cdot 3^{\circ} \\
-0.6^{\circ}\end{array}$ & $\begin{array}{r}3.65 \\
-3.52 \\
-\quad 0.13\end{array}$ & $\begin{array}{l}9,125 \\
8,800 \\
-325\end{array}$ & $\begin{array}{l}4,550 \\
4,000 \\
-550\end{array}$ & $\begin{array}{r}66 \cdot 0 \\
68 \cdot 0 \\
+\frac{2 \cdot 0}{2}\end{array}$ \\
\hline 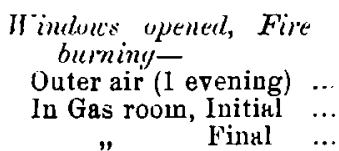 & $\begin{array}{l}61 \cdot 8^{\circ} \\
69 \cdot 0^{\circ} \\
73 \cdot 0^{c}\end{array}$ & $\begin{array}{l}54 \cdot 8^{\circ} \\
61 \cdot 0^{\circ} \\
63 \cdot 2^{\circ}\end{array}$ & $\begin{array}{l}7 \cdot 0^{\circ} \\
8 \cdot 0^{\circ} \\
9 \cdot 8^{\circ}\end{array}$ & $\begin{array}{l}3 \cdot 85 \\
4 \cdot 70 \\
4 \cdot 86\end{array}$ & $\begin{array}{r}9,625 \\
11,750 \\
12,150\end{array}$ & $\begin{array}{l}\dddot{7}, 6.0 \\
9,900\end{array}$ & $\begin{array}{l}62 \cdot 0 \\
61 \cdot 0 \\
55 \cdot 0\end{array}$ \\
\hline $\begin{array}{lll}\text { Change } & \ldots & \ldots\end{array}$ & $++0^{0}$ & $+2 \cdot 20$ & $+1.8^{\circ}$ & +016 & +400 & +2.2511 & -60 \\
\hline $\begin{array}{c}\text { In Electric room, Initial. } \\
,\end{array}$ & $\begin{array}{l}69 \cdot 6^{\circ} \\
7: 6^{\circ}\end{array}$ & $\begin{array}{l}59 \cdot 3^{\circ} \\
61.20\end{array}$ & $\begin{array}{l}10 \cdot 3^{\circ} \\
1.2 \cdot 1^{\circ}\end{array}$ & $\begin{array}{l}4 \cdot 13 \\
4 \cdot 20\end{array}$ & $\begin{array}{l}10,325 \\
10,500\end{array}$ & $\begin{array}{r}9,450 \\
11,975\end{array}$ & $\begin{array}{l}5 \cdot 0 \\
47 \cdot 0\end{array}$ \\
\hline Change $\quad \ldots \quad \ldots$ & $+4 \cdot 0^{\circ}$ & $+1 . \mathrm{jo}^{-}$ & $+2.1^{0}$ & $+0 \cdot 07$ & +175 & $+2,50$ & $-5 \cdot 11$ \\
\hline
\end{tabular}

* Not worked out from urerare thermometer rexdings, but averaged irom actual moisture and bumidity Hgures. 
Moisture balance-sheets have been prepared, showing on one side the hourly amount of water vapour brought into the room by the incoming air, and that vielded by the gas and the occupants respectively, and on the other the amount carried off ly the outgoing air. As a rule the output appeared to be less than the supply, the ratio of the former to the latter ranging down to eight-tenths. With natural ventilation, lowerer, the output generally exceeded the supply, in one cise by as much as 28 per cent. The explanation of these results probably lies in the fact that the amount of moisture produced exceeded that required to maintain the humidity of the smaller air supplies, the excess being absorbed by the furniture, walls, and ceiling. (On the other hand, when large quantities of air were admitted, their capacity for moisture at the higher temperature of the room exceeded the supply, the balance being taken up from the wall surfaces in the manner already described. It should be adder that, except on March 20th and 21st, when the walls were slightly clammy, there was nerer any inclication of condensation thereon, the changes in their hygroscopic state being well within the limits of apparent dryness.

The balance-sheets were calculated from the readings of the wet and dry bulb thermometers, the ascertained amount of water produced by combustion, and the assumed quantity expired by the occupants. They were thus manifestly approximate only, and are therefore not appencled, but the results are so consistent as fully to justify the above conclusions.

Humidity.-The figures relating to the humidity of the air are given in Appendix 5 and 6, pp. 124, 130, and are abstracted below, the occasions on which moisture was purposely added to the air being excluded.

At the beginning of the evening the rooms were generally from 4 to 10 per cent. drier than the onter air, but in the course of the run the difference was as a rule materially reduced. An exception occurs in the case of the nights with fires, when the humidity, initially low, was reduced by 6 per cent. and 5 per cent. respectively. Throughout the experiments there is a remarkably close agreement between the results under electricity and gas, showing that the illuminant plays a very small part in determining the condition of the room.

It is interesting to notice also within what limits the differences between the wet and dry bulbs at the end of each evening, and the corresponding humidities, ranged in the course of the experiments. These, with the average values, are summarised below :- 
Relative Hygienic Values of Gas and Electric Lighting.

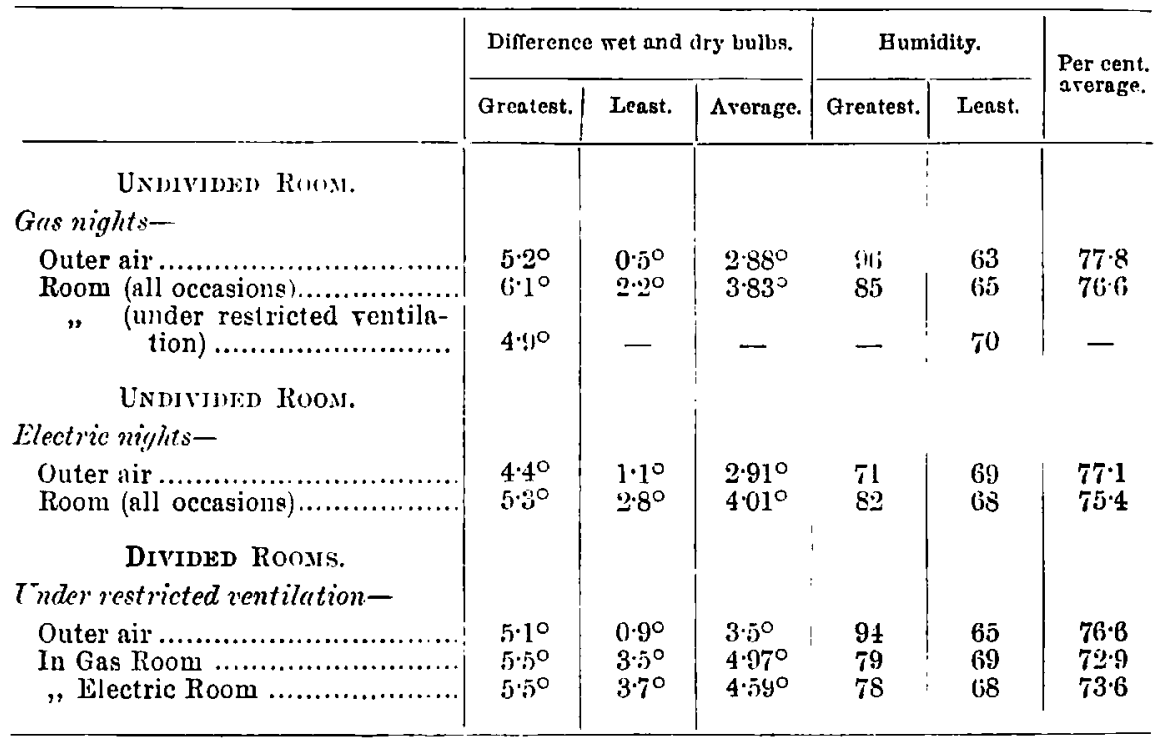

Billings summarises the matter by stating that to secure health and comfort under English conditions the air for respiration should contain from 65 to 75 per cent. of moisture. De ('haumont agrees that the percentage should not exeecl $i 5$ per cent.; lut IIood considers thit in artificially-heated rooms we should endeavour to maintain 82 per cent. Expressing the matter in terms of thermometer readings, De Chaumont states that the difference between ihe wet and dry bull, thermometers ought not to be less than $4^{\circ}$ nor more thin $5^{\circ}$.

\section{The Organic Matrtili in the Alli.}

It has been asserted by many observers that, in addition to respiratory $\mathrm{CO}_{2}$, the breath contains volatile organic substances which are injurious to health. The incorrectness of this statement has been already shown (p. 79). Carbon dioxide is now known to be without injurious effects in any proportion which could arise in a living room; and when limits are set (as in the Factory Acts) to the amount of $\mathrm{CO}_{2}$ permissible, it is always looked upon as a matter of these lyppothetical organic substances of indefinite nature. This is generally emphasised, as already mentioned, by setting two limits, one for respiratory $\mathrm{C}^{\prime} \mathrm{O}_{2}$ alone, the other including the gas given off by illuminants.

A method that has been of ten tried for estimating these vague substances is the determination of the oxygen required to oxidise them- 
potassium permanganate solution being the usual oxidant. It seemed desirable to apply this method in the present experiments, as two possible effects were anticipated. As a considerable proportion of the air of the room comes within the high temperature of the flame, some of these organic substances, if really existing, might be burnt, and the air purified to a corresponding extent. On the other hand, the burning gas itself might add substances capable of reducing permanganate solution.

The method of Carnelly and Mackie was expedited so that the determinations were macle at the same time as those of carbonic acid. This necessitated smaller samples of a Winchester quart each. The bottle was filled by aspiration with a suitable bellows and 40 c.c. of a millinormal solution of acil permanganate introduced. After shaking thoroughly for three minutes, 35 c.c. were introduced into a Nessler tube with 50 c.c. of distilled water and matched against 35 c.c. of the original

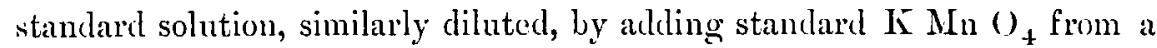
burette until the colour of the standard was reached, when the amount required was the anount of permanganate that harl been reduced by the air. The tubes were shielded with cardboard, so that the colours were matched by light trinsmitted throughout the whole length of the liquid: this was found to assist the eyes and to lessen the difficulty of conducting the experiments by artificial light. The results have been calculated to the rolumes of oxygen used up by one million volumes of air.

A simple calculation shows that the sulphur dioxide which may be evolved from the gas is in negligible quantity in these experiments, even on the extreme supposition (known experimentally to be inaccurate) that all the sulphur in the gas is evolved as $\mathrm{SO}_{2}$.

The results, summarised in the two tables un p.95, are not casy to interpret. ()ne or two facts are clear.

1. The substance measured increases in an electric-lit room in which people are present, and is presumably therefore a respiratory product.

About 19 hour's' continuous gras-burning with no people present also gave fairly const:unt and high values. There are thus two kinds of organic matter in a gas-lit inhabited room, in the same way as there are two kinds of carbonic acid.

2. On those evenings on which the carbon clioxide reached a stationary equilibrium value the amount of "oxygen absorbed" also reached a stationary value, and at about the same time of the evening.

3. In rooms in which no gas was burning the increase in this figure was about $5 \cdot 8$ volumes of oxygen per million volumes of air in the undivided room and 4.7 in the divided room. 


\section{Relative Hygienic Values of Gas and Electric Lighting.}

4. This increase is less when gas is substituted for electric light, $3 \cdot 7$ in the first period and $2 \cdot 7$ in the second period. With gas alight there is thus a lecrease in the organic contents of the room. The obvious conclusion is that some of these organic sulstances, generally held to be injurious to lealth, are destroyed by the incinerating action of the gas flame.

The average results in the divided room confirm those ohtained from the undivided room. The considerable divergences between single observations on different evenings, divergences not attributable to changes in the number of occupants or other factors under control, would tend to shew that organic dust particles in the air probably account for many of the high figures which have been put forward by other oiservers, and which have also been found in the course of this investigation.

Some of the respiratory products, a rough measure of which is supposed to be given by the oxidation with potissium permanganate, are proluably nitrogenous, and attempts have been made to identify one of them with formamide. It appeared to be of sufficient interest to attempt to confirm the conclusions drawn from the permanganate experiments by seeing if it were possible to directly determine the total organic nitrogen of the air. The problem proved to be one of extreme difticulty, and many abortive experiments were made. The apparatus deemed likely to give the best results was as follows:-An ordinary tower, such as is used in the Gas Referees' apparatus for determining sulphur, was fillerl with large glass beads and moistened with specially purified distilled water. The air was drawn through this at the rate of 6 r.f. per hour, and measured, after passing through the tower, by an ordinary dry meter. The tower was then repeatedly washed with small quantities of organically pure water until the total amounted to 300 c.c. This was then distilled for the free ammonia and the residue submitted to a Kjeldahl determination. The method is unavoidably wasteful as regards time, and attempts were being made to simplify it when the experiments were stopped.

\section{Organic Matter in the Air.}

The figures shown (p. 95) are expressed in volumes of Oxygen consumed, per million volumes of $A$ ir, and are the results obtained on sixteen evenings between the 13th Jamuary and 7th February.

Gas was burnt on nine and Electricity on seven evenings. 
Samuel Rideal.

Primanganate Absorption Resicter.

I.-Undivided Room.

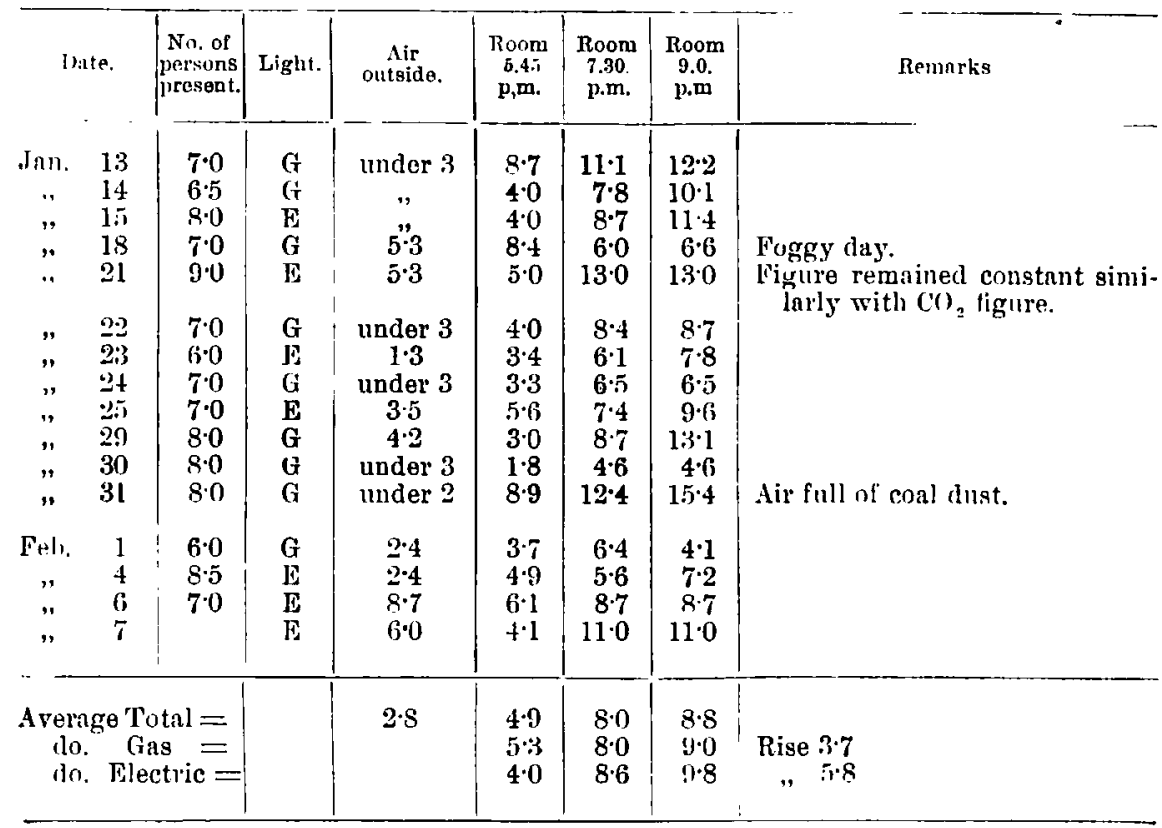

II.-Room Divided Nareh 14th to 2tith.

Gas was burnt on five and Electricity on seven evenings.

\begin{tabular}{|c|c|c|c|c|c|c|c|}
\hline \multirow{2}{*}{\multicolumn{2}{|c|}{ Date. }} & \multirow{2}{*}{ Room. } & \multirow{2}{*}{ Light. } & \multirow{2}{*}{$\begin{array}{c}\text { Po. of } \\
\text { Per- } \\
\text { gons. }\end{array}$} & \multicolumn{2}{|c|}{$\begin{array}{c}\text { Oxygen } \\
\text { Equivalents - }\end{array}$} & \multirow{2}{*}{ Remarks. } \\
\hline & & & & & $\begin{array}{l}\text { At } \\
\text { is.m. }\end{array}$ & $\begin{array}{c}\text { At } \\
\mathrm{s} \text { p.m. }\end{array}$ & \\
\hline Mar. & 15 & $\begin{array}{l}4 \\
6\end{array}$ & G & $\begin{array}{l}7 \cdot 3 \\
6 \cdot 5\end{array}$ & $\begin{array}{l}10 \cdot 0 \\
11 \cdot 0\end{array}$ & $\begin{array}{l}160 \\
18 \cdot 0\end{array}$ & \multirow{7}{*}{$\begin{array}{l}\text { (ias had been burning since previous night } \\
\text { when frst readings wele taken. } \\
\text { Gas burnt since previous night, hut room } \\
\text { ventilated to some extent. } \\
\text { CO constant, } 51 \text {; highest recorded for } \\
\text { electric light, Ventilation extremely low. } \\
\text { co. constant, } 32 \text {. } \\
\text { No gas burnt in Room } t \text { all clay. } \\
\text { Gas burnt since night in Room } 6 . \\
\text { Fireplaces and rents open in both rooms. } \\
\text { Fireplaces, loors and windows open all } \\
\text { through. } \\
\text { Each room contained } 8 \text { parts per } 10,000 \mathrm{CO}_{2} \text {. }\end{array}$} \\
\hline$"$ & 19 & & $\mathbf{G}$ & $\begin{array}{l}7 \\
8\end{array}$ & $\begin{array}{l}8.9 \\
7.7\end{array}$ & $\begin{array}{r}12 \cdot 9 \\
9 \cdot 0\end{array}$ & \\
\hline$"$ & 2] & 4 & $\mathrm{E}$ & 8 & 6.9 & $17 \cdot 5$ & \\
\hline " & $2 \cdot 2$ & $\begin{array}{l}6 \\
+ \\
t i\end{array}$ & $\begin{array}{l}E \\
B \\
G\end{array}$ & $\begin{array}{l}7 \\
7 \\
7\end{array}$ & $\begin{array}{r}3 \cdot 8 \\
7 \cdot 5 \\
12.5\end{array}$ & $\begin{array}{r}8.7 \\
13.7 \\
12.5\end{array}$ & \\
\hline 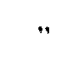 & 25 & 4 & G & 7 & $\begin{array}{l}5.0 \\
8.7\end{array}$ & 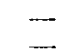 & \\
\hline \multirow[t]{2}{*}{ " } & 26 & 4 & ii. & 7 & $5 \%$ & 38 & \\
\hline & & 6 & $\mathbf{G}$ & 8 & $3 \cdot 1$ & $:: 8$ & \\
\hline
\end{tabular}

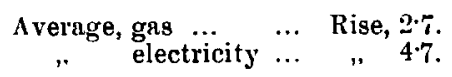




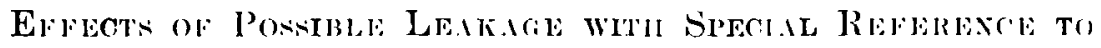
Cinime Munoxitie.

In these investigations every care was taken that all the gas and electric light fittings, which were present thronghout in both rooms, should be without fault.

In order to insure that no appreciable amount of unburnt coal gas was present in the rooms during the investigations, a very delicate test was made at frequent intervals by the determination in the room air of the amount of carbon monoxide, which is a constant constituent of coal gas, averaging 5 to 8 per cent.

It will be seen that the average of the figures obtained was a practically equal trace in both rooms under gas and electric light, and that carbon monoxide was only present in inappreciable quantities, and on no occasion amounted to one part $\mathrm{CO}$ per hundred thousand of air, except when a leak of coal gas was purposely arranged in the room.

Much objection has been raised to the use of gas on the ground of its poisonous properties if allowed to escape into the air unburnt, as might happen by the accidental turuing of a tap, or by some leak occurring in a pipe. $\Lambda$ simular objection could equally be advanced that injury or even death might be brought about by the imperfect insulation or fusing of an electric lighting cable. In each case it is simply a matter of good or bad workmanship or material, and therefore seems outside the hygienic question.

No doubt public attention has been called somewhat prominently to this subject by the increasing numbers of accidental and suicidal deaths reported in this country and America. Also by the increasing consumption of water gas alone, and mixed with coal gas.

The only poisonous product of moment in coal gas is carbon monoxide, and there are plenty of published data as to its poisonous effects. It was thought, however, that it would be not altogether outside this enquiry to test the amount of carbon monoxide present in the air, and also when various quantities had been allowed to escape in the gas in imitation of leakages, such as might happen to the gas fittings of an ordinary dwelling house. Besides this, three persons remained for four hours and twenty minutes in a room where a considerable quantity of gas was escaping, their symptoms were noted and frequent physiological observations made during the time they were there.

The determinations of carbon monoxide were made by Nicloux's process, the iodine liberated from iodic anhydride by the $\mathrm{CO}$ being collected 
and taken up with chloroform. The tint was then matched with that obtained from a standard solution of potassium iodide.

The following table shows the dates on which the determinations were made, and the results obtained :-

Crriton Monoride Determinations.

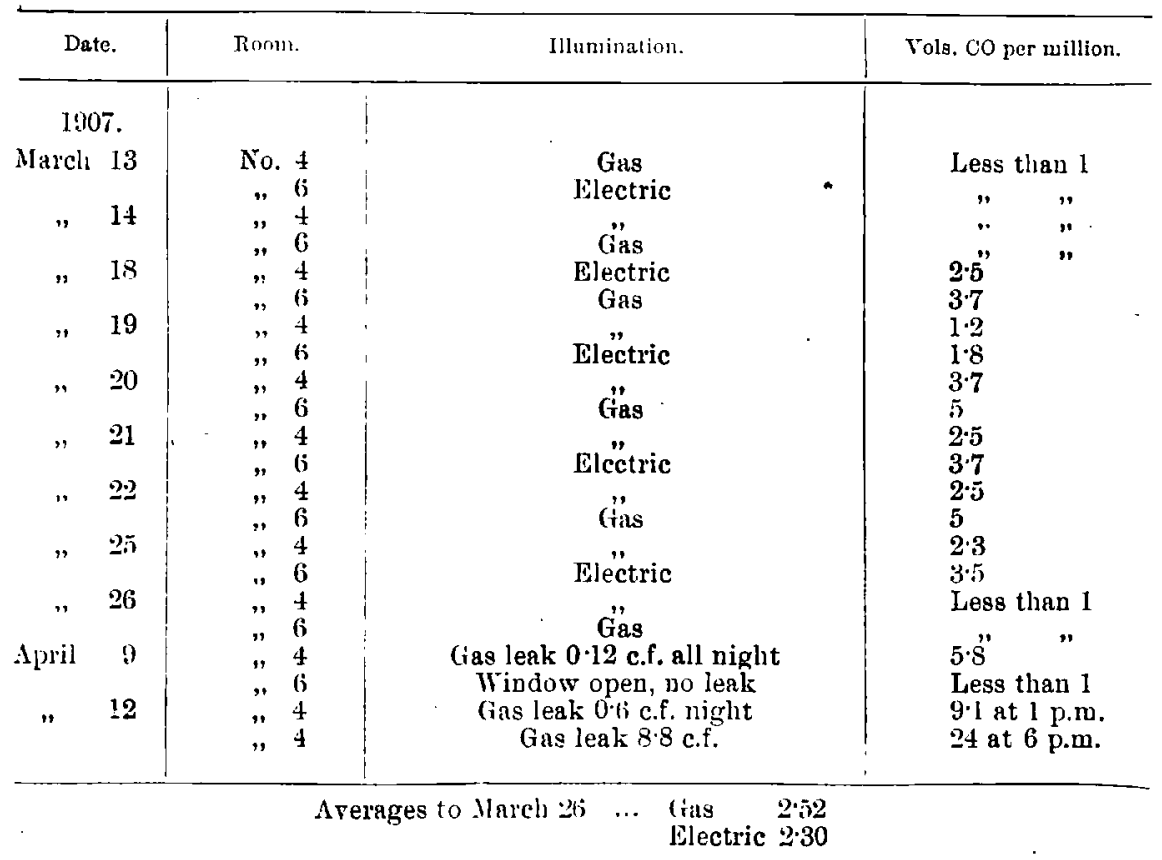

On April 9th, 0.12 c.f. of coal gas per hour had been passed into Room No. $t$ for the previous fourteen hours with the winclows, doors, etc., closed. In No. 6 Room no gas was turned on and the doors and windows were left. open. Taking the ventilation of Room No. 4 as 2,000 c.f. per hour and the coal gas as containing 5 per cent. of $\mathrm{CO}$, then the constant of $\mathrm{CO}$ in the room would be three rolumes per million.

The determination at 1 p.m., on April 12th, in Room 4 was made after $0 * 4$ c.f. of coal gas had been passed into the room per hour for the previous eighteen hours. The amount was then increased at 3.25 p.m. to 8.8 c.f. per hour, and allowed to flow at this rate continuously with half an hour's intermission until another determination was made at 6.50 p.m. The ventilation was specially determined and found to be equal to 1,830 c.f. per hour. As the room was not airtight and a steady state had not been reached, the content of $\mathrm{CO}$ given in the table, 24 per million, shows that

VOL. SXIX. NO. 2. 


\section{Relative Hygienic Values of Gas and Electric Lighting.}

the effects thus artificially produced were the same as would have occurred with a permanent leak of about 0.9 c.f. of gas per hour. On this occasion three subjects remained in the room of 2,500 c.f. air space, for four hours twenty minutes. Before entering, their pulses, respirations, body temperatures, diastolic and systolic blood pressures, the corpuscular richness of their blood and body weights were accurately taken. When in the room all these observations were repeated at nearly hourly intervals and symptoms constantly noted. The air was fanned for two minutes every quarter of an hour to insure a proper mixing. It is sufficient to note that no serious symptoms became manifest, in fact, in the case of one subject, pulsation in the temples was the only inconvenience felt; the other two were more affected; all, after a time, lost their sense of smelling gas while in the room, although it was described by those outside the door of the room as "very strong" and could not under any ordinary circumstances have remained long undetected. The physiological observations showed but a slight rise in the pulse rate, but a considerable rise in two instances of the respirations, and only a slight rise in the other subject. The blood pressures afforded no information, in one instance the difference between the diastolic and systolic pressures increased, in another it diminished, while in the third it remained the same. There was well marked relative increase in the coloured corpuscles and this has been noticed to occur with the inhalation of carbon monoxide and coal gas. The loss of body weight was very little in excess of the average.

From this experiment the inference is that in any quantity of gas likely to escape from an ordinary leakage there is no fear of any immediate danger to health.

The Bacterial Content of the Rooms.-In comparing the bacteriological conditions of an inhabited room, illuminated with gas or electricity, the contamination of the air being constant, the following factors would all tend towards lessening its bacterial content with gas lighting as against electricity :-

1. The cremation of organisms in the flames.

2. The sterilising effect of the sulphur acids from the gas.

3. The increased condensation on the cold surfaces removing organisms as well as the sulphur products.

4. Any increased ventilation of the room.

Under certain conditions increased ventilation (4) would not diminish the number of organisms, as for example, a room with only a few people present adjoining a crowded thoroughfare.

The temperature of the ordinary electric glow lamps has been dealt 
with elsewhere in this investigation, but it must be remembered that this is sufficient to destroy the majority of living germs coming in contact with the globe-an ordinary 16 c.p. electric lamp immersed in a cup of water will maintain a temperature of over $80^{\circ} \mathrm{C}$., which is beyond the thermal death-point of non-sporing organisms.

The quantity of air raised to a sterilising temperature by the heat from an incandescent gas-burner is greater than that required for the actual combustion of the coal gas. The temperatures of the escaping air from the two gas-burners in the Room No. 6 were found to average $448^{\circ}$ and $508^{\circ} \mathrm{F}$. respectively; the ordinary temperature of the room at the time being $57^{\circ} \mathrm{F}$, the mean increase produced by the burners was $420^{\circ} \mathrm{F}$. The net calorific value of the gas consumed was 1,382 B.T.U., of which possibly one-third was carried off by conduction and radiation; the balance of 921 B.'T.U. is capable of heating 120 c.f. of air from $57^{\circ}$ to $477^{\circ} \mathrm{F}$. or 324 c.f. to the boiling-point of water.

During the early part of the above investigation, and before the rooms Nos. 4 and 6 were divided by the wooden partition, upwards of 100 bacteriological observations were taken in order to determine whether it is possible to demonstrate any reluction in the number of organisms with gas lighting.

Beyond protection from any gross contamination, all the determinations were made under normal conditions, that is to say, during the medical, chemical, and physical observations, but, owing to the unavoidable disturbances created at the commencement of each evening's work, by the various entries into the room, and the preliminary ventilation with the fan, the doors and windows being open, a marked decrease in the bacteria was found to occur (with exception to be noted) during each evening, irrespective of the illumination. In order to control this diminution the bacteriological olservations were invariably made in duplicate, 30 minutes after closing the doors and windows, and again at the end of the evening.

As certain air-borne organisms capable of growth on nutrient gelatine develop slowly, the cultures were incubated as long as possible and for a definite number of days, before finally counting the number of colonies. Preliminary tests showed that the average numbers of moulds and rapidly liquefying organisms present in the rooms, were not excessive and that the subsequent incubation of the cultures could be protracted to 7 days at $20^{\circ} \mathrm{C}$. The nutrient gelatine employed throughout the experiments was prepared from fresh beef broth containing 10 per cent. of gelatine and having a reaction of $+1 \cdot 5$. During the earlicr experiments gelatine plates 


\section{Relative Hygienic Values of Gas and Electric Lighting.}

were exposed in duplicate in one position, but as closely agreeing results were obtained, it was found preferable to expose the plates simultaneonsly in different positions in the two rooms.

The organisms falling by gravity and air currents have been determined by the exposure of nutrient gelatine plates (Petri dishes) for a definite time in various positions in the rooms, and in the following tables the results obtained with the two illuminants are recorded as organisms per sq. ft. per minute.

Mean results from exposures on the centre table, Room No. 6 .

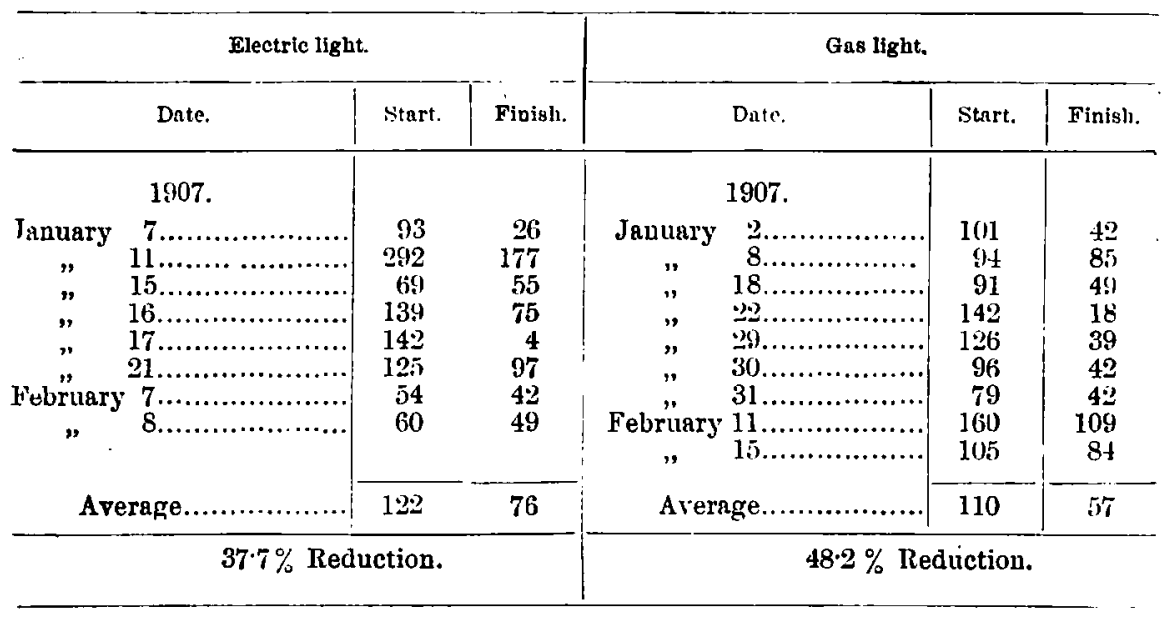

Eiprosure in various positions in the rooms.

\begin{tabular}{|c|c|c|c|c|c|c|}
\hline \multirow[b]{2}{*}{ Position. } & \multicolumn{3}{|c|}{ Electhic Light. } & \multicolumn{3}{|c|}{ GAS LieHT. } \\
\hline & Date. & start. & Finish. & Date. & Start. & Finish. \\
\hline Between Burners, Room 6... & \begin{tabular}{cc}
\multicolumn{2}{c}{1907} \\
Feb. & 6 \\
$"$ & 7 \\
$"$ & 8
\end{tabular} & $\begin{array}{l}57 \\
55 \\
37\end{array}$ & $\begin{array}{l}35 \\
43 \\
25\end{array}$ & $\begin{array}{c}190 \bar{\gamma} \\
\mathrm{reb} .11 \\
\Rightarrow \quad 12 \\
\Rightarrow \quad 13\end{array}$ & $\begin{array}{r}157 \\
84 \\
65\end{array}$ & $\begin{array}{l}76 \\
48 \\
73\end{array}$ \\
\hline Centre, Room 4 ............... & $\begin{array}{cc}\text { Jan. } & 15 \\
" & 16\end{array}$ & $\begin{array}{l}55 \\
73\end{array}$ & $\begin{array}{l}34 \\
48\end{array}$ & $\begin{array}{ll} & 11 \\
" & 13\end{array}$ & $\begin{array}{r}115 \\
85\end{array}$ & 85 \\
\hline 1 ft. from ceiling, Room $4 \ldots$ & $\begin{array}{cl}\text { Feb. } & 7 \\
" & 8\end{array}$ & $\begin{array}{l}43 \\
22\end{array}$ & $\begin{array}{l}25 \\
19\end{array}$ & $" 12$ & $\begin{array}{l}64 \\
45\end{array}$ & $\begin{array}{l}30 \\
27\end{array}$ \\
\hline Centre, Room 6 .............. & Jan. 17 & 42 & 43 & Jan. 18 & 69 & 37 \\
\hline & $\begin{array}{l}\text { Average... } \\
\text { Reduction }\end{array}$ & $\begin{aligned} & 48 \\
= & 29.2\end{aligned}$ & $\begin{array}{c}34 \\
\text { per cent. }\end{array}$ & $\begin{array}{l}\text { Average... } \\
\text { Reduction }\end{array}$ & $\begin{aligned} & 85 \\
= & 35 \cdot 3\end{aligned}$ & $\begin{array}{c}55 \\
\text { per cent. }\end{array}$ \\
\hline
\end{tabular}


Although, owing to the conditions of the tests, there is a considerable variation in the numbers of bacteria, the averages show a gain of over 10 per cent. reduction of the organisms falling on the table during gas illumination. This greater reduction with the gas is also maintained at various points in the rooms, but it is interesting to notice that this does not appear to be augmented, as might be expected, even directly between the burners.

Haldane has shown that the air of a room contains fewer bacteria after occupation than before, owing to the purification effected by the lungs of the inmates. The diminution observed is therefore partly due to this cause, and thus lowers the amount of purification attributable to both lights.

The organisms in suspension in the air were estimated by (a) filtering a definite volume through a small sugar filter, and (b) drawing a known volume of air through a glass tube coated inside with nutrient gelatine (Hesse's method). Unfortunately, these observations are not sufficiently numerous to strike any average; they had to be abandoned, as each of the filtrations required upwards of an hour, and it was not found practicable to adequately protect the tubes, with the varions other investigations simultaneously being carried on in the rooms. The results are recorded as number of organisms per c.f. of air.

\begin{tabular}{|c|c|c|c|c|c|c|}
\hline \multicolumn{4}{|c|}{ Electric Light. } & \multicolumn{3}{|c|}{ Gras Light. } \\
\hline & Date. & Start. & Finish. & Date. & Start. & Finish. \\
\hline Sugar tube .......... & $\begin{array}{c}1907 . \\
\text { February } 18\end{array}$ & 189 & 208 & $\begin{array}{c}1907 . \\
\text { January } 18\end{array}$ & 340 & 132 \\
\hline Hesse,$\ldots . . . .$. & " 18 & 181 & 130 & $\begin{array}{ll}" & 18 \\
" & 2 .\end{array}$ & $\begin{array}{l}221 \\
2055\end{array}$ & $\begin{array}{r}142 \\
96\end{array}$ \\
\hline
\end{tabular}

The condition of the moisture condensing on the cool surfaces such as the walls and windows, during the periods the rooms were closed with gas and electric light, was also studied. As the quantity of condensed water that could be expeditiously collected was very small, especially during electric lighting, an artificially-cooled surface had to be employed. In a previous investigation as to the condensation of the products of gas consumption in 1904, large glass globes filled with melting ice were suspended in the experimental rooms, and the condensed water dripping from the exterior surfaces examined; a modification of this method has been employed to determine the bacteriological condition of the condensed moisture. 


\section{Relative Hygienic Talues of Gus and Electric Lighting.}

The exterior surfaces having been sterilised, the globes of ice were suspended in the rooms some hours previous to the evening's work, so as to insure that the dripping of the condensed moisture was normal. 'The condensed water was collected and the number of organisms determined. In the subjoined table, the globes were in each case suspended $3 \mathrm{ft}$. from the ceiling in the corner of Room 4.

Organisms per Culic Centimeter in Condensed Water.

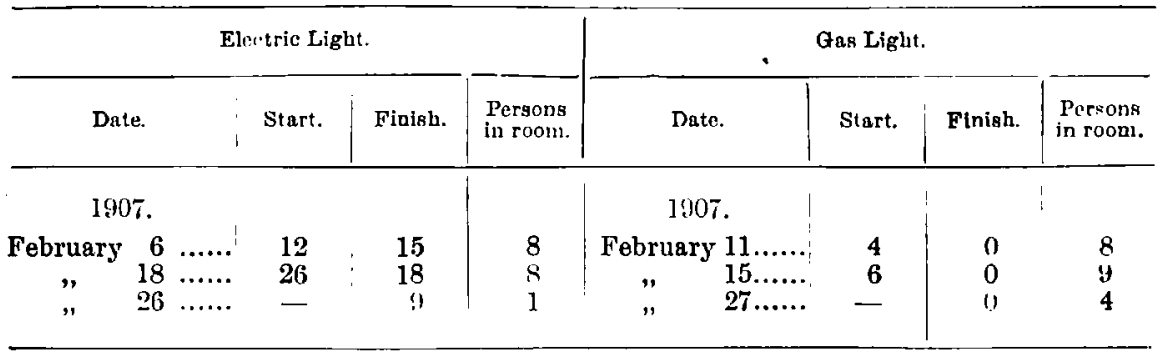

It has previously been shown* that the minute traces of sulphur acids in the condensed water has a marked germicidal action, and these results very clearly demonstrate the destruction of living germs by the condensation continually taking place on cool surfaces of the moisture from the combustion of coal gas. It will be noticed that with the gas lighting the number of bacteria was found to be low at the start, due to the destruction of the germs taking place so soon as the gas was lit and before the required amount of condensed water could be collected. Further experiments are required in this direction to ascertain the rate of sterilisation and the absolute degree of sterility produced in the water.

\section{Phisiological.}

The question as to whether there is, from the physiologist's point of view, any advantage to be gained in choosing between gas and electricity for illumination has now to be considered. If a complete answer, as to the combined action of moisture and heat with and without other respiratory products and those derived from combustion, is to be arrived at, further research, on strictly physiological lines, should be conducted without any restrictions or limitations as to the method to be pursued.

Effect of Accommodation.-To make this perfectly clear it must be remembered that in every living being there is a certain range of

* "On the Hygienic Significance of Sulphur in Coal Gas." Rideal, Joum. R. Stm. I., XXV., 
functional capacity, within which organs are capable of working, which determines the condition known as health. One organ or system may, by its increased activity, relieve the work of some other organ or system, and this is occurring from moment to moment during the whole of life. For example, everyone is aware that moisture is excreted more freely by the skin in a warm atmosphere than in a cold one. In damp air the action of the skin is greatly reduced, but no ill effects are experienced, since the kidneys freely take on the work of eliminating the excess of fluid from the blood. Again, note how the pupil of the eye contracts when exposed to a brilliant light, and so permits us to view without discomfort that which we could not otherwise look at. This compensating power is universal in the animal economy, and is of ten of a very complex character. So long as compensation can take place health is maintained, and no special inconvenience felt; but when the limit of compensation is reached, then discomfort and disease follow. Exceed the boundary of compensation, and then the domains of physiology end and those of pathology begin.

From the foregoing it will be gathered that those conditions are the most favourable to health in which the various organs are working at their mean, and no organ is compelled to perform its functions on the boundary line between a physiological and pathological state.

Hence it followed that, when considering the hygienic effects of the two illuminants, the necessity arose to determine first by clinical observation the states of functional activity maintained by various organs under each system of lighting. So far as the limitations imposed rendered it possible, this has been accomplished, and tables of the results are appended, pp. 131, 132, these also show averages and differences under gas and electric light.

\section{Cirgclattuli and Renpiratory Srstems.}

The separate results of (1) the pulse, (2) respiration, (3) arterial pressure were carefully tabulated, but it will be more convenient to consider the three physiological functions under one heading.

1. The Pulse Rate.-The pulse is simply the dilatation and contraction of an artery caused by the forcing of blood into it by the contractions of the heart until full expansion is reached. When the cardiac valves close the artery then contracts, forcing the blood onwards into the arterioles. The arteries are always full, even when least extended, but of course the tension is higher when they are filled with blood to their fullest.

The pressure they sustain when they are at their least calibre (i.e., 


\section{$10+$ Relative Hygienic Values of Gas and Electric Lighting.}

just before the valve of the large artery, the aorta, is opened) is called the diastolic pressure, while when they are at their greatest calibre (i.e., at the moment they have received the blood-flow from the heart) is called the systolic pressure.

These two pressures have been determined in this investigation by means of the hæmomanometer devised by Dr. ()liver of Harrogate, and he has been good enough to examine the results obtained and compare them with the sphygmographic records.

The rate of the pulse primarily depends upon the frequency of the heart's contractions, while the heart's pulsations depend upon a very large variety of causes, according to the requirements of the whole organism, and it should therefore form a sensitive index to minute changes in environment.

The tension of the arteries is altered by change of temperature : when the skin is subjected to chill it becomes blanched, that is to say, the minute arteries contract, causing a diminution of their cubic contents and proclucing increased tension and pressure in the larger vessels. Heat causes an exactly opposite effect, and it was thought that any marked heat changes in the room due to variation in the mode of lighting would thus be detected, provided care was taken to eliminate any alterations in blood pressure due to nerve stimulus and nerve depression.

The total number of differential pulse-rate observations in the undivided room was $212 ; 107$ with gas and 105 with electric light.

As a rule the pulse-rate fell in the interval between the first and second observation, the daily average only showing an increase on three occasions under gas. The greatest fall noticed with gaslight was an hourly average rate per man of 4.33 beats, on February 22 nd, while the least was $\cdot 36$, on February $2 i$ th. Similarly, with electric light the figures were $6^{*}$ on February 25th and 63) on January 15th. Of the three average gains the highest for gas was $\cdot 5$ beats on January 1 st. Taling the whole period mentioned above, the hourly average daily loss per man per hour was, under gaslight, $1 \cdot 6$ beats per minute; and under electric light the corresponding figure was $1 \cdot 78$, the difference being only $0 \cdot 18$.

After the room was divided, the 66 differential observations with gas and 63 with electric light on 14 days in both rooms, from March 7th to 28th, showed a daily average fall on every occasion. The greatest arerage hourly fall was on the 19th with gaslight, and on the 7 th with electric light; the figures were respectively $5 \cdot 26$ and $5 \cdot 23$, corresponding to the

* One observation only. 
two evenings when the ventilation was at a maximum, the air being changed 1.68 times per hour on the 7 th, and $1 \cdot 6 \pm$ times on the 19 th. The least average fall for gaslight was one on the $22 \mathrm{nd}$, and on the 12 th for electric light, the respective figures being $\cdot 8 i$ and $1 \cdot 07$, while the hourly average fall for the whole period was, in the case of gaslight, $2 \cdot 54$, and in the case of electric light, $2 \cdot 92$.

Most of the variants, such as age, time of day, exertion, rest, mental excitement, fatigue, depression, temperament, position, whether standing, sitting, or prone, were to a great extent eliminated in these tests. After a meal the pulse rate is accelerated, and increased respiration (irrespective of exercise) generally renders it higher. At the close of a day's work there is usually, apart from actual exercise or excitement, a progressive decline of the pulse rate, and this is in accordance with what was observed.

Contrasting the two periods, a very decided drop in the pulse rate, independent of the source of light, occurred after the room was divided. Whether this drop was caused by increase in temperature or moisture due to the alteration in ventilation, or to a tendency to overcrowding, or entirely to the fact that the men in the second period started immediately after exercise is outside the scope of this inquiry.

As the drop in the pulse rate may be comparatively sudden, the conclusion based upon the assumption of a uniform fall per hour may be open to criticism. A comparison of the actual changes shows that in the earlier period 107 observations were made on the staff, giving an average pulse rate of 65.4 , and that after exposure to the gas-light environment their average pulse rate dropped to 60.5 , or a fall of 4.9 .

105 observations on other days under electric conditions were made; the average pulse rate was $65 \cdot 4$ and it declined to $60 \cdot 0$, or a fall of $5 \cdot 4$.

During the second period 66 observations were made on an average pulse rate of $70 \cdot 7$, falling to 62.3 or a loss of 8.4 under gas; whilst $63 \mathrm{ob}$ servations gave a pulse rate of $70 \cdot 7$, falling to 61.2 or a loss of 9.5 beats per minute under electric light. It will be noticed that all four records show a very similar, indeed, almost identical, pulse rate at the end of the evening run, a sufficiently striking result to warrant the conclusion that the environment was essentially identical. A slightly lower rate was, however, observed in both periods in the electric light rooms. The figures, as a whole, conclusively prove that the difference in the mode of lighting has practically no influence on the rate of pulse.

2. Respiration Frequency.-Differential observations were made from 7th January to 1st March in the undivided room, and from 7th March to 28th March in the divided room, the number in the first period being 98 


\section{Relative Hygienic Values of Gas and Electric Lighting.}

with gaslight, and 101 with electric on 18 evenings in each case. In the second period of 16 evenings, 64 gas and 63 electric light observations were simultaneously made.

In the first period, January 1st to March 1st, the observations on 17 evenings showed a diminution in frequency, and those of only 2 a gain, under gas light; on 13 evenings there was a diminution under electric light, and on 4 an increase; on one occasion the gains and losses balanced each other. The average hourly loss in frequency was;-gas, $\cdot 329$, electric, 206 . In the second period, 7th to 28th March, on 11 evenings the average hourly frequency fell, and on 3 it rose, both in the gas and electric lighted rooms. The average hourly loss in frequency in the divided room was for gas, $\cdot 328$, and for electric light, $\cdot 323$.

$\mathrm{Up}$ to 1st March the average hourly rate per subject showed the maximum increase to be $\cdot 678$ and the minimum increase 213 uncler gas light, while the corresponding figures for electric light are 421 and 082 . The greatest hourly average loss of rate under gas was $1 \cdot 227$ and the least $\cdot 025$, and for electric the greatest $1 \cdot 17$ and the least $\cdot 03$. Taking all the observations, 98 with a frequency of 15.4 fell 0.9 to 14.5 under gas, and 101 with $15 \cdot 24$ fell $0 \cdot 54$ to $14 \cdot 7$ under electric light.

From the 7 th to 28 th March the maximum gain in rate under gas was 1.33 and the minimum $\cdot 03$, under electric light it was 0.37 and $0 \cdot 13$ respectively. The diminution in the average hourly rate shows the greatest fall under gas light to be $1 \cdot 17$ and the least $\cdot 21$, and the diminution under electric light to be 1.67 and $\cdot 01$.

The respirations fell from $16 \cdot 2$ to $14 \cdot 95$ per minute under gas, or a drop of $1 \cdot 27$, and from 15.74 to 14.9 under electric light, being a drop of 0.86 .

Here again it will be noticed that the change in environment, clue to the altered condition of ventilation and density of population, has caused a greater difference in the respiratory act than change in the mode of lighting. In both periods, however, the respiration rate was lowered to a slightly greater extent under gas than under the electric light, thus according with the change noticed when studying the pulse rate. This does not necessarily mean that functional activity was diminished, as a very slight increase in the depth of respiration compensates for loss in rate.

3. Blood pressures.-The involuntary muscular fibres of the arteries are governed by nerves derived from the vasor-motor centres, and thus are enabled to contract or expand, and to excrt or reduce pressure on the blood within them, balancing the hæmostatic pressure exerted by the 
cardiac contractions. The hemomanometer indicates the pressure exerted and sustained by the blood vessels, while the sphygmograph by its tracings shows the relative extent of the distension and the character of the movements of the arterial walls, so that the first of these instruments may be regarded as a pressure gauge showing tension, and the second as an instrument recording form and rate of movement, or tone.

From January 1st to February 1st only systolic blood pressures were recorded in m.m. of mercury, but from February 4th to March 1st diastolic as well as systolic were noted, and both these pressures were then taken regularly to the end of the investigations, all being from the brachial artery.

Before the room was divided the total number of observations on the systolic pressure during gas light was 208, and diastolic 78 . Under electric light 206 were taken of the systolic, and 102 of the diastolic.

In the period from 1st to 28 th March, under each system of lighting, 50 observations were made on the systolic pressure, and 52 on the diastolic.

Sphygmographic record.-106 sphygmographic tracings have been examined, derived from subjects before and after exposure to gas and electric light, each pair of observations having been macle on the same subject, and each tracing having been taken under identical conditions. It was found-

1. That there are recognisable indications of a slight rise of arterial tone upon the whole after exposure to both kinds of light, 28 (or 53 per cent.) of the 53 pairs of tracings affording clistinctive evidence of this rise, 20 (or $37 \frac{1}{2}$ per cent.) showing no recognisable change, and 5 (or $9 \frac{1}{2}$ per cent.) indicating a reduction of tone. This general improvement in arterial tone may fairly be ascribed to rest.

2. That on comparing the tracings obtained under each of the two modes of lighting there is a greater rise of arterial tone apparent after exposure to gas light than to electric light, the rise being 68 per cent. in the case of gas light, and 39 per cent. in that of the electric light. This conclusion is moreover supported by the larger relative percentage (61 as agrainst 32) in which the arterial tone was apparently unchanged or but slightly fell under the electric light exposure. But the observations recorded are not sufficiently numerous or sufficiently decisive to warrant an assured conclusion on the different effects of the two modes of lighting on the arterial tone. So far as they go they do, however, seem to point to the advisability of further incuiry.

The difference between diastolic and sustolic pressure has been 


\section{Relative IIygienic Values of Gas and Electric Lighting.}

mentioned on page 104. Tables are appended (pp. 131, 132) showing in figures the results of observations on both pressures. Too much importance must not be given to the actual figure value of these, because vascular tension varies considerably, accommodating itself both to the internal and external requirements of the organism. It will be perfectly fair, however, to class all the cases together in the following way :(1) Those pressures which rose; (2) those which remained stationary, and (3) those in which there was a fall. Besides this, the lifference between the lower (diastolic) and the higher (systolic) pressure may be expressed as Increasing, Decreasing, or Constant.

An examination of these data will be of interest, and are here given in tabular form :--

Summary of Hiemomanometric Observations.

\begin{tabular}{|c|c|c|c|c|c|c|c|c|c|c|c|c|c|}
\hline \multirow{2}{*}{ Dare. } & \multirow{2}{*}{ Light. } & & \multicolumn{2}{|c|}{$\begin{array}{l}\text { Number of } \\
\text { Obserra- } \\
\text { tions. }\end{array}$} & \multicolumn{2}{|c|}{ Riscs. } & \multicolumn{2}{|c|}{ Falls. } & \multicolumn{2}{|c|}{ Stationary. } & \multicolumn{2}{|c|}{$\begin{array}{c}\text { Difference } \\
\text { botween } \\
\text { D. \& } \mathrm{S} .\end{array}$} & \multirow{2}{*}{ 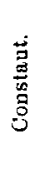 } \\
\hline & & & D. & s. & D. & s. & D. & s. & D. & s. & $\begin{array}{c}\text { In- } \\
\text { crease. }\end{array}$ & $\begin{array}{c}\text { De- } \\
\text { creasc. }\end{array}$ & \\
\hline 1907. & & & & & & & & & & & & & \\
\hline $\begin{array}{l}\text { lst Jan. } \\
\text { to } \\
\text { lat }\end{array}$ & $\begin{array}{l}\text { (ias ... } \\
\text { Electric }\end{array}$ & $\ldots$ & - & $\begin{array}{l}67 \\
52\end{array}$ & - & $\begin{array}{l}25 \\
23\end{array}$ & - & $\begin{array}{l}31 \\
20\end{array}$ & - & $\begin{array}{r}11 \\
9\end{array}$ & - & - & $=$ \\
\hline $\begin{array}{c}\text { 4th Feb. } \\
\text { to } \\
\text { lst Mar. }\end{array}$ & $\begin{array}{l}\text { Gas } \ldots \\
\text { Electric }\end{array}$ & $\ldots$ & $\begin{array}{l}39 \\
51\end{array}$ & $\begin{array}{l}39 \\
51\end{array}$ & $\begin{array}{l}18 \\
25\end{array}$ & $\begin{array}{l}21 \\
29\end{array}$ & $\begin{array}{l}16 \\
16\end{array}$ & $\begin{array}{l}13 \\
16\end{array}$ & $\begin{array}{r}5 \\
10\end{array}$ & $\begin{array}{l}5 \\
6\end{array}$ & $\begin{array}{l}21 \\
20\end{array}$ & $\begin{array}{l}13 \\
202\end{array}$ & $\begin{array}{l}5 \\
9\end{array}$ \\
\hline $\begin{array}{c}\text { 7th Feb. } \\
\text { to } \\
\text { 28th Jar. }\end{array}$ & $\begin{array}{l}\text { Gas ... } \\
\text { Electric }\end{array}$ & $\begin{array}{l}\cdots \\
\cdots\end{array}$ & $\frac{25}{26}$ & $\begin{array}{l}25 \\
206\end{array}$ & $\begin{array}{l}1.5 \\
14\end{array}$ & $\begin{array}{l}7 \\
8\end{array}$ & ? & $\begin{array}{l}13 \\
12\end{array}$ & $\begin{array}{l}7 \\
6\end{array}$ & 5 & $\begin{array}{l}6 \\
7\end{array}$ & $\begin{array}{l}15 \\
14\end{array}$ & $\begin{array}{l}4 \\
5\end{array}$ \\
\hline
\end{tabular}

Arranged in percentage, these results are as follows:-

\begin{tabular}{|c|c|c|c|}
\hline \multirow{5}{*}{ Ith February to 1st Marcl } & & \multicolumn{2}{|c|}{ Blood pressure changes } \\
\hline & & Gas. & Electricity. \\
\hline & (Inerease & $53 \cdot 8$ & $39 \cdot 2$ \\
\hline & Decrease & $33 \cdot 3$ & $43 \cdot 1$ \\
\hline & Constant & $12 \cdot 8$ & $17 \cdot 64$ \\
\hline \multirow{3}{*}{ 7th to 28th March } & Increase & 24 & $26 \cdot 9$ \\
\hline & Decrease & 60 & 53.83 \\
\hline & Constant & 16 & $19 \cdot 23$ \\
\hline
\end{tabular}

There is thus an apparent increase in the difference of the two pressures in the undivided room under gas; but after the room was rlivided the results obtained under the two lights show no marked difference on the hæmomanometric readings. 
Number of Blood Corpuscles.-Frequent examinations were made of the number of corpuscles of the blood. The instrument used was Gower's modification of Hayem and Nachet's Homocytometer. It consists of a micrometrical cell so divided that each space equals two cubic decimillimetres. Into this a drop of diluted blood is placed, and by counting over a sufficient area under the microscope the number of corpuscles present is ascertained.

The number of corpuscles in a culic millimetre of normal blood raries from about 5,000,000 to 6,000,000. Any marked diminution in their numbers indicates that the destruction of corpuscular elements is proceeding more rapidly than their production, or that the serum in which they are immersed is increased. Conversely, apparent increase in their number means relative decrease in the amount of serum.

Three tables were prepared: the first showing the quality of the samples taken from subjects who were in the rooms, but who were not specially under the illuminants. A second table showed the results obtained from the blood of two specially chosen subjects who remained under the direct rays for the time stated during five consecutive nights. The third table gives the result obtained from the mixed blood of all the persons present in the room. This was done for the object of comparison with the other tables.

The amount of moisture given off from the body reduces the serum and so increases the corpuscular richness of the blood. Taking this into account with other factors, it does not appear that either illuminant cau be said, per se, to affect the corpuscular quality of the blood-i.e., so far as these particular experiments have reached; more extreme conditions were outside the scope of this restricted enquiry.

\section{Aximal Heat aro Bowy Texpeliateres.}

The thermometers were specially made (Casella) graduated in tenths of a degree $\mathbf{F}$., and rerified at Kew. Temperatures were taken in the mouth at the beginning and end of each experiment, and Tables showing averages and differences are appended, pp. 131, 132.

It is hardly necessary to recall the parallelism between the production of animal heat and the combustion of gas and fuels, both depending on the oxidation of carbon and hydrogen or their compounds, and both including among final products carbonic acid and water. In the body the blood circulates and distributes the heat. The activity of internal organs and the rapidity of chemical change varies in different parts and under different conditions, but the amount of heat produced is usually more than 


\section{Relative Hygionic Values of Gas and Electric Lighting.}

sufficient to maintain the uniform body temperature. The excess is carried off by evaporation, chiefly from the skin and lungs, and the balance is controlled in health by the nervous system. Hence the value of the observations on body heat as an indication whether there is any disturbance of the natural functions by either mode of lighting.

The average body temperature, $98 \cdot 4^{\circ} \mathrm{F}$., however, varies in health from hour to hour within well-clefined limits of about $1 \cdot 5^{\circ}$, the maximum being reached late in the afternoon, followed by a gradual decline to a minimum late at night. Under the conditions of these tests, with temporary occupation of the room and absence of feeding or physical exertion, a fall of body temperature naturally occurred in the subjects. If the average fall were sensibly different under the two systems of illumination, it would point to a difference in their influence.

As with the pulse rate, variation of environment may cause a comparatively sudden instead of a gradual drop in the body temperature, but as the time of observation on all the evenings was approximately the same, the changes are comparable.

During the initial period, 112 observations were taken on individuals entering a gas-lit room. Their mean body temperature was $98.5^{\circ}$; at the end of the run they had a mean temperature of $97 \cdot 6^{\circ}$, showing a loss of $0.9^{\circ} \mathrm{F}$. With electric illumination 106 subjects had an average initial body temperature of $98.4^{\circ}$ and a final temperature of $97.6^{\circ}$, showing a loss of $0.8^{\circ} \mathrm{F}$.

In the divided room also the final temperatures were very close to each other and the losses under the two lights were identical. 60 observations showed before gas-light influence $98.7^{\circ} \mathrm{F}$. mean average body temperature, and $98 \cdot 0^{\circ}$ after about 3 hours' exposure, or a loss of $0 \cdot 7^{\circ} .67$ observations gave 98.60 as the mean body temperature before, and 97.9 as the mean body temperature after, electric light influence, or a loss of $0.7^{\circ}$.

There is thus no physiological difference between the two lights affecting the body temperature.

The following table shows the average differential temperatures under gas and electric light, calculated as a uniform loss of temperature per hour, per person, for each evening's observation :- 
Observations from January 1st to March 1st before the Room was divded.

\begin{tabular}{|c|c|c|c|c|}
\hline Illuminating agents. & $\begin{array}{c}\text { Number of } \\
\text { erenings on } \\
\text { which obserra- } \\
\text { tions were made. }\end{array}$ & $\begin{array}{l}\text { Total time of } \\
\text { Illumination. }\end{array}$ & $\begin{array}{l}\text { Total number } \\
\text { of persuns } \\
\text { stabjected to } \\
\text { examination. }\end{array}$ & $\begin{array}{l}\text { Actual loss } \\
\text { averaged for } 1 \\
\text { persog in I hour. } \\
\text { o Fah. }\end{array}$ \\
\hline Gas Light .... ................. & 20 & $\begin{array}{c}\text { hrs. mins. } \\
66 \quad 32\end{array}$ & 9 males & .264 \\
\hline Electric Light ................ & 19 & 645 & $9 \quad$, & .253 \\
\hline
\end{tabular}

Observations from March ' $t$ th to 98 th after the single was divided into 2 rooms.

\begin{tabular}{|c|c|c|c|c|c|}
\hline Gas Light ..................... & 16 & th $2:$ & 10 & " & $\cdot 252$ \\
\hline Electric Light ................ & $11 ;$ & $48 \quad 25$ & 10 & " & $\because 16$ \\
\hline
\end{tabular}

From 1st January to 1st March, out of 218 observations taken, only 3 temperatures remained stationary during the evening, while 3 others rose slightly under gas light. Similarly under electric light 6 were stationary, (curiously all on the same day) when the loss of weight was also the highest, except when the ventilators were open and 4 rose. From 7 th to 28 th March, out of $\mathbf{3 2 7}$ observations taken 2 temperatures remained stationary, and 3 rose under gas light; and 2 were stationary while 4 rose under electric light. The rises in each cases were traced to a slightly catarrhal state.

It has already been mentioned that the average mean temperature of the divided room was $2^{\circ} \mathrm{F}$. higher than in the earlier period. This rise of temperature, associated with an increase in the percentage humidity should cause the rate of fall in the body temperature to be retarded and at higher temperature, with greater saturation, should change the fall into a rise. The final body temperatures in the second period being about $0 \cdot 3^{\circ} \mathrm{F}$. higher may be taken as an indication in this direction.

It would appear that, as the number of observations has been suffciently numerous to give mean body temperatures showing this distinct difference in the rate of fall with a slight increase in the mean temperature of the room, accommodation has not prevented the above indication of this influence in the present investigation.

Pembrey (J. Physiol., Vol. XVIII., p. 363) and Martin (Phil. Trans. 1902 B., Vol. 195 p. 1) have studied the effect of variations in external temperatures upon the output of carbonic acid and body temperature of young animals and marsupials, and point out that an increase in external 


\section{Relative Hygienic Values of Gas and Electric Lighting.}

temperature causes a falling off in the output of carbonic acid. A warm room tends, therefore, to quietness and a smaller evolution of carbonic acid, and this is accompanied by a rise in the body temperature.

Dr. Haldane (Jounal of Hygiene, 1905) has shown that the temperature regulation of the body begins to fail under conditions of rest and still-air environment when the wet bulb temperature rises above $88^{\circ} \mathrm{F}$. As no rise in the body temperature has been observed in these experiments, except in a few catarrhal cases mentioned, it is evident that the temperature and humidity of the air environment has been well maintained below the puint at which they begin to produce objective evidence of harmful effect.

\section{Bori Weicitits.}

Losses of weight may be computed to show the rate of loss, either per individual or per unit of weight, such as the kilogramme or the 100 lbs.

Pembrey says", referring to these alternative methods, "The physiologrical unit, it cannot be too of ten insisted, is the animal, and there is some danger of misunderstanding when the results are always expressed in terms of 1 kilogramme of body weight. The ratio of surface to mass is in the case of warm-blooded animals a much more important factor." So far as the comparison between gas and electricity is concerned, the danger here indicated would have been minimised by the system pursued, of subjecting the same men alternately to both lights, but an error might have crept into the comparisons of the results obtained on particular evenings, if the men on one occasion had been heavier or lighter than those on another.

The records for the first three weeks were accordingly analysed, in order to ascertain which mode of computation was more applicable to the present case. During this period 8 men were under observation, and of these it was found that 4 weighed over and 4 under $9 \frac{1}{2}$ stone each.

The records for the two sets of men were therefore separated with the following result :-

\begin{tabular}{|c|c|c|}
\hline & Meu over 9! stone. & Men under 9 stono. \\
\hline 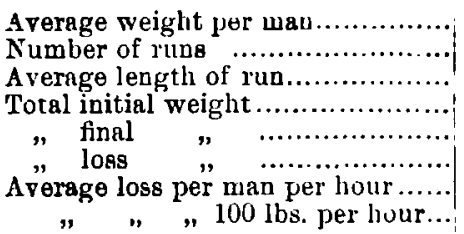 & 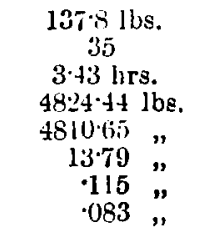 & $\begin{array}{c}122 \cdot 4 \text { lus. } \\
42 \\
3 \cdot 44 \text { hrs. } \\
5140 \cdot 37 \text { lbs. } \\
5124 \cdot 15, " \\
16 \cdot 22, " \\
.11 \% " \\
.091, "\end{array}$ \\
\hline
\end{tabular}

* Recent Advances in Physiology, p. 491. 
It will be seen that the hourly loss per man is thus much more nearly uniform than that per $100 \mathrm{lb}$. Pembrey's observation is thus cunfirmed.

During the whole period of the investigations at the beginuing and end of each evening all heavy clothing and pocket contents were removed. The results prior to January 24 th are given on page 112, and show that the aerial loss was equal to $\cdot 113 \mathrm{lb}$. per man per hour or at the rate of $2.72 \mathrm{lb}$. per 24 hours. The loss due to the difference in the weight of the oxygen inspired and the carbonic acid expired is not great and probably does not exceed $\cdot 2 \mathrm{lb}$. This leaves $2 \cdot \overline{\mathrm{l}} \mathrm{lbs}$. for water lost by respiration and sweat. Trentz and Schumberg give for men at rest the figure of $2 \cdot 06$ lbs. per day which is increased by hard physical work to $6 \cdot 27$ Ibs. After January 24 th the bladder was emptied each time and identical conditions: were observed in the first and second weighings. It was not considered necessary to correct for the difference of weight from moisture absorber by clothing as this is well known to be small.

The total average loss for each night was calculated into average loss per man per hour.

Between January 24th and March 1st the maximum loss under gas was $0.416 \mathrm{lb}$., and under electric light $0.458 \mathrm{lb}$., the minima were respectively $0.225 \mathrm{lb}$. and $0.139 \mathrm{lb}$, and the mean arerage loss was, for gas $0.304 \mathrm{lb}$., and for electric light $0.292 \mathrm{lb}$. per man per lour.

After the room was divided (March 7 th to 28 th) the maximum under gas light reached $0.348 \mathrm{lb}$, and under electric light $0.41 \mathrm{i}$ lb., while the minima were $0.220 \mathrm{lb}$. and $0.243 \mathrm{lb}$. respectively. The averages are practically the same as in the first series, being $0.305 \mathrm{lb}$. with gas and 0.302 for electricity. The details are given in the Appendix 7 and 8 , pp. 131, 132 .

\section{Mental Fatigue.}

The expression mental fatigue here means that a jerson who is so fatigned has less ability to perform mental work; that is to say, in doing work he will perform it with less accuracy and with greater loss of time, although he is still well within the limits of his power to work.

Enviromment has much to do with the production of fatigue, and it is probable that the cause of the affection of the afferent nerves in general may be brought about by the state of the blood imparting or not imparting that which is required by the tissues.

To test this, sums in ardition were set at the beginning and end of each evening's investigation. Usually ten subjects took part in this test, the time occupied by each in performing his task was accurately taken,

vol. xxix. No. 2 . 


\section{Relative Hygienic Values of Gas and Electric Lighting.}

and the difference in time occupied counted as gain or loss; similarly the number of errors made were counted; if they were less in the first calculation than in the second the difference was taken as a loss, while if they were less in the second than in the first it was counted as a gain. If the task was equally performed on each occasion both as regards time and number of errors, it was not considered that any fatigue had been experienced.

This test was applied on 13 different nights in the divided room.

The number of sums calculated in a gas-lit room was 65 and in an electric 54 between March 7 th and 28 th. The results are as follows:-

\section{In Time.}

\begin{tabular}{|c|c|c|c|c|c|c|c|c|}
\hline \multirow{2}{*}{\multicolumn{4}{|c|}{$\begin{array}{l}\text { Neither loss nor gain } \\
\text { Gains in minutes and seconds }\end{array}$}} & \multirow{2}{*}{ Gas, } & \multicolumn{2}{|l|}{8} & \multicolumn{2}{|c|}{ Electricity, 15} \\
\hline & & & & & $34^{\prime} 46^{\prime \prime}$ & &, & $34^{\prime} 10^{\prime \prime}$ \\
\hline Losses & $\eta$ & , & $\ldots$ & $"$ & $22^{\prime} 25^{\prime \prime}$ & $\ldots$ & , & $18^{\prime} 8^{\prime \prime}$ \\
\hline \multicolumn{9}{|c|}{ In Errors. } \\
\hline Increas & in errors &. & $\ldots$ & . & 70 & $\ldots$ & , & 72 \\
\hline Decreas & & $\ldots$ & $\ldots$ & ", & 26 & $\ldots$ & $"$ & 51 \\
\hline Correct & esults & $\ldots$ & $\ldots$ & ", & 14 & $\ldots$ & , & 8 \\
\hline
\end{tabular}

Now it will be seen from these figures that so far as mental ability to perform work is concerned, those who made an equal number of errors in their first and last calculations stood at the same level of mental ability on both occasions, and should therefore be added to those who on both occasions did the work correctly, so that the total under gas light who showed no mental fatigue really equalled twenty-seven, as against electric light fifteen.

On the other hand the gain in making less errors must be taken as the difference between the losses and gains in each case, which shows that under gas light the increase in errors was 44 as against 21 for electric light, thus making 23 in favour of electric light.

With reference to speed, deducting the losses from the gains, we have in the case of gas light an improvement equal to 12 mins. 21 secs. as against 16 mins. 2 secs. with electric light. This shows in favour of electric light 3 mins. 41 secs, while 8 under gas light and 15 under electric light indicated no signs of fatigue.

It should be mentioned that accuracy is more important than speed. Fatigue first shows itself not by losing pace, but by irregularity and the loss of power to co-ordinate. The loss of pace only becomes manifest later. Besides this, practice in performing any function certainly means 
gain of time, before gain of dexterity and refinement of perception in performing work is seen.

The conclnsion is that there was a general improvement in speed under both conditions, due to the fact that the subjects engaged were resting in the interval.

\section{IMPREsSION ON SENSES.}

It has already been noticed in this investigation that the Nicloux test for carbon monoxide records the presence of this gas in the air long before any smell of coal gas is perceptible.

In most of the investigations on ventilation in recent years, the sense of smell as well as the gencral impression on the senses has held a place as a physiological test of the purity of the air. Olfactory perception can be far more sensitive than the most delicate chemical tests, and might be able to detect a difference attributable to the mode of lighting which had not been otherwise indicated.

On five different occasions this test was carefully carried out, nine persons in all giving their opinion. Every care was taken so that no suggrestion should be made by one to influence the opinion of another. Before anybody was allowed to enter the room the gas and electric lights were both turned on, though only one or the other had been kept alight from three to twelve hours in the closed room previously, gas light on four occasions and electric light on one only. Fifteen opinions were given as "doubtful," i.e., they could not detect by their sense of smell or general sensation that gas had been burning; eight opinions were recorded that gas had been burning and were correct; while two were of opinion that electricity had been employed as the illuminating agent, which was also correct.

It would appear from this that no change can have been produced in the air of the room sufficient to affect so delicate a sense as smell with any degree of certainty, although each person giving an opinion had been requested to sniff the air through the nose, as well as to inhale it through the mouth, and to endeavour to detect any change between the air of the room and the outside air which might indicate gras as having been burnt.

\section{The Reaction.}

A time reaction apparatus was used for testing the interval required for muscle to respond to "will force." The Page's electric reed employed vibrated 104 times per second; and a Pfeil's electric signal (set in motion by a dry-cell battery) marked the time interval, which was recorded on a revolving drum covered with carbon paper and driven by a small motor.

The subject was placed so that his back was towards the apparatu' 


\section{Relative Hygienic Values of Gus and Electric Lighting.}

and his hand on a switch in the electric circuit; the drum being in motion the operator switched on the current, so that the vibrations of the tuningfork begin to be recorded on the drum.

The subject hearing the click of the operator's switch acted upon ' another switch which instantly cut off the current. The interval of time is thus shown by the number of vibrations recorded on the drum, and by counting these the exact time required by the subject, between the time of his recognition of sound and his action, was calculated in decimal parts of a second.

Observations at 5.30 and 9.30 were made on nine evenings between March 18th and 28th, eight subjects being taken on each occasion, the results showed a very slight slowing down of the velocity of the transmission of nerve force at the end of the evening, both under gas and electric light, the change of illumination making no appreciable difference.

\section{Ophthalmic Work.}

In an investigation connected with artificial lighting, it is obvious that one of the most important lines for research will be that one which is directed to determine the effect of the light employed upon the organ which transmits it to the brain. To arrive at a reliahle conclusion, an examination of sufficient subjects to eliminate accidental error was made on each evening during the time the general medical and, physical clat: were being collected.

After careful consideration it was decided that it was compulsory to limit the inquiry to eye fatigue tests, though it is worth while to point out that a more extended line of research, including a determination of the variation in the power of judging and comparing colours, and its concomitants, would be of the utmost utility, since in many occupations the choice between gas and electricity as an illuminant might be governed by such considerations.

In order to test the variation in the different kinds of fatigue experienced by the eye four series of tests were arranged, and 928 different observations were made between March 7 th and 27th, and these are referred to as follows;-

1. The Perception Test, determined by recording the visual acuity at the commencement of the evening and three hours after, on Snellin's types at a distance of six metres.

2. The Orbicular Muscle Test gave the amplitude of convergence as ascertained by noting the strongest prisms that could be overcome, bases up, down, and out and in at the same distance. The unit of measurement 
is the degree prism, and the figures give the difference in degrees before and after.

3. The Accommodative or Ciliary Muscle Test recorded the punctum proximum with the standard type at the beginning and end of the exposure to light for three hours.

t. The Retinal Test denoted the change in the light perception after three hours as measured by the difference in the number of opal glasses (1 sq. ft. to $1 \mathrm{lb}$.) through which the subjects saw light from a standard candle at 1 metre from the eye.

It must be borne in mind that these calculations merely show the gain w loss especially observed in each person subjected to the test, and have no reference to the question whether each individual possesses sight above or below the normal, nor would the figures be the same if the same sights were tested under some other illuminint. The results are relative, however, with regard to gas and electricity, the tests having been made under identical conditions for each light, and so are perfectly reliable for the particular purpose of comparison.

The general results of the investigation on sight are summed up in the following condenserl table, from which it will be seen that under gas light there were eight gains and only two losses of visual ability, whereas under electric light there were only six gains against four losses on the same ten subjects, and in the preferential column the advantage for gas accrues to seven subjects and for electric light to only three, while on the whole ten subjects, gas appears as 54, against $8 \cdot 5$ units for electric light, giving a difference of $45 \cdot 5$ in favour of gas.

It will be seen that the sensitiveness of the eye to light, as measured in the perception test, is diminished very markedly after exposure to the electric light, whilst no corresponding effect is noticeable after the eye has been subjected to gas light.

The power of co-ordinating and using the motor muscles of the eyeball recorded in the orbicular muscle tests was diminished to a greater extent after subjection to electric than to gas light. It was found also that the ciliary muscles of the eye are more accommodative after three hours' exposure to the light of 50 candles derived from the Darwin incandescent gas lamps than to a similar amount of illumination produced by the incandescent carbon filaments. The acuity of vision measured by the retinal test again shows that the optic nerve or centre was more susceptible in the case of the gas illumination.

The total advantage accruing to the individuals examined shows that there were only two small gains under electric light, while there were 
118 Relative Hygionic r'alues of Gas and Electric Lighting.

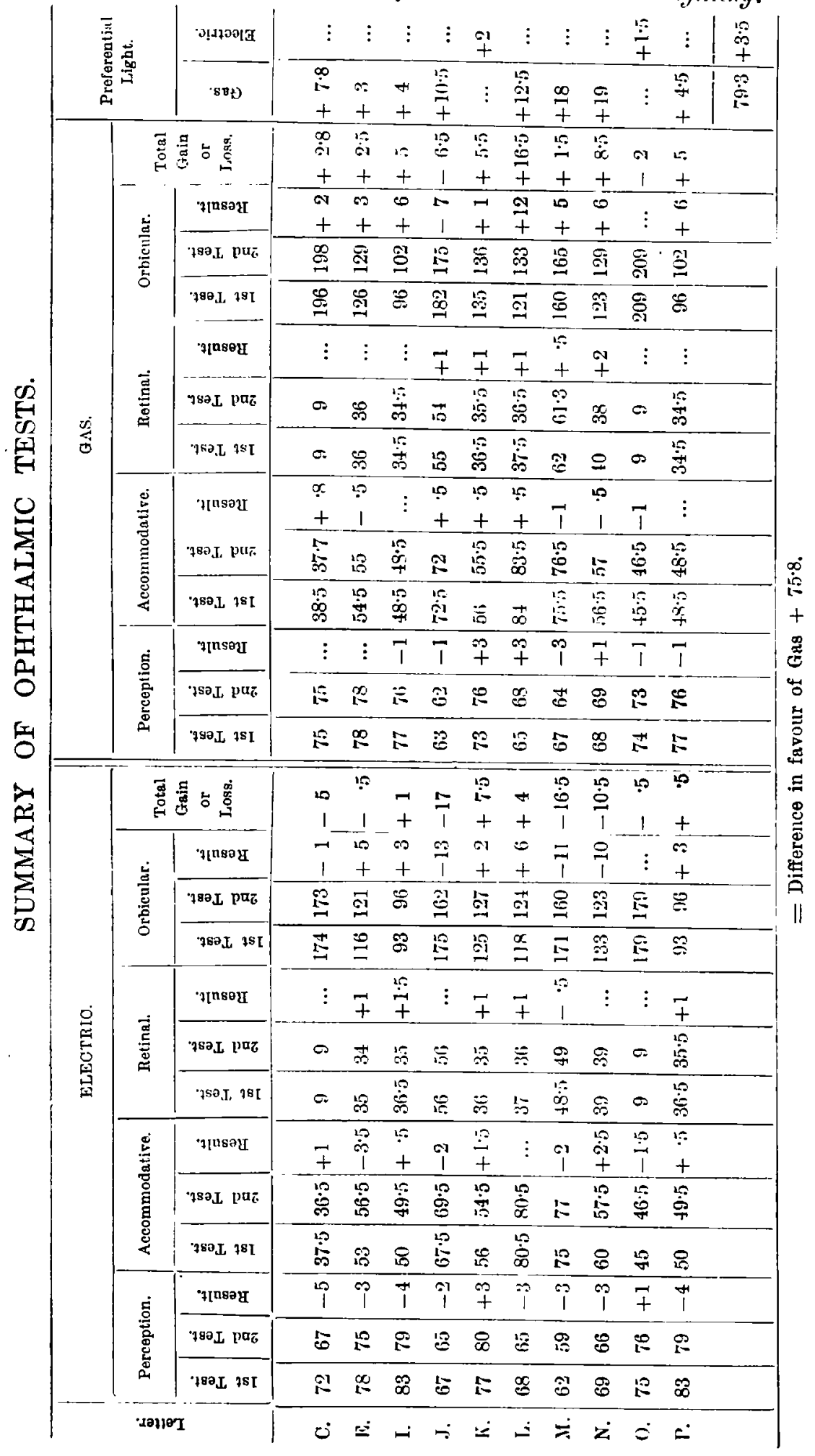


cight considerable gains with the gas light. Adding up all the advantages gained by the 10 subjects they stand as 79.3 to 3.5 , leaving a difference in favour of gas of $7.5 \cdot 8$ units, which gives an average gain of 7.58 units per man.

It will be seen that all the results point strongly in the same direction, namely, that gas light, as used in these experiments, is less fatiguing to the eye than electric light. The consistent character of the results is very satisfactory, but in view of the great importance of the subject further tests, conducted under conditions more favourable for ophthalmic work, would seem to be desirable.

\section{GENERAL SUMMARY.}

1. The whitewash on the walls of the room was able to absorb all the sulphur products of the gas-burning for a period much beyond the investigation : the power would not be exhausted for twenty-five years.

2. The gas and electric burners and supply were arranged to be of normal type, with an ordinary good and equal illumination. The experiments were alternated from room to room, in order to neutralise any difference there might be in the characteristics of the two rooms; and in order to accentuate any effects, the ventilation was mostly restricted to an average of 2,000 c.f. per hour.

3. The changes in the air of the room by the human contributions far exceed those by either illuminant.

4. Carbonic acid per se, in quantities up to 50 parts per 10,000 , even when of respiratory origin, is not responsible for any physiological effects.

5. Although gas combustion originally develops more heat than electricity does, it was found that the final result was equalised by the following causes:-

a. The gas-burners gave rise to stronger air-currents and invariably produced a more active ventilation and diffusion of air than electric lights; hence, along with the products of the gasburning, the exhalations from the persons present were more rapidly removed.

$b$. The ascending currents of air from the gas lights on reaching the ceiling rapidly parted with their heat, which was conducted away by the rafters and joists.

c. The electric lamps really produced more heat than is commonly credited to them. 


\section{Relative Hygienic Values of Gas and Electric Lighting.}

This seems to be the explanation of the unexpected result that the average temperature of the rooms was practically the same under either illuminant, and that the electric light did not show the superiority in coolness usually claimed.

6. The relative humidity of the air was in general 70 to 75 per cent. during the experiments, and was, therefore, such as the best authorities have laid down as most agreeable. On the score of humidity the use of either illuminant is therefore consistent with correct hygienic conditions.

7. Determinations of the organic matter in the air of the rooms showed that :-

a. The amount was very small and required, for oxidisation, 4 to 18 parts by weight of oxygen per million volumes of air.

b. It increased in quantity in 3 hours in an electrically-lit room in which persons were present, therefore it was, for the most part, a respiratory product.

c. Nineteen hours' gas burning in a room without occupants also gave fairly constant and comparatively high values.

$d$. There were thus two kinds of organic matter, parallel to the two kinds of carbonic acid, from respiration and combustion.

e. A great part is due to organic dust.

$f$. The rise in the course of the evening was less with gas than with electric light, probably because the organic matter produced by persons is partially destroyed by the gas.

8. That no appreciable amount of unburnt gas was present in the rooms during the investigation was proved by delicate tests for carbon monoxide, which is a constant constituent of coal gas. Only minute traces were found, in no case reaching $\cdot 01$ parts per 10,000 .

In order to observe the physiological effects of a large leakage, three of the subjects remained in one of the rooms while 8.8 c.f. of gas per hour was intentionally escaping, an excessive amount. The symptoms were observed, and the recovery. The inference from the experiment is that in any quantity of gas likely to escape from an ordinary leakage there is no fear of any immediate danger to health.

9. The bacterial contents of the air of the rooms were less with gas than with electricity, owing to (a) Cremation of the organisms in the gas flames; (b) Sterilizing effect of the sulphur acids from the gas; (c) increased condensation on the surfaces removing organisms, together with sulphur products. As a consequence the condensed moisture under electric light contained a number of living organisms, while that under gas was sterile. 
10. As a rule the Pulse Rate fell in the interval between the beginning and the end of the experiments, and a greater fall occurred after the room was divided, which was independent of the source of light. All the four series were almost identical at the end of the evening run, and although a slightly lower rate was observed in both periods under the electric light, the figures, as a whole, prove that the difference in the mode of lighting has no influence on the rate of the pulse.

11. Respiration frequency; the change in environment due to the altered condition of ventilation and density of population occasioned by the division of the room, caused a greater difference in the respiratory act than change in the morle of lighting.

12. There was an apparent increase in the difference of the Blood pressures in the undivided room under gas, but after the room was divided the results obtained uncler the two lights show no marked difference on hamanometric readings.

13. Sphygmographic tracings and blood pressure determinations indicated generally a slight rise of arterial tone under both kinds of light, but there was more general improvement under gas than under electricity.

14. There is no physiological difference between the two lights affecting the body temperature, although this factor is very sensitive to slight alterations in the temperature and humidity of the room.

15. In changes of body weight the influence of the two illuminants was too small to affect the result either way.

16. Calculations set to 10 persons at the besimning and end of 13 evenings to ascertain if any mental futigue was occasioned by either mode of illumination, showed that, owing to the subject being comparatively at rest in the interval, a general improvement occurred, electricity giving the greater average gain in speed and also in accuracy. The results distinctly proved that the evening's rest had done more good on the whole under electric light than under gas, but there were more cases under gas in which no change took place.

17. Tests on 9 persons on 5 different occasions after the gas and electric lights had been burning for 3 to 12 hours, showed that neither had affected the air sufficiently to make any certain difference to the sense of smell.

18. With 8 subjects on each of 9 evenings, there was a very slight slowing down of the velocity of transmission of nerve force at the close of the three hours, to a like degree under gas and electric light.

19. In the Ophthalmic experiments :-

$a$. The sensitiveness of the eye to light as measured in the 


\section{Relative Hygienic Values of Gas and Electric Lighting.}

Perception test is diminished rery markedly after exposure to the electric light, while no corresponding effect is noticeable after the eye has been subjected to the gas light.

$b$. The power of co-ordinating and using the motor muscles of the eyeball recorded in the orbicular muscle tests was diminished to a greater extent after subjection to electric than to gas light.

c. It was found that the ciliary muscles of the eye are more accommodative after three hour's' exposure to the 50-c.p. light from the Darwin incandescent mantle than after a similar exposure to a 50-c.p. electric light.

d. The acuity of vision measured by the retinal test again shows that the optic nerve or centre was more susceptible in the case of gas illumination.

$e$. The total advantage accruing to the individuals examined shows that there were only two small gains under electric while there were eight considerable gains under gas light. Adding up all the advantages gained by the ten subjects, they stand as $79 \cdot 3$ to $3 \cdot 5$, learing a difference in favour of gas of 75.8 units, or an arerage gain of 7.58 units per man.

\section{Generay, Observitions on the Resclits of the Ixquirt.}

The burning of gas for lighting purposes consumes oxygen and is accompanied by the production of considerable quantities of carbonic acid, water vapour, and other substances, and of twice as much heat as results from an equal illumination by electricity.

If the gas were burnt in an air-tight box, with sides of some nonconducting material, the oxygen would be quickly exhausted, and the products would accumulate to an indefinite extent.

These conditions are not even distantly approached in any actual room, since there is always an active and continuous interchange of air, and heat is freely conducted and radiated through the walls, windows, and ceiling.

By reason of their massive construction, the rooms used for these experiments were more nearly air-tight than any ordinary living room is likely to be, the rate of ventilation through the walls being only one-half of that noted by Pettenkofer in his own house. Notwithstanding this, and the special precautions taken to prevent the ingress of further air, the composition of the air under gas illumination showed no marked difference from that under electricity, and the condition of the room as regards heat was practically the same under both illuminants. 
With natural ventilation the proportion of carbonic acid in the air was practically iclentical for both illuminants.

The ventilating effect of the gas burners has thus proved competent to carry off the whole of their products, or an equivalent amount of the products of respiration.

It is therefore not surprising that the search for the physiological effects of lighting by gas has been in the main a fruitless one.

The fifteen men have been subjected on more than fifty occasions to some 6,000 tests of the kind best calculated to detect any sucl falling-off in condition as might be expected to take place under either mode of illumination. The results of these tests have been carefully examined and averaged, and, with few exceptions, they absolutely fail to disclose any measurable difference betwcen one mode of lighting and the other. Not only so, but in no case do they show any deviation from any normal conditions. It is not merely that the changes noted were well within the limits of accommodation. If this were all it would be a rery poor answer to the question propounded, for it would obviously be unsatisfactory that a system of lighting should trench, no matter how slightly, upon that power of accommodation on which the body depends to safeguard it in the presence of adverse influences. Not only were the limits of accommodation never exceeded, but they were in no case even distantly approached, and the conditions which the physiological tests disclosed were in all cases entirely satisfactory. The differences found between the two lights were so small as to be absolutely devoid of any hygienic significance; they were, in fact, much less than those that are constantly produced in healthy subjects by slight changes in their condition or environment.

Not less important than the negative indication of the statistical results is the fact that fifteen men, after a more or less exacting day's work, were confined for several hours each evening in crowded and scantily ventilated rooms in which the products of gas combustion or the heat from electric lighting were allowed to accumulate to an extent which would hardly be possible in any ordinary living room, that they were under continuous medical observation, and that in no case was there any adverse influence of any kind whatever exerted by the lights or their products. It is true that in the arithmetical tests the mistakes at the end of the evening exceeded those at the begimning, but from a physiological point of view the gain in speed may fairly be regarded as offsetting the loss in accuracy. It was found also by the very delicate optical tests employed that some slight falling-off in visual power took place under the electric light. Any trouble from this cause could, howerer, be effectually guarded 


\section{Relative Hygienic Values of Gas and Electric Lighting.}

against by adopting an arrangement of lights suitable for the use to which the room is to be put.

There may be, and doubtless are, persons so peculiarly constituted as to find one light or other objectionable, or even to be unable to tolerate any artificial light whatever. Such cases belong to the domain of pathology rather than that of hygiene. On a review of the whole of the facts collected, it may be said, without reservation, that there is nothing in either mode of lighting which is incompatible with the best hygienic conditions.

The main conclusions may be therefore summed up as follows :-

(1) Owing to the better ventilation obtained by gas, the products of combustion are not found in the air in anything like the proportion which might be expected, the temperature and humility in an occupied room being no greater than when the room is lit with electric.light.

(2) Carbonic acid has not the injurious effect which was formerly attributed to it, but considerable rises in the temperature and moisture content of a room, from whatever source, do have a prejudicial effect upon the well-being of the occupants. Even under adverse conditions of ventilation purposely created for this inquiry, neither the temperature nor percentages of moisture in the room reached a point at which any such effect could be detected by any of the recognised physiological tests.

(3) It has been established that the products, viz., heat, carbonic acid and moisture, so far as they modify the health of the occupants of a room, are derived from the inmates more than from the illuminant, and that a room of moderate size can be efficiently lighted by gas without sensibly affecting the amount of these three factors.

(4) Whilst undoubtedly, it is important to ensure adequate ventilation in domestic rooms, this, with present methods of construction, is better ensured the smaller the room. The problem of securing sufficient ventilation in public rooms of a larger size has been outside the scope of this inquiry.

(5) The medical conclusions are in accord with those arrived at from the chemical and physical data, and also demonstrate that the choice between the two systems of lighting does not depend upon hygienic considerations. 